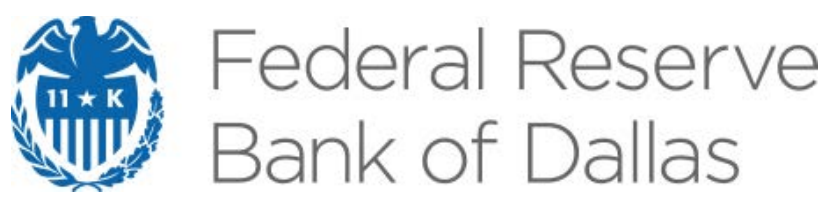

\title{
Identifying Global and National Output and Fiscal Policy Shocks Using a GVAR
}

Alexander Chudik, M. Hashem Pesaran and Kamiar Mohaddes

Globalization Institute Working Paper 351

Research Department

https://doi.org/10.24149/gwp351

Working papers from the Federal Reserve Bank of Dallas are preliminary drafts circulated for professional comment. The views in this paper are those of the authors and do not necessarily reflect the views of the Federal Reserve Bank of Dallas or the Federal Reserve System. Any errors or omissions are the responsibility of the authors. 


\title{
Identifying Global and National Output and Fiscal Policy Shocks Using a GVAR*
}

\author{
Alexander Chudik ${ }^{\dagger}$, M. Hashem Pesaran ${ }^{\ddagger}$ and Kamiar Mohaddes ${ }^{\S}$
}

December 26, 2018

\begin{abstract}
The paper contributes to the growing Global VAR (GVAR) literature by showing how global and national shocks can be identified within a GVAR framework. The usefulness of the proposed approach is illustrated in an application to the analysis of the interactions between public debt and real output growth in a multi-country setting, and the results are compared to those obtained from standard single-country VAR analysis. We find that on average (across countries) global shocks explain about one-third of the long-horizon forecast error variance of output growth, and about onefifth of the long-run variance of the rate of change of debt-to-GDP. Evidence on the degree of cross-sectional dependence in these variables and their innovations is exploited to identify the global shocks, and priors are used to identify the national shocks within a Bayesian framework. It is found that posterior median debt elasticity with respect to output is much larger when the rise in output is due to a fiscal policy shock, as compared to when the rise in output is due to a positive technology shock. The cross-country average of the median debt elasticity is 1.58 when the rise in output is due to a fiscal expansion as compared to 0.75 when the rise in output follows from a favorable output shock.
\end{abstract}

Keywords: Factor-augmented VARs, Global VARs, identification of global and countryspecific shocks, Bayesian analysis, public debt, output growth, debt elasticity.

JEL Classification: C30, E62, H6

*We are grateful to Ambrogio Cesa-Bianchi, Essie Maasoumi, Alessandro Rebucci, and Ron Smith for helpful comments. We would also like to acknowledge comments by the participants at the 2018 Advances in Econometrics conference in honor of Cheng Hsiao, and the USC Dornsife INET seminar participants. The views expressed in this paper are those of the authors and do not necessarily represent those of the Federal Reserve Bank of Dallas or the Federal Reserve System.

${ }^{\dagger}$ Alexander Chudik, Federal Reserve Bank of Dallas, alexander.chudik@dal.frb.org.

${ }^{\ddagger} \mathrm{M}$. Hashem Pesaran, University of Southern California, USA, and Trinity College, Cambridge, UK, pesaran@usc.edu.

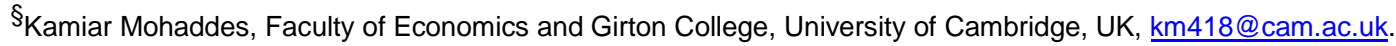




\section{Introduction}

The relationship between public debt expansion and economic growth became a widely discussed topic of policy importance in the aftermath of the 2007-2008 financial crisis, and the ensuing euro area sovereign debt crisis. Some of the debate and the related literature on the causes and consequences of rising public debt relative to GDP is reviewed below in Section 2. This paper contributes to this literature by developing an empirical model of the inter-connections between output growth and public debt in a multi-country setting where global and national effects are separately identified.

This paper also contributes to the growing Global VAR (GVAR) literature, originally introduced by Pesaran, Schuermann, and Weiner (2004). ${ }^{1}$ Our starting point for modelling a large (multi-country) set of interconnected macroeconomic variables is a factor-augmented panel vector error correcting model, where strong cross-country linkages are modelled using unobserved common factors. We assume that the number of countries $(N)$ and the number of available time periods $(T)$ are both large. Using our setup, we derive a GVAR representation that features a global (common) and national (country-specific or idiosyncratic) error structure. ${ }^{2}$ These derivations build on the previous contributions by Dées, di Mauro, Pesaran, and Smith (2007), Chudik and Pesaran (2011), Chudik, Grossman, and Pesaran (2016), and recently Cesa-Bianchi, Pesaran, and Rebucci (2018). GVAR models in the literature typically do not distinguish between global and national shocks. We argue in favor of the representation derived in this paper, which explicitly takes the two types of shocks into account. In addition, we discuss the problem of identification of global and national shocks, within the context of the empirical application.

Country-specific models estimated in our framework feature (lagged) domestic variables, (lagged) cross section averages, and (contemporaneous) global shocks estimated using a VAR model in cross section averages. The individual country models in this paper thus differ from the traditional VAR models in the literature, which contain domestic variables only. The omission of global shocks and lagged cross section averages can result in miss-specified country-specific models. Cross section averages could be replaced by principal component (PCs). ${ }^{3}$ But, if PCs are employed, we suggest that the first principal component of each variable type is used in place of cross section averages, as opposed to the standard practice where a pre-selected number of PCs are estimated from all the variables under

\footnotetext{
${ }^{1}$ A survey of GVARs is provided in Chapter 33 of Pesaran (2015b).

${ }^{2}$ This is in contrast to the traditional factor-augmented VAR models in the literature (Bernanke, Bovian, and Eliasz, 2005, Stock and Watson, 2005, and Bai, Li, and Lu, 2016, among others), which typically assume a single cross-section unit $(N=1)$, and treat the factors as given or estimated from a large set of additional variables.

${ }^{3}$ Note that large $N$ is sufficient for the convergence of cross section averages, whereas PCs rely on both $N$ and $T$ large.
} 
consideration together.

We apply the proposed modelling approach to annual data on debt and output growth covering a diverse set of advanced and emerging economies, over the period 1965-2015. We first investigate the evidence on the long-run relationship between public debt and real output, and consider the main theoretical result from balanced growth models in the literature (Diamond (1965), Blanchard (1985), or Saint-Paul (1992)) that predict log output and log public debt must cointegrate with coefficients $(1,-1)$. We find the evidence to be mixed, with cointegration supported for only half of the countries in our sample; and even in such cases we still find statistically significant departures from the cointegrating vector of $(1,-1)$. Therefore, in the empirical analysis we focus on business cycle effects, and abstract from the long run influences. Much longer time series seem to be required if we are to allow for long run effects in our analysis, as well.

We find that global shocks are statistically significant and economically important, and argue that they should be included in individual country models to avoid biased estimates. Our findings suggest that two global shocks are sufficient for modelling of output and public debt in a multicountry setting. Motivated by evidence on the cross-sectional dependence of debt and output variables, and following Cesa-Bianchi, Pesaran, and Rebucci (2018), we impose a triangular ordering to identify a global growth shock, which alone explains the strong pattern of cross-sectional dependence of output growth well, and a residual global debt shock, which, together with the global growth shocks, is necessary to explain the strong pattern of cross-sectional dependence for the debt-to-GDP variable. Global shocks are found to be responsible for 31 percent of variance (at long horizons) for the output growth, and 21 percent of the variance of the debt-to-GDP variable. In addition to the identification of global shocks, we also consider the problem of identification of national shocks, where following Baumeister and Hamilton (2015), we employ priors in a Bayesian framework to point identify and estimate country-specific elasticity of debt with respect to output when output expands due to technology and fiscal policy shocks. We find considerable heterogeneity in mean and median debt elasticities across countries with large posterior interquartile ranges, which could be due to estimation uncertainty as well as weak prior identification. On average the median elasticity of debt to GDP is 0.75 following a positive technology shock, and much higher at 1.4 following a fiscal expansionary shock. Thus debt accumulation is likely to be much more serious when output growth is driven by fiscal expansion as compared to technologically driven growth. Finally, the results from our multicountry models are compared to standard single country VAR analyses and their differences highlighted.

The remainder of this paper is organized as follows. Section 2 briefly reviews the literature on debt 
and growth. Section 3 derives GVAR representation featuring global and national shocks. Section 4 provides a long-run perspective on public debt and output. Sections 5 and 6 discuss the problem of identification, and present the empirical results on the effects of global and national shocks. Some concluding remarks are provided in Section 7. The paper is accompanied by an appendix and an online supplement that give the mathematical derivations, data sources, and additional results.

\section{Literature on debt and growth}

The relationship between public debt expansion and economic growth has attracted interest in recent years, spurred by the sharp increase in government indebtedness in some advanced economies following the 2007-2008 global financial crisis. However, this relationship is a complex one, and economic theory alone does not provide a clear guidance as the quantitative importance or the causal nature of the relationship between debt and growth. Elmendorf and Mankiw (1999) argue that profligate debtgenerating fiscal policy (and high public debt) can have a negative impact on long-term growth by crowding out private investment, although it is acknowledged that this effect could be quantitatively

small. There are several other channels through which sustained debt accumulation can harm economic growth. For example, an upward sloping debt trajectory beyond certain levels could lead investors to worry about the country's debt sustainability. Reflecting this risk, economic agents would be willing to hold government securities only at higher borrowing costs. The lower demand and investment due to higher interest rates in turn can have negative consequences for economic growth in the long run. Since the higher cost of government borrowing poses an additional strain on fiscal balances, an increase in government bond yields could lead to further loss of confidence and become self-fulfilling. In an extreme case, a crisis could occur. The negative growth effect of public debt could also be larger in the presence of policy uncertainty or expectations of future confiscation (possibly through inflation and financial repression). See, for example, Cochrane (2011b) and Cochrane (2011a).

Contrary to this view, DeLong and Summers (2012) argue that hysteresis arising from recessions can lead to a situation in which expansionary fiscal policies may have positive effect on long-run growth. Krugman (1988) argues that nonlinearities and threshold effects can arise from the presence of external debt overhang, but it is not clear whether such an argument is applicable to advanced economies where the majority of debt-holders are residents. Nonlinearities may also arise if there is a turning point above which public debt suddenly becomes unsustainable; see, for instance, Ghosh et al. (2013). 
Although economic theory provides mixed results on the relationship between public debt and growth, the arguments so far abstract from the composition of additional government spending that gives rise to higher public debt. Such additional government expenditure could be invested in productive public capital (such as infrastructure, education or health) and could be growth enhancing. Consequently, the net effect of debt accumulation on economic growth cannot be established theoretically and requires a careful empirical analysis.

The empirical evidence on the relationship between debt and growth until recently focussed on the role of external debt in developing countries, and so far there has been only a few studies that include evidence on the advanced economies. Moreover, while the focus of the earlier literature was on the long-run effects of public debt, the possibility of a threshold effect between public debt and output growth became a heated debate in the literature and among policy-makers in advanced economies in particular. A well-known influential study is Reinhart and Rogoff (2010), who argue for a non-linear relationship, characterized by a threshold effect, between public debt and growth in a cross-country panel. Their main result is that the median growth rate for countries with public debt over 90 percent of GDP is around one percentage point per annum lower than median growth of countries with debtto-GDP ratio below 90 percent. In terms of mean growth rates, this difference turns out to be much higher and amounts to around 4 percentage points per annum.

The analysis of Reinhart and Rogoff (2010) has generated a considerable degree of debate in the literature, not to mention among policy-makers, some of whom have used the 90 percent threshold to justify austerity programs, while others have questioned whether such a threshold is relevant across all countries. See, for example, Woo and Kumar (2015), Checherita-Westphal and Rother (2012), Eberhardt and Presbitero (2015), and Reinhart et al. (2012); who discuss the choice of debt brackets used, changes in country coverage, data frequency; econometric specification, and reverse causality going from output to debt. ${ }^{4}$ These studies address a number of important modelling issues not considered by Reinhart and Rogoff (2010), but they nevertheless employ panel data models that impose slope homogeneity and do not adequately allow for cross-sectional dependence across individual country errors. It is implicitly assumed that different countries converge to their equilibrium at the same rate, and there are no spillover effects of debt overhang from one country to another. These assumptions do not seem plausible given the diverse historical and institutional differences that exist across countries, and the increasing degree of interdependence of the economies in the global economy. More specifically, neglecting error cross-sectional dependencies can lead to spurious inference and

\footnotetext{
${ }^{4}$ See also Panizza and Presbitero (2013) for a survey and additional references to the literature.
} 
false detection of threshold effects, since global factors (including interest rates in the U.S., crosscountry capital flows, global business cycles, and world commodity prices) play an important role in precipitating sovereign debt crises with long-lasting adverse effects on economic growth. For example, favorable terms of trade trends and benign external conditions typically lead to a borrowing rampup and pro-cyclical fiscal policy. When commodity prices drop or capital flows reverse, borrowing collapses and defaults occur followed by large negative growth effects.

To address these shortcomings Chudik et al. (2017) use a cross-country dynamic panel data model that allows for endogeneity of debt and growth, fixed effects, slope heterogeneity, and cross-sectional error dependence. They conduct a formal statistical analysis of debt threshold effects using data on a sample of 40 countries (as well as to two sub-groups of advanced and developing economies) over the 1965-2010 period, but do not find a universally applicable simple threshold effect in the relationship between public debt and growth. However, they find statistically significant evidence when the threshold effects are interacted with the growth of debt-to-GDP, thus concluding that the trajectory of debt-to-GDP is more important for economic growth than the level of debt-to-GDP itself. $^{5}$

Although the long-term economic impact of public debt accumulation is subject to a heated debate, economists tend to agree that in the short run an increase in public debt, following an expansionary fiscal policy shock, such as a lowering of the income tax rate, can improve domestic demand and raise output. However, both negative and positive relationships between output and deb-to-GDP are possible over the course of the business cycle. More specifically, an unexpected increase in output, following a positive technology shock, for example, can result in larger fiscal revenue, and an improved debt-to-GDP ratio, whilst the output rise primarily initiated through increased government expenditure or lower tax rates can result in higher debt-to-GDP ratio. In this paper we focus on the business cycle effects of fiscal and technology shocks and identify such shocks at both global and national levels, and provide empirical evidence on conditions under which increases in debt-to-GDP has or does not have a dampening effect on economic growth. Our empirical analysis is thus complementary to the recent empirical literature on the long-run effects of rising debt on output growth.

\footnotetext{
${ }^{5}$ Note that while it is theoretically possible for governments to inflate the local-currency-denominated debt away by monetizing (printing money), this is impossible for foreign-currency-denominated debt. In the latter case, a public debt crisis could also trigger currency and/or banking crises with more profound consequences for economic growth. High and increasing public debt might also constrain the ability of fiscal authorities to smooth economic cycles. These considerations provide some support for the negative association between growth and debt trajectory in conjunction with a sufficiently high level of debt.
} 


\section{GVAR representation of factor-augmented panel VAR models}

Suppose there are $N$ countries, and let $\mathbf{x}_{i t}$ be a $k \times 1$ vector of domestic variables in country $i=$ $1,2, \ldots, N$, that are also subject to an $m \times 1$ vector of unobserved common factors denoted by $\mathbf{g}_{t}$. We consider the following factor-augmented VAR specification for $\mathbf{x}_{i t}$

$$
\Delta \mathbf{x}_{i t}=\mathbf{a}_{i}-\boldsymbol{\Pi}_{i} \mathbf{z}_{i, t-1}+\sum_{\ell=1}^{p-1} \boldsymbol{\Gamma}_{i \ell} \Delta \mathbf{z}_{i, t-\ell}+\mathbf{e}_{i t}, \text { for } i=1,2, \ldots, N
$$

where $\mathbf{z}_{i t}=\left(\mathbf{x}_{i t}^{\prime}, \mathbf{g}_{t}^{\prime}\right)^{\prime}$, and suppose that $\Delta \mathbf{g}_{t}$ follows the $\operatorname{VAR}(p)$ model $^{6}$

$$
\Delta \mathbf{g}_{t}=\mathbf{a}_{g}+\sum_{\ell=1}^{p-1} \boldsymbol{\Gamma}_{g \ell} \Delta \mathbf{g}_{t-\ell}+\mathbf{v}_{g t}
$$

The innovations of the country-specific models, $\mathbf{e}_{i t}$, are allowed to be cross-sectionally correlated, as well as being correlated with $\mathbf{v}_{g t}$. Let $E\left(\mathbf{e}_{i t} \mid \mathbf{v}_{g t}\right)=\boldsymbol{\Gamma}_{v i} \mathbf{v}_{g t}$, in which $\boldsymbol{\Gamma}_{v i}$ is a $k \times m$ loading matrix, and let $\boldsymbol{\varepsilon}_{i t}=\mathbf{e}_{i t}-E\left(\mathbf{e}_{i t} \mid \mathbf{v}_{g t}\right)$. Then, without loss of generality, $\mathbf{e}_{i t}$ can be decomposed as

$$
\mathbf{e}_{i t}=\boldsymbol{\Gamma}_{v i} \mathbf{v}_{g t}+\boldsymbol{\varepsilon}_{i t}, \text { for } i=1,2, \ldots, N,
$$

where $\mathbf{v}_{g t}$ and $\varepsilon_{i t}$ are serially uncorrelated with zero means, and by construction, $\varepsilon_{i t}$ and $\mathbf{v}_{g t}$, are uncorrelated. This represents a decomposition of the reduced-form errors, $\mathbf{e}_{i t}$, into the $m \times 1$ vector of reduced-form global shocks, $\mathbf{v}_{g t}$, and the $k \times 1$ vector of reduced-form national shocks, $\boldsymbol{\varepsilon}_{i t}$. Also to identify the national shocks we shall assume that $\varepsilon_{i t}$ are cross-sectionally weakly correlated.

Following Pesaran (2006), we use cross section averages

$$
\overline{\mathbf{x}}_{t}=\mathbf{W}^{\prime} \mathbf{x}_{t}=\sum_{i=1}^{N} \mathbf{W}_{i} \mathbf{x}_{i t}
$$

and their lags to estimate the global shocks $\mathbf{v}_{g t}$ (up to a non-singular $m \times m$ transformation matrix), where $\mathbf{W}=\left(\mathbf{W}_{i}, \mathbf{W}_{2}, \ldots, \mathbf{W}_{N}\right)^{\prime}$ is the $n \times k$ weight matrix, satisfying the usual granularity conditions:

$$
\|\mathbf{W}\|=O\left(N^{-1 / 2}\right), \text { and } \frac{\left\|\mathbf{W}_{i}\right\|}{\|\mathbf{W}\|}=O\left(N^{-1 / 2}\right), \text { for any } i
$$

In order to derive large- $N$ representation of cross section averages in model (1)-(2), we require a number

\footnotetext{
${ }^{6}$ A more general global factor-augmented error-correcting model with detailed derivations is presented in Section A.1 of the Appendix.
} 
of regularity assumptions. Under: ( $i)$ the standard assumptions on VECM models in the literature (see Assumption 1 in the Appendix), (ii) weak cross-sectional dependence of $\varepsilon_{i t}$ (see Assumption 2 in the Appendix), and (iii) full rank of $\overline{\boldsymbol{\Gamma}}_{w v}=\sum_{i=1}^{N} \mathbf{W}_{i} \boldsymbol{\Gamma}$ and invertibility requirements that rule out long memory features in $\Delta \overline{\mathbf{x}}_{t}$ (see Assumption 3 in the Appendix), we obtain

$$
\Delta \overline{\mathbf{x}}_{t}=\mathbf{a}_{\bar{x}}+\sum_{\ell=1}^{p_{T}} \overline{\mathbf{\Psi}}_{w \ell} \Delta \overline{\mathbf{x}}_{t-\ell}+\mathbf{v}_{t}+O_{p}\left(N^{-1 / 2}\right)+O_{p}\left(\rho^{p_{T}}\right),
$$

for some $0<\rho<1$, where $\overline{\mathbf{\Psi}}_{w \ell}$ are exponentially decaying coefficient matrices in $\ell$, and

$$
\mathbf{v}_{t}=\overline{\mathbf{\Gamma}}_{w v} \mathbf{v}_{g t},
$$

are the reduced-form global shocks. $\mathbf{v}_{t}$ is identified from (6) as $N \rightarrow \infty$. Following the arguments in Chudik and Pesaran (2011, 2013), VAR representation for cross section averages (6) can be estimated by least squares. ${ }^{7}$ We denote orthogonalized LS residuals from the regressions of $\Delta \overline{\mathbf{x}}_{t}$ on the constant and its lagged values by $\widehat{\mathbf{v}}_{t}$.

Using this approximation of common shocks, we obtain the following large- $N$ country-specific representations. When $\boldsymbol{\Pi}_{i}=0$ (as in our application below), and omitting the large- $N$ approximation and the truncation lag error terms for ease of exposition, we obtain

$$
\Delta \mathbf{x}_{i t}=\mathbf{a}_{x i}+\sum_{\ell=1}^{p_{T}} \boldsymbol{\Lambda}_{i \ell} \Delta \overline{\mathbf{z}}_{i, t-\ell}+\mathbf{B}_{i} \hat{\mathbf{v}}_{t}+\boldsymbol{\varepsilon}_{i t}
$$

where $\overline{\mathbf{z}}_{i t}=\left(\mathbf{x}_{i t}^{\prime}, \overline{\mathbf{x}}_{t}^{\prime}\right)^{\prime}$ and $\mathbf{B}_{i}=\boldsymbol{\Gamma}_{v i}\left(\overline{\boldsymbol{\Gamma}}_{w v}^{\prime} \overline{\boldsymbol{\Gamma}}_{w v}\right)^{-1} \overline{\boldsymbol{\Gamma}}_{w v}^{\prime}$. Augmented country-specific VAR representations (8) can be estimated separately and then stacked and solved in a global VAR representation for $\mathbf{x}_{t}=\left(\mathbf{x}_{1 t}^{\prime}, \mathbf{x}_{2 t}^{\prime}, \ldots, \mathbf{x}_{N t}^{\prime}\right)^{\prime}$.

Augmented country VARs in (8) explicitly account for a global and national error structure, and differ from the conventional GVAR specifications, namely ${ }^{8}$

$$
\Delta \mathbf{x}_{i t}=\mathbf{a}_{x i}+\sum_{\ell=1}^{p_{T}} \boldsymbol{\Lambda}_{x i \ell} \Delta \mathbf{x}_{i, t-\ell}+\sum_{\ell=0}^{p_{T}} \boldsymbol{\Lambda}_{\bar{x} i \ell} \Delta \overline{\mathbf{x}}_{t-\ell}+\varepsilon_{i t} .
$$

GVAR literature stacks the estimates of (9) in one large system and solves for the VAR representation of $\mathbf{x}_{t}$. It is easily seen the two representations, (9) and (8) are equivalent and yield the same estimates

\footnotetext{
${ }^{7}$ As $N, T \rightarrow \infty$ jointly such that $N / T \rightarrow \kappa>0$ and $p_{T}=\Theta\left(T^{1 / 3}\right)$, where $\Theta($.$) denotes the exact order of magnitude.$

${ }^{8}$ See, for example, Pesaran, Schuermann, and Weiner (2004), Dées, di Mauro, Pesaran, and Smith (2007), or the references provided in Chapter 33 of Pesaran (2015b).
} 
of the reduced-form national shocks, $\varepsilon_{i t} .{ }^{9}$ However, (8) allows the identification of the global shocks whereas (9) does not. ${ }^{10}$

Stacking the country-specific equations in (8), we obtain:

$$
\Delta \mathbf{x}_{t}=\mathbf{a}_{x}+\sum_{\ell=1}^{p_{T}} \mathbf{G}_{\ell} \Delta \mathbf{x}_{t-\ell}+\mathbf{B} \hat{\mathbf{v}}_{t}+\varepsilon_{t}
$$

where $\Delta \mathbf{x}_{t}=\left(\Delta \mathbf{x}_{1 t}^{\prime}, \Delta \mathbf{x}_{2 t}^{\prime}, \ldots, \Delta \mathbf{x}_{N t}^{\prime}\right)^{\prime}, \varepsilon_{t}=\left(\varepsilon_{1 t}^{\prime}, \varepsilon_{2 t}^{\prime}, \ldots, \varepsilon_{N t}^{\prime}\right)^{\prime}, \mathbf{B}=\left(\mathbf{B}_{1}^{\prime}, \mathbf{B}_{1}^{\prime}, \ldots, \mathbf{B}_{N}^{\prime}\right)^{\prime}, \mathbf{G}_{\ell}=\mathbf{\Lambda}_{\ell} \widetilde{\mathbf{W}}$, for $\ell=1,2, \ldots, p, \boldsymbol{\Lambda}_{\ell}$ is block-diagonal with diagonal blocks given by $\boldsymbol{\Lambda}_{i \ell}$, and $\widetilde{\mathbf{W}}$ is defined by the identity: $\overline{\mathbf{z}}_{t}=\widetilde{\mathbf{W}} \Delta \mathbf{x}_{t}, \overline{\mathbf{z}}=\left(\overline{\mathbf{z}}_{1 t}^{\prime}, \overline{\mathbf{z}}_{2 t}^{\prime}, \ldots, \overline{\mathbf{z}}_{N t}^{\prime}\right)^{\prime}$. The GVAR representation (10) features reduced-form global and national shocks, and can be used for a structural analysis where both types of shocks can be identified.

We summarize the practical steps involved in obtaining the GVAR representation in (10), with the errors decomposed into reduced-form global and national shocks:

Step 1: Compute the orthogonalized residuals $\hat{\mathbf{v}}_{t}$, by estimating a $\operatorname{VAR}\left(p_{T}\right)$ model in cross section averages $\Delta \overline{\mathbf{x}}_{t}$. The ordering of the variables in $\Delta \overline{\mathbf{x}}_{t}$ will be discussed below. Principal Components (PCs) can also be used instead of cross section averages if the method of PCs is applied to individual variables $\Delta x_{i j t}$, over $i$. The lag order, $p_{T}$, can be estimated using Akaike or Bayesian Information Criteria, or set to $p_{T}=T^{1 / 3}$ as argued in Chudik and Pesaran $(2011,2013)$.

Step 2: Estimate the country-specific VAR models augmented with $\hat{\mathbf{v}}_{t}$, plus the lagged values $\Delta \overline{\mathbf{x}}_{t-1}, \ldots, \Delta \overline{\mathbf{x}}_{t-p_{T}}$.

Step 3: Stack country-specific models from Step 2 in the full GVAR representation, (10), to be used for impulse response analyses and error variance decomposition.

The estimated reduced-form global shocks $\left(\hat{\mathbf{v}}_{t}\right)$ are by construction orthogonal to the countryspecific residuals $\left(\hat{\varepsilon}_{i t}\right)$. The strong cross section dependence of global shocks, and the weak cross section dependence of national shocks help to identify (as $N \rightarrow \infty$ ) the common shocks from the national shocks. Individual common shocks themselves are identified only up to a rotation matrix, and so are the individual national shocks. Identification of the two types of shocks need to be treated separately and will be discussed in the context of our application below.

\footnotetext{
${ }^{9}$ This follows because $\hat{\mathbf{v}}_{t}$ are computed as residuals from regressions of $\Delta \overline{\mathbf{x}}_{t}$ on its lagged values.

${ }^{10}$ In addition, Chudik, Grossman, and Pesaran (2016, Section 4.1) show that stacking (9) could result, under certain conditions, in an undetermined system when the unobserved common factor is strong, and $N \rightarrow \infty$. This problem is avoided by using (8).
} 


\section{Long-run perspective on public debt and output}

Balanced growth models with government debt financing predict that in the long run steady state the debt-to-GDP must be stationary. Let $\boldsymbol{\xi}_{i t}=\left(y_{i t}, d_{i t}\right)^{\prime}$, where $y_{i t}$ is the log of real output and $d_{i t}$ is the $\log$ of public debt, broadly defined. Then the long run theory predicts that $y_{i t}-d_{i t}$ must be stationary, regardless of the global factors $\mathbf{g}_{t}$. See, for example, Diamond (1965), Blanchard (1985), and Saint-Paul (1992). Suppose further that $y_{i t}$ are integrated of order one, or $I(1)$ for short. Then two important conclusions follow. First, $d_{i t}$ must also be $I(1)$. Second, $y_{i t}$ and $d_{i t}$ must be cointegrated

such that $\boldsymbol{\beta}_{i}^{\prime} \boldsymbol{\xi}_{i t} \sim I(0)$, where $\boldsymbol{\beta}_{i}=(1,-1)^{\prime}$ is the cointegrating vector. It is also worth noting that such cointegrating relationship holds regardless of country interlinkages, captured above by $\mathbf{g}_{t}$. However, error-correcting terms as well as country-specific innovations could still be affected by global shocks, but $\mathbf{g}_{t}$ cannot enter the country-specific cointegrating relationships between debt and output.

Table 1: Country coverage

\begin{tabular}{llll}
\hline Europe & MENA Countries & Asia Pacific & Latin America \\
Austria & Egypt & Australia & Argentina \\
Belgium & Iran & China & Brazil \\
Finland & Morocco & India & Chile \\
France & Tunisia & Indonesia & Ecuador \\
Germany & Turkey & Japan & Peru \\
Italy & & Korea & Venezuela \\
Netherlands & & Malaysia & \\
Norway & North America & New Zealand & Rest of Africa \\
Spain & Canada & Philippines & Nigeria \\
Sweden & Mexico & Singapore & South Africa \\
Switzerland & United States & Thailand & \\
United Kingdom & & & \\
& & & \\
\hline
\end{tabular}

Notes: See Section A.5 in the Appendix for the description of data.

The long-run relationship between $y_{i t}$ and $d_{i t}$, although theoretically compelling, there are many reasons that it might not hold in practice, due to measurement problems, bond market imperfections and the ability of the governments to shift the burden of debt from one generation to the next through debt monetization. ${ }^{11}$ As a result there could be prolonged periods over which $y_{i t}$ and $d_{i t}$ deviate from

\footnotetext{
${ }^{11}$ Debt monetization involves the government issuing new government bonds which are then purchased by the central bank thereby increasing the money supply.
} 
one another with only a very slow rate of adjustment towards equilibrium. To shed light on the long run relationship between $y_{i t}$ and $d_{i t}$, we constructed an annual database featuring the real GDP and the gross government debt time series for a panel of 39 countries covering the sample period 19652016. This panel features a diverse set of advanced and emerging economies. The panel is slightly unbalanced at the beginning of the sample due to unavailability of data in the case of some of the emerging economies. The list of the countries in our sample is provided in Table 1, while details on data sources are given in the Appendix A.5.

Figure 1 provides the time series plots of $y_{i t}$ and $d_{i t}$. These charts show a mixed picture. There appears to be a close relationship between output and debt in Austria, China, India, and perhaps Egypt. In contrast, the long-run relationship does not appear to hold for Australia and Chile over the particular sample period we consider. For the remaining countries the figures alone do not help and a more formal statistical investigation is required. To this end we first carried out unit root tests to confirm that both $y_{i t}$ and $d_{i t}$ are $I(1)$ as opposed to being $I(0)$. The results are in line with our expectations and other similar studies in the literature, in particular for $y_{i t}$. Next we carried out maximum eigenvalue and trace cointegration tests of Johansen (1991) using a VAR(4) with unrestricted intercepts. The test results for all the 39 countries are reported in Table A1 in the Appendix. As can be seen the test outcomes give a mixed picture. With data spanning a few decades, the null of no cointegration between $y_{i t}$ and $d_{i t}$ cannot be rejected for about half of the countries in our sample. In addition, even when the cointegrating relationship between $y_{i t}$ and $d_{i t}$ is statistically confirmed, it does not necessarily follow that the cointegrating vector is $(1,-1)^{\prime}$. See Table A2 in the Appendix for estimates of the long run relationships. In the steady state we must have $d_{i t}-y_{i t} \sim I(0)$, otherwise a balanced growth path cannot exist. But in the medium-to-long run we could have $\boldsymbol{\beta}_{i} \neq(1,-1)^{\prime}$ (or no cointegration), as we find in our sample which might not be sufficiently long for the purpose of long run analysis. 
Figure 1: Plots of real GDP and public debt (right scale), in logs

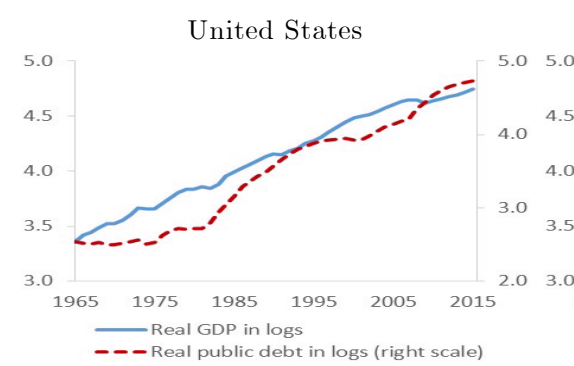

United Kingdom

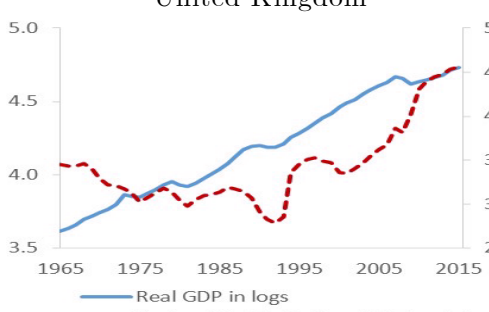

Spain

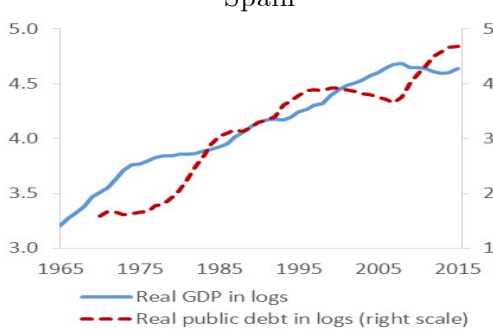

Finland

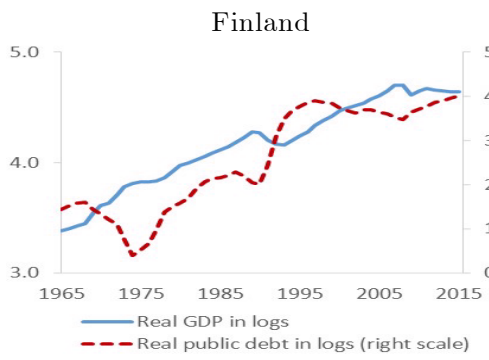

Netherlands

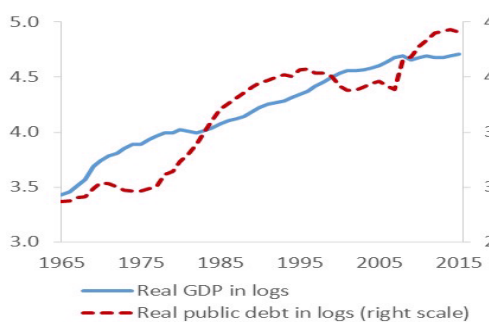

Switzerland

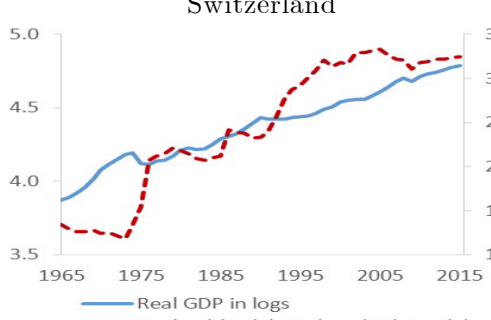

Japan

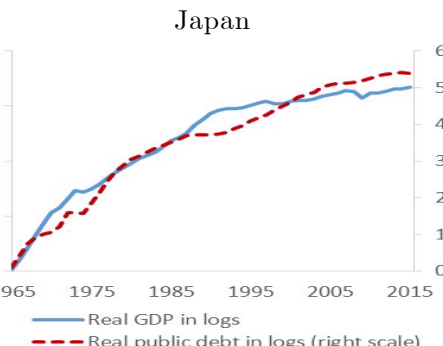

France

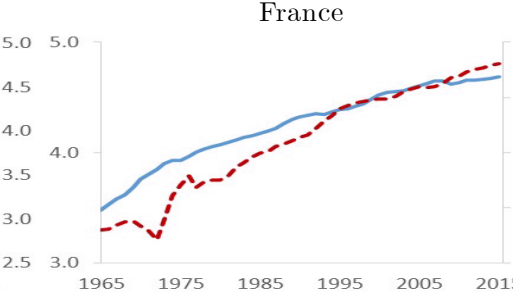

- Real GDP in logs

Canada

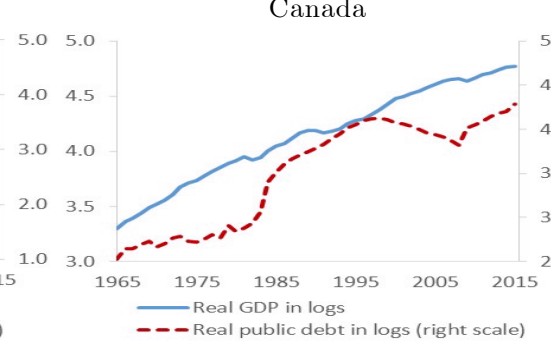

Norway

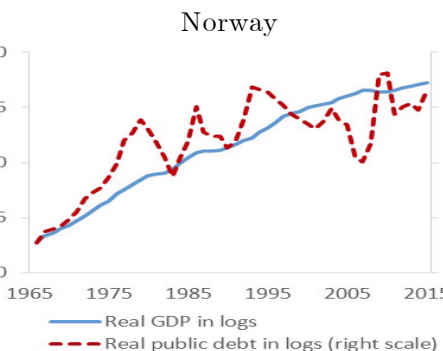

Belgium

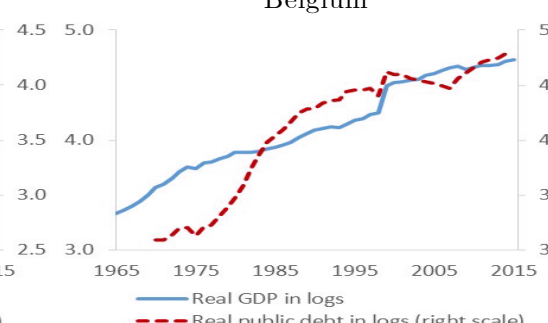

- - Real public debt in logs (right scale)

Sweden

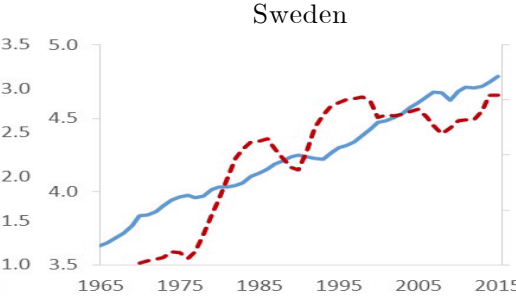

- Real GDP in logs
Germany

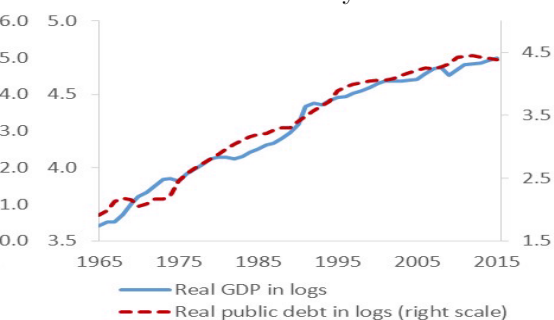

Italy

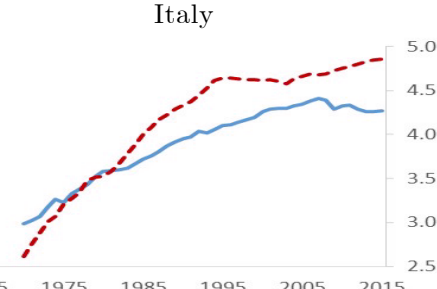

- Real GDP in logs

Australia

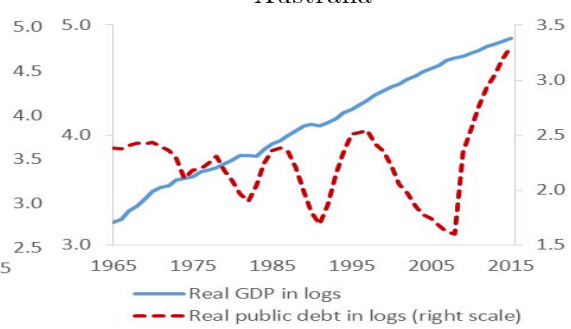

New Zealand

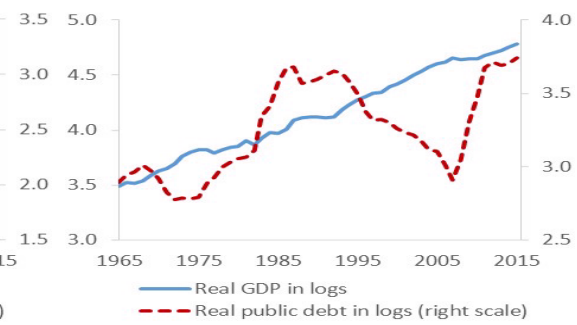

Austria

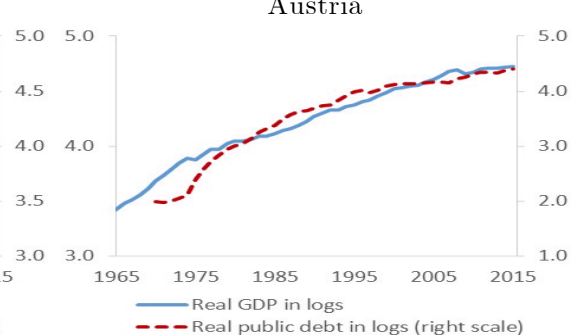

Korea

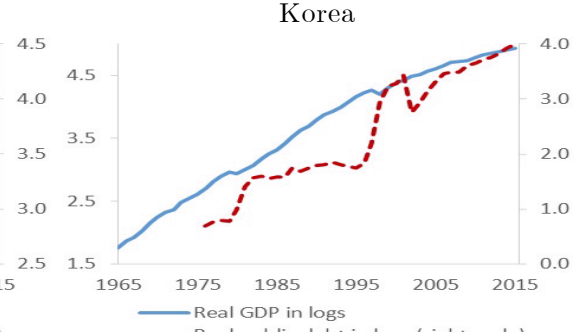




\section{Figure 1 (Ctd.) Plots of real GDP and public debt (right scale), in logs}
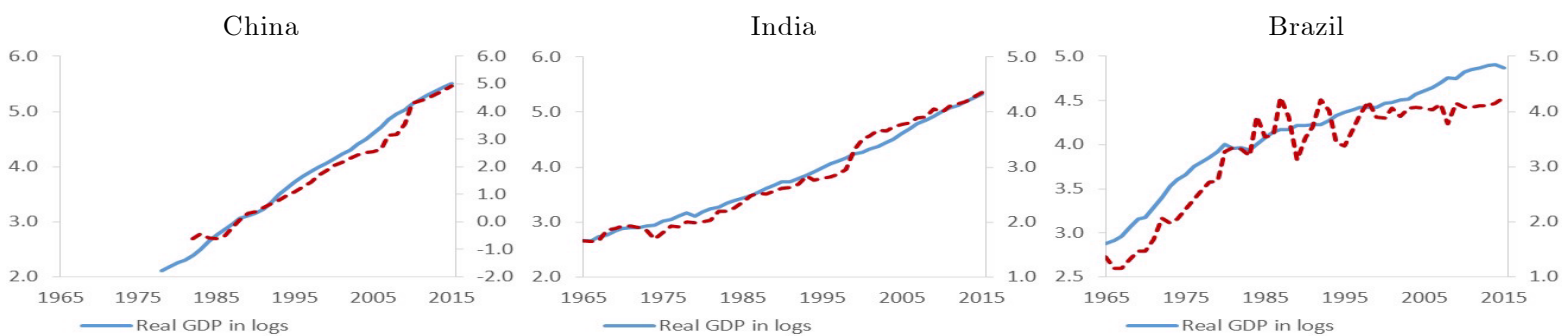

Mexico
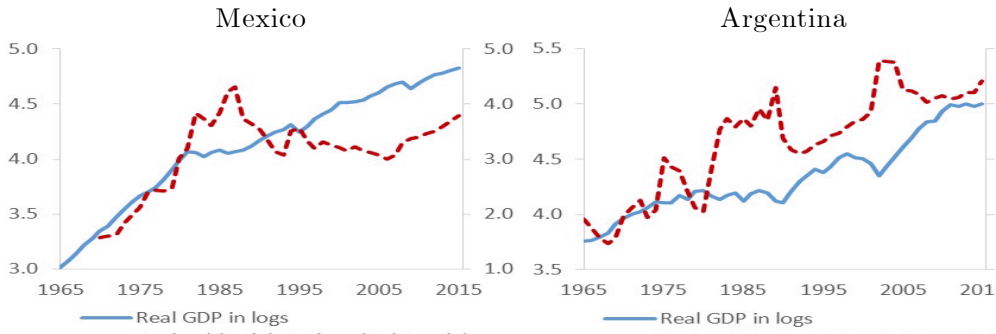

- - - Real public debt in logs (right scale)

Venezuela

Chile

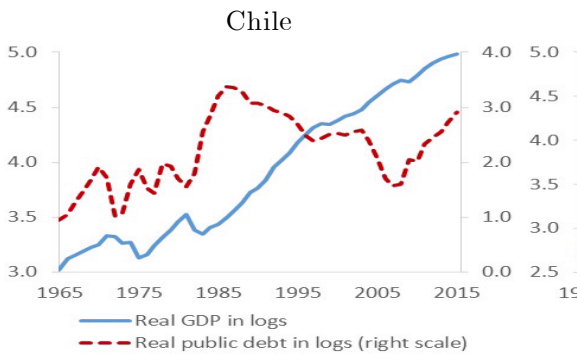

_ Real GDP in logs

- - Real public debt in logs (right scale)

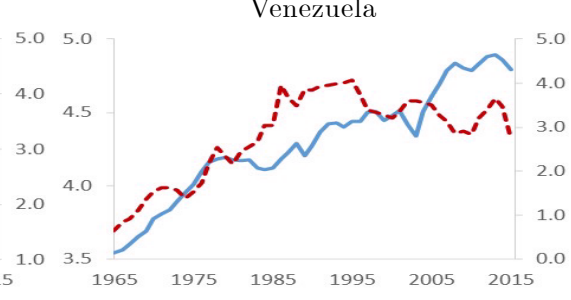

Real GDP in logs

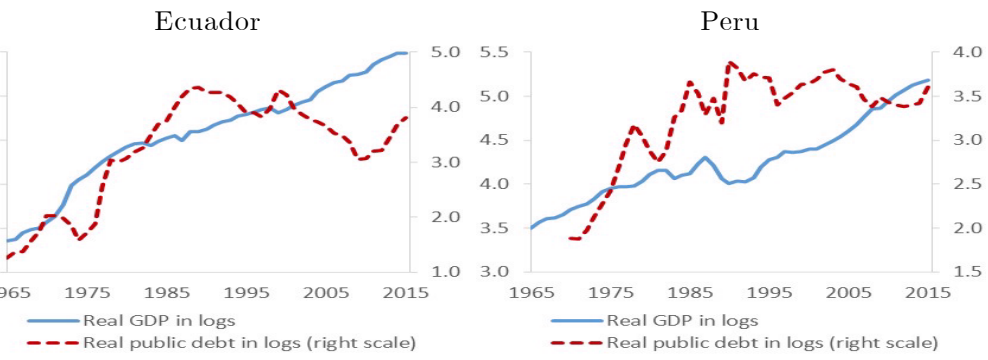

South Africa

Iran

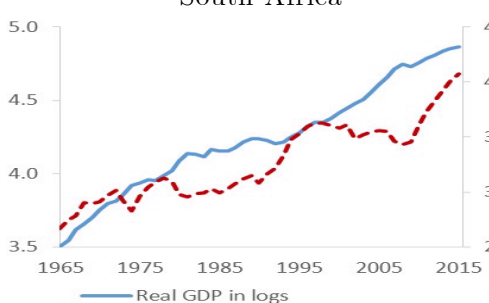

$\begin{array}{ll}4.5 & \\ 4.0 & 4.5 \\ -3.5 & \\ & 3.5 \\ 3.0 & \\ 2.5 & 2.5 \\ 15 & 19\end{array}$
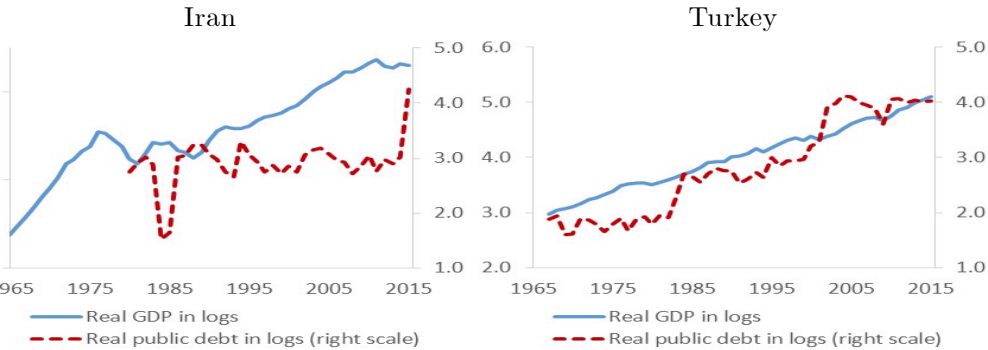

- - - Real public debt in logs (right scale)

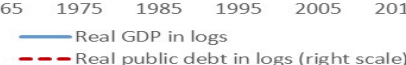

Real GDP in logs

- - Real public debt in logs (right scale)

Egypt
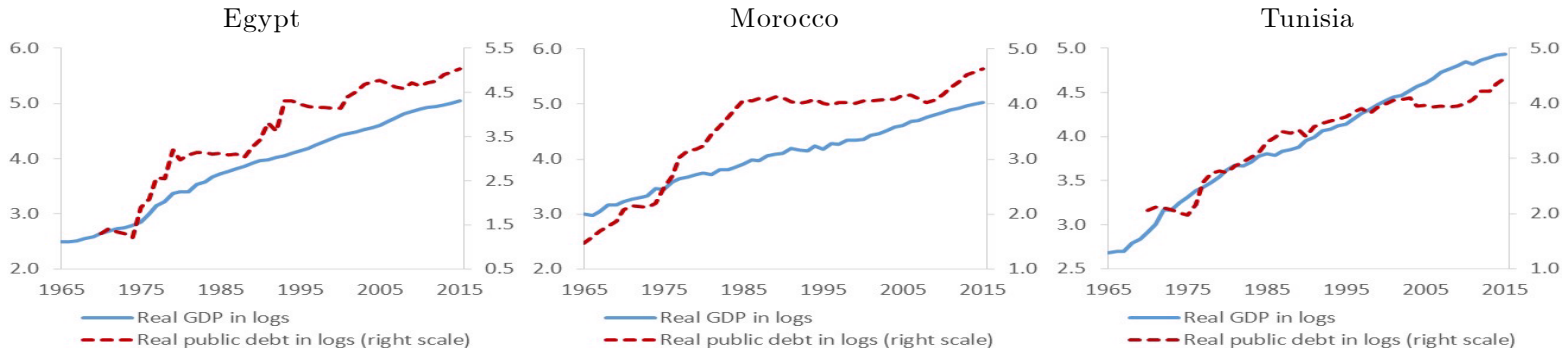

Malaysia

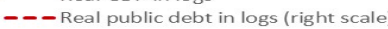

Indonesia

Philippines
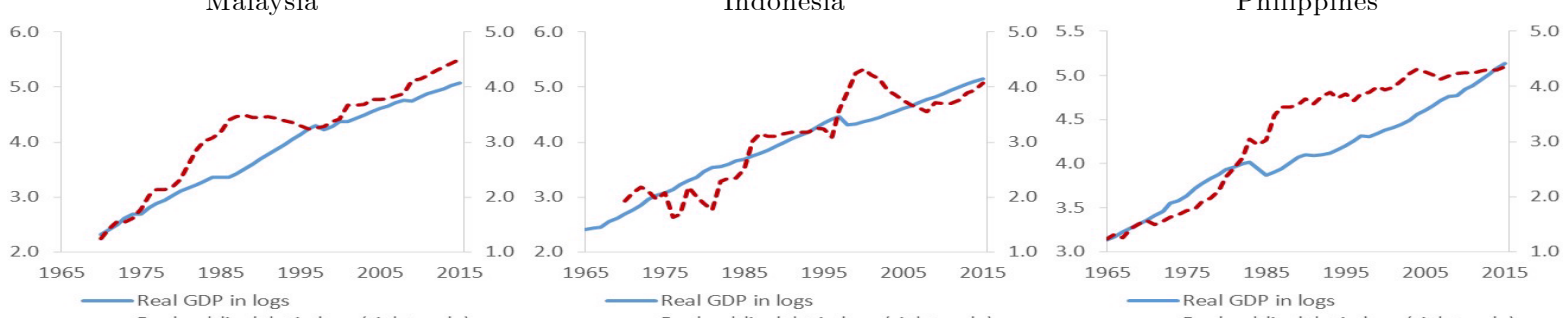

Real GDP in logs

- Real GDP in log

Real GDP in logs

- - Real public debt in logs (right scale)

- - Real public debt in logs (right scale)

- - Real public debt in logs (right scale) 


\section{Global output and fiscal policy shocks and their effects}

Given the mixed long-run evidence, in this paper we abstract from the error-correcting terms in (1) and focus on the relationship of output growth and the rate of change of debt-to-GDP over the business cycle. Accordingly, we define $\Delta \mathbf{x}_{i t}=\left(\Delta b_{i t}, \Delta y_{i t}\right)^{\prime}$ to aid the subsequent discussion of shock identification, where $\Delta b_{i t}=\Delta d_{i t}-\Delta y_{i t}$ is the rate of change of debt-to-GDP, and $\Delta y_{i t}$ is the real output growth. Empirically, country-specific VAR models in terms of $\left(\Delta b_{i t}, \Delta y_{i t}\right)$ and $\left(\Delta y_{i t}, \Delta d_{i t}\right)$ are equivalent, but identification of the shocks is simpler to motivate under the former formulation.

The reduced-form global shocks $\mathbf{v}_{t}$ are identified from (6) when $N$ is large, but the common factors, $\mathrm{g}_{t}$, and a rotated global shocks that have an economic interpretation are not identified. For identification of the global shocks, a suitable linear combination of the reduced-form global shocks, defined by $\mathbf{A}_{v} \mathbf{v}_{t}$, could be considered. The choice of $\mathbf{A}_{v}$ can be based on economic theory considerations. This could be done in the context of a VAR in cross section averages (4), by considering the impact of global structural shocks on the global aggregates alone. Alternatively, the choice of $\mathbf{A}_{v}$ can be based on a characterization of the impacts of structural common shocks on individual cross-section units, using the GVAR representation (10).

The choice of $\mathbf{A}_{v}$ could also be guided by the pattern of cross section dependence observed in data with or without conditioning on a suitably defined set of cross section averages, as in Cesa-Bianchi, Pesaran, and Rebucci (2018, hereafter CPR). CPR consider a quarterly multicountry model of real output growth and equity market volatility, and propose a novel identification scheme whereby the differential pattern of cross-sectional correlation of the innovations to output growth and volatility are used to identify the global shocks as a global growth shock from a global financial shock. Specifically, they find that output growth and volatility are both cross-sectionally strongly dependent (CSD), but conditional on world output growth, the resultant country-specific output growth innovations are no longer strongly cross-correlated, but in contrast residuals of the regressions of volatility series on world output growth continue to be CSD, thus suggesting a recursive scheme for identification of the global shocks. We follow the same approach below, and use evidence on cross section dependence of $\Delta y_{i t}$ and $\Delta b_{i t}$ and their innovations conditional on their global counterparts, namely $\Delta \bar{y}_{t}=N^{-1} \sum_{i=1}^{N} \Delta y_{i t}$ and $\Delta \bar{b}_{t}=N^{-1} \sum_{i=1}^{N} \Delta b_{i t}$, to motivate identification of global shocks. 


\subsection{Evidence on cross section (CS) dependence}

We use the exponent of CS dependence, average pair-wise correlations and Pesaran's CD test to measure the significance and degree of CS dependence in $\Delta y_{i t}$ and $\Delta b_{i t}$ and their innovations computed as residuals from the regressions of $\Delta y_{i t}$ and $\Delta b_{i t}$ on $\Delta \bar{y}_{t}$ and/or $\Delta \bar{b}_{t}$ and their lagged values, namely regressions that are augmented with cross section averages, $\Delta \bar{y}_{t}$ and $\Delta \bar{b}_{t}$. Bailey et al. (2016, hereafter BKP) define the parameter $\alpha$ as the exponent of CS dependence of $x_{i t}$ if $\operatorname{Std}\left(\bar{x}_{t}\right)=\ominus\left(N^{\alpha-1}\right)$, where $\bar{x}_{t}=N^{-1} \sum_{i=1}^{N} x_{i t}$. Consequently, $\alpha=1$ corresponds to the standard factor model, whereas the typical spatial models imply much weaker CS dependence with $\alpha \leq 1 / 2$. BKP show that it is possible to identify and consistently estimate $\alpha$ for values of $\alpha>0.5$. Pesaran (2004)'s CD test is based on the average of pair-wise correlations,

$$
C D=\sqrt{\frac{T N(N-1)}{2}} \widehat{\bar{\rho}} \text {, where } \widehat{\bar{\rho}}=\frac{2}{N(N-1)} \sum_{i=1}^{N-1} \sum_{j=i+1}^{N} \hat{\rho}_{i j}
$$

and $\hat{\rho}_{i j}$ is the sample correlation of $x_{i t}$ and $x_{j t}$. Pesaran (2015a) show that the null of CD test depends on relative expansion rates of $N$ and $T$. When $T=O\left(N^{\epsilon}\right)$ for some $0<\epsilon \leq 1$, the implicit null is given by $\bar{\rho}=O\left(N^{2 \alpha-2}\right)$, for $0 \leq \alpha<(2-\epsilon) / 4$, which gives $0 \leq \alpha<0.25$ when $\epsilon=1$. Under the null, $C D$ is asymptotically distributed as $N(0,1)$.

Findings for these three measures of CS dependence, applied to $y_{i t}$ and $b_{i t}$ as well as residuals obtained from country-specific VAR models with or without CS augmentation are reported in Table 2. These results suggest that: (1) $y_{i t}$ and $b_{i t}$ are quite strongly cross-sectionally dependent, since the estimates of $\hat{\alpha}$ fall in the range of $0.92-0.94$ with an upper 95 percent confidence bound 0.99 , and the reported values of CD test statistics are very high, in the range of $27-37$, (2) $\Delta y_{i t}$ is weakly CS dependent conditional on the world growth factor, since $\hat{\alpha}$ falls to 0.63 , and CD test statistics falls to -2.4, and (3) $\Delta b_{i t}$ conditional on the world growth factor continue to be strongly CS correlated with the CD test statistics falling to 8.8 which is still statistically highly significant, and the estimates of the exponent of CS dependence falling only to 0.78, which is still sizable. Hence, there is evidence for a single world growth factor in $\Delta y_{i t}$. But an additional factor is required for modelling of $\Delta b_{i t}$. These conclusions match the ones obtained by CPR in their analysis of growth and volatility. We use these differences in the patterns of cross country correlations to motivate our proposed identification of innovations to world growth factor, as in CPR. 
Table 2: Average pair-wise correlations $(\bar{\rho})$, Pesaran's CD test statistics, and estimates of the exponent of CS dependence $(\hat{\alpha})$.

\begin{tabular}{|c|c|c|c|c|c|}
\hline & \multirow[b]{2}{*}{$\widehat{\bar{\rho}}$} & \multirow[b]{2}{*}{$C D$} & \multicolumn{3}{|c|}{ Estimates of $\alpha$} \\
\hline & & & Lower $5 \%$ & $\hat{\alpha}$ & Upper $95 \%$ \\
\hline \multicolumn{6}{|c|}{ Data in rates of change (de-meaned) } \\
\hline$\Delta b_{i t}$ & 0.15 & 27.5 & 0.88 & 0.94 & 0.99 \\
\hline$\Delta y_{i t}$ & 0.19 & 37.0 & 0.85 & 0.92 & 0.99 \\
\hline \multicolumn{6}{|c|}{ VAR in $\Delta \mathbf{x}_{i t}$ without augmentation with CS avg. } \\
\hline$\Delta b_{i t}$ residuals & 0.11 & 20.9 & 0.86 & 0.92 & 0.97 \\
\hline$\Delta y_{i t}$ residuals & 0.17 & 31.5 & 0.86 & 0.94 & 1.01 \\
\hline \multicolumn{6}{|c|}{ VAR in $\Delta \mathbf{x}_{i t}$ augmented with lags of $\Delta \overline{\mathbf{x}}_{t}$} \\
\hline$\Delta b_{i t}$ residuals & 0.12 & 21.4 & 0.87 & 0.93 & 0.98 \\
\hline$\Delta y_{i t}$ residuals & 0.16 & 29.9 & 0.87 & 0.94 & 1.01 \\
\hline \multicolumn{6}{|c|}{ VAR in $\Delta \mathbf{x}_{i t}$ augmented with $\hat{v}_{y, t}$ and lags of $\Delta \overline{\mathbf{x}}_{t}$} \\
\hline$\Delta b_{i t}$ residuals & 0.05 & 8.8 & 0.75 & 0.78 & 0.81 \\
\hline$\Delta y_{i t}$ residuals & -0.01 & -2.4 & 0.57 & 0.63 & 0.69 \\
\hline \multicolumn{6}{|c|}{ VAR in $\Delta \mathbf{x}_{i t}$ augmented with $\hat{v}_{y, t}, \hat{v}_{b, t}$, and lags of $\Delta \overline{\mathbf{x}}_{t}$} \\
\hline$\Delta b_{i t}$ residuals & 0.00 & 0.9 & 0.64 & 0.68 & 0.72 \\
\hline$\Delta y_{i t}$ residuals & -0.01 & -2.3 & 0.58 & 0.64 & 0.70 \\
\hline
\end{tabular}

Notes: The top part of this table presents the average pair-wise cross-sectional correlations $(\widehat{\bar{\rho}})$ and the $C D$ test defined in (11), and the estimates of the exponent of CS dependence by Bailey et al. (2016), all applied to the data $\Delta b_{i t}$ and $\Delta y_{i t}$ (de-meaned). CD test is proposed and discussed by Pesaran (2004) and Pesaran (2015a). The remaining parts of this table report these statistics for the residuals of country-specific VARs with or without augmentations.

\subsection{Estimated global shocks}

In line with the evidence above, we follow CPR and identify the innovations to world growth factor $\left(v_{y, t}\right)$, and the innovations to world debt factor $\left(v_{b, t}\right)$ as:

$$
\begin{aligned}
& v_{y, t}=\Delta \bar{y}_{t}-E\left(\Delta \bar{y}_{t} \mid \mathcal{I}_{t-1}\right), \text { and } \\
& v_{b, t}=\Delta \bar{b}_{t}-E\left(\Delta \bar{b}_{t} \mid \Delta \bar{y}_{t}, \mathcal{I}_{t-1}\right),
\end{aligned}
$$

where $\mathcal{I}_{t-1}$ is the information set consisting of all information available up to period $t-1$. This ensures that $v_{y, t}$ and $v_{b, t}$ are mutually and serially uncorrelated. We use the VAR representation in cross-section averages (6), estimated by LS, and the ordering scheme (12)-(13) to obtain estimates of the global shocks, denoted by $\hat{\mathbf{v}}_{t}=\left(\hat{v}_{y, t}, \hat{v}_{b, t}\right)^{\prime}$. In what follows, we refer to $v_{y, t}$ and $v_{b, t}$ as global output and global fiscal policy shocks, respectively.

\subsection{Country-specific effects of the global shocks}

To corroborate the evidence on the pattern of CS dependence, we present additional tests summarizing the significance of the global shocks in country-specific regressions. Table 3 reports the coefficients of 
the global shocks and their $t$-ratios for all the 39 countries in our sample. As can be seen the global growth shock is statistically significant in output equation in the majority of countries (28 out of 39), and to a lesser degree in the debt-to-GDP regressions (6 out of 39). In contrast, the global debt shock is (with the exception of Nigeria, Singapore and Switzerland) statistically significant only in the debt equation (15 out of 39$).{ }^{12}$

Regarding the magnitude of coefficients of the output shock in the output equation, it is interesting to observe that the largest coefficients belong to emerging economies (Peru 2.6, Malaysia 2.06, Brazil 1.83, and Argentina 1.36 among others), whereas advanced economies tend to have smaller coefficients, albeit highly significant in most cases, and generally close to one (for example USA 0.87, France 0.82, Germany 1.08, and Japan 1.02). The size of the economy and industry mix are both likely to be important determinants of the size of these coefficients, in addition to their degree of integrations to the global economy. The countries with statistically insignificant loadings on the global growth factor (at the 10 percent level) includes Australia, New Zealand, India, Iran, Nigeria, and Chile. From this set only three of these countries had a negative loadings, namely India, Iran, and Nigeria. These outcomes could be the result of many factors, such as inward-looking economic policies, wars, revolutions, and economic sanctions. For example, Indian economy started to become liberalized and integrated to the rest of the world economy only from late 1990s, whilst both Iran and Nigeria have experienced prolonged periods of wars and economic instability. The low estimates of the coefficients on the global growth factor for Australia and New Zealand could be due to the remoteness of these economies from Europe and the US.

Significant loadings on the global shocks relate to the contributions of the global shocks to the overall fit of country-specific models. Standard errors of the reduced-form errors in the models with and without CS augmentations are provided in Table A3 in the Appendix. Standard errors of reducedform errors are larger by about 23 percent in the case of output equation and by about 15 percent in the case of debt equations, with somewhat larger differences observed for advanced economies in the case of output equations. Low ratios are observed in countries where CS augmentation did not contribute to a meaningful increase in the fit (e.g. Iran), and the reported differences are well in line with the reported findings in Table 3 .

\footnotetext{
${ }^{12}$ These tests are carried out at the 5 percent significance level.
} 
Table 3: Evidence on statistical significance of global shocks in country-specific VARs

\begin{tabular}{|c|c|c|c|c|c|c|c|c|}
\hline & \multicolumn{4}{|c|}{ output eq. $\left(\Delta y_{i t}\right)$} & \multicolumn{4}{|c|}{ debt eq. $\left(\Delta b_{i t}\right)$} \\
\hline & \multicolumn{2}{|c|}{$\hat{v}_{y, t}$} & \multicolumn{2}{|c|}{$\hat{v}_{b, t}$} & \multicolumn{2}{|c|}{$\hat{v}_{y, t}$} & \multicolumn{2}{|c|}{$\hat{v}_{b, t}$} \\
\hline & coef. & t-stat & coef. & t-stat & coef. & t-stat & coef. & t-stat \\
\hline Argentina & $1.36^{\dagger}$ & 2.03 & -0.04 & -0.25 & -1.24 & -0.27 & $3.04^{\dagger}$ & 2.77 \\
\hline Australia & 0.32 & 1.51 & -0.03 & -0.49 & $-2.69^{\star}$ & -1.74 & $1.31^{\dagger}$ & 3.47 \\
\hline Austria & $0.73^{\dagger}$ & 3.18 & $-0.10^{\star}$ & -1.75 & 0.40 & 0.51 & $0.66^{\dagger}$ & 3.56 \\
\hline Belgium & $0.96^{\star}$ & 1.69 & -0.03 & -0.26 & -0.12 & -0.19 & 0.06 & 0.47 \\
\hline Brazil & $1.83^{\dagger}$ & 4.49 & 0.13 & 1.31 & -0.16 & -0.04 & $1.74^{\dagger}$ & 2.06 \\
\hline Canada & $0.82^{\dagger}$ & 3.99 & 0.01 & 0.25 & $-1.52^{\star}$ & -1.75 & 0.21 & 0.98 \\
\hline Chile & 0.44 & 0.62 & -0.25 & -1.42 & $-8.50^{\dagger}$ & -2.87 & 1.03 & 1.41 \\
\hline China & $0.90^{\dagger}$ & 2.52 & $0.15^{\star}$ & 1.70 & 2.14 & 0.73 & 0.39 & 0.53 \\
\hline Ecuador & 0.71 & 1.32 & -0.13 & -1.00 & 3.41 & 1.53 & $1.74^{\dagger}$ & 3.21 \\
\hline Egypt & 0.68 & 1.29 & 0.14 & 1.18 & -1.99 & -0.62 & 0.55 & 0.78 \\
\hline Finland & $1.05^{\dagger}$ & 3.10 & -0.08 & -0.92 & $-2.95^{\star}$ & -1.86 & $1.07^{\dagger}$ & 2.77 \\
\hline France & $0.82^{\dagger}$ & 5.94 & 0.01 & 0.26 & -0.68 & -0.48 & 0.08 & 0.22 \\
\hline Germany & $1.08^{\dagger}$ & 3.67 & -0.05 & -0.68 & -1.03 & -1.30 & $0.36^{\star}$ & 1.94 \\
\hline India & -0.42 & -1.10 & -0.04 & -0.43 & 0.44 & 0.40 & $0.62^{\dagger}$ & 2.26 \\
\hline Indonesia & $1.62^{\dagger}$ & 3.42 & 0.16 & 1.45 & -3.05 & -0.93 & $1.29^{\star}$ & 1.73 \\
\hline Iran & -0.76 & -0.67 & -0.19 & -0.69 & -4.77 & -0.48 & -0.96 & -0.41 \\
\hline Italy & $0.98^{\dagger}$ & 4.08 & -0.05 & -0.99 & -0.20 & -0.31 & $0.41^{\dagger}$ & 2.95 \\
\hline Japan & $1.02^{\dagger}$ & 3.58 & -0.01 & -0.22 & 1.32 & 1.43 & $0.84^{\dagger}$ & 4.10 \\
\hline Korea & $1.96^{\dagger}$ & 3.37 & $0.24^{\star}$ & 1.85 & -5.30 & -1.30 & -0.91 & -0.99 \\
\hline Malaysia & $2.06^{\dagger}$ & 4.72 & 0.01 & 0.09 & $-3.19^{\dagger}$ & -2.25 & 0.47 & 1.40 \\
\hline Mexico & $1.42^{\dagger}$ & 3.20 & 0.05 & 0.44 & -0.42 & -0.14 & 0.66 & 0.91 \\
\hline Morocco & 0.71 & 1.42 & 0.06 & 0.48 & -0.01 & -0.01 & $0.73^{\dagger}$ & 2.48 \\
\hline Netherlands & $0.91^{\dagger}$ & 4.03 & 0.00 & -0.07 & $-1.47^{\star}$ & -1.84 & 0.10 & 0.52 \\
\hline New Zealand & 0.37 & 1.08 & 0.02 & 0.17 & $-2.19^{\dagger}$ & -2.29 & 0.07 & 0.26 \\
\hline Nigeria & -0.89 & -1.33 & $-0.49^{\dagger}$ & -3.42 & -4.51 & -1.04 & $1.62^{\star}$ & 1.76 \\
\hline Norway & $0.63^{\dagger}$ & 3.13 & 0.06 & 1.24 & -2.06 & -0.93 & $0.89^{\star}$ & 1.66 \\
\hline Peru & $2.60^{\dagger}$ & 3.33 & 0.27 & 1.56 & -2.80 & -0.89 & 0.51 & 0.72 \\
\hline Philippines & $0.85^{\dagger}$ & 2.55 & 0.01 & 0.17 & -0.43 & -0.32 & $0.74^{\dagger}$ & 2.27 \\
\hline Singapore & $2.68^{\dagger}$ & 6.35 & $0.19^{\dagger}$ & 2.01 & -0.02 & -0.02 & $1.09^{\dagger}$ & 3.70 \\
\hline South Africa & $0.69^{\dagger}$ & 2.84 & -0.09 & -1.60 & 0.09 & 0.09 & $0.48^{\dagger}$ & 2.21 \\
\hline Spain & $0.83^{\dagger}$ & 3.16 & -0.05 & -0.77 & $-2.71^{\dagger}$ & -2.65 & 0.24 & 1.02 \\
\hline Sweden & $0.83^{\dagger}$ & 3.14 & -0.06 & -1.05 & $-2.42^{\dagger}$ & -2.44 & 0.02 & 0.10 \\
\hline Switzerland & $0.38^{\star}$ & 1.87 & $-0.16^{\dagger}$ & -3.38 & 1.62 & 1.25 & $0.78^{\dagger}$ & 2.57 \\
\hline Thailand & $1.44^{\dagger}$ & 3.36 & 0.05 & 0.48 & 2.14 & 0.79 & 1.02 & 1.57 \\
\hline Tunisia & $0.96^{\dagger}$ & 2.25 & 0.15 & 1.59 & -0.30 & -0.20 & 0.41 & 1.23 \\
\hline Turkey & $1.49^{\dagger}$ & 2.17 & 0.19 & 1.18 & 3.68 & 1.60 & 0.74 & 1.36 \\
\hline UK & $0.51^{\dagger}$ & 2.39 & -0.04 & -0.73 & 0.52 & 0.40 & 0.04 & 0.12 \\
\hline USA & $0.87^{\dagger}$ & 3.85 & 0.05 & 0.85 & $-1.01^{\dagger}$ & -2.01 & 0.00 & 0.01 \\
\hline Venezuela & $1.62^{\dagger}$ & 2.51 & 0.08 & 0.53 & $5.13^{\star}$ & 1.65 & $3.26^{\dagger}$ & 4.30 \\
\hline \multicolumn{9}{|c|}{ Number of rejections } \\
\hline${ }^{\dagger}$ significance at $5 \%$ & 28 & & 3 & & 6 & & 15 & \\
\hline$\star$ significance at $10 \%$ & 30 & & 6 & & 11 & & 19 & \\
\hline
\end{tabular}

Note: This table reports the coefficients and $t$-statistics of the global output shock, $v_{y, t}$, and global fiscal policy shock, $v_{b, t}$, in the country-specific VARs. Significant values at $5 \%$ and $10 \%$ are denoted by subscripts ${ }^{\dagger}$ and $^{\star}$, respectively. The lower panel of this table summarizes the number of rejections at 5 percent and 10 percent nominal levels. There are 39 countries in the dataset. 


\subsection{FEVDs and IRFs of the global shocks}

Using the global shocks, $\hat{\mathbf{v}}_{t}$, we estimate the country-specific models in (8) and form the associated GVAR model, as defined by (10). ${ }^{13}$ Based on this representation, we compute forecast error variance decomposition for the two sets of shocks (global versus national), and compute impulse response functions for the two global shocks. By orthogonality of the two types of shocks, the Forecast Error Variance Decomposition (FEVD) contributions of the two sets of shocks (common and country-specific) sum up to 100 percent. For details of the derivations of the forecast error variance decompositions see Appendix A.2.

Table 4 reports a summary of FEVD results. These findings do not depend on the chosen ordering (12)-(13). We note that global shocks are clearly important, but their importance vary with the variable type and the horizon being considered. On average, global shocks account for about one third of the total variance of output growth across countries. The importance of global shocks for output growth is slightly lower, about a quarter, for short (year $\mathrm{Y}=0$ ) horizon as compared to 31 percent at long horizons $(Y=10)$. Global shocks are comparatively less important for the debt-to-GDP variable, about one eights at short horizon $(\mathrm{Y}=0)$ and one fifth of total variance at longer horizons.

Figure 2 shows the effects of one standard error (s.e.) increase in $\hat{v}_{y, t}$ and $\hat{v}_{b, t}$. These impulseresponse functions depend on the ordering (12)-(13). As can be seen, the effects of both global shocks tend to vanish within 4-5 years, with the effects of shocks to the global growth factor being relatively more persistent. Global growth shocks lower debt-to-GDP ratio, with one percentage point (ppt) increase in median output growth (across countries) following the global growth shock resulting in about $2 p p t$ decline in the median debt-to-GDP ratio in $\mathrm{Y}=0$. Global fiscal policy shock, $\hat{v}_{b, t}$, stimulates output with a lag, and the positive effects on output persists for $2-3$ years. A 1ppt increase in debt-to-GDP following the global fiscal policy shock results in $0.18 p p t$ increase in median output in $\mathrm{Y}=1$, and $0.17 \mathrm{ppt}$ in $\mathrm{Y}=2$, before declining to $0.08 \mathrm{ppt}$ in $\mathrm{Y}=3$ (median across countries).

\footnotetext{
${ }^{13}$ We allow for country-specific lag orders for domestic variables, $p_{i}$, and cross-section averages, $q_{i}$, both selected by $\mathrm{BIC}$ with the maximum lag orders $p_{\max }=q_{\max }=2$.
} 
Table 4: FEVD: Global and national shocks (medians across countries)

\begin{tabular}{rllll}
\hline \hline & \multicolumn{4}{c}{ output growth } \\
\cline { 2 - 5 } Years & $Y=0$ & $Y=1$ & $Y=5$ & $Y=10$ \\
\hline Global shocks & $24.3 \%$ & $27.4 \%$ & $30.9 \%$ & $31.1 \%$ \\
National shocks & $71.9 \%$ & $63.2 \%$ & $58.2 \%$ & $58.1 \%$ \\
\hline & \multicolumn{4}{c}{ debt-to-GDP growth } \\
\cline { 2 - 5 } Years & $Y=0$ & $Y=1$ & $Y=5$ & $Y=10$ \\
\hline Global shocks & $12.2 \%$ & $17.2 \%$ & $20.7 \%$ & $20.8 \%$ \\
National shocks & $77.5 \%$ & $67.1 \%$ & $62.8 \%$ & $62.8 \%$ \\
\hline \hline
\end{tabular}

Notes: Columns refer to the chosen horizon $Y=0,1,5$, and 10 years. Median values across $R=2000$ bootstrap replications are reported. The details on the variance decompositions are provided in Appendix A.2. The details of the bootstrapping procedure are provided in Appendix A.3.

Figure 2: Impulse response function for the effects of global shocks (median across countries)

Positive one s.e. global output shock
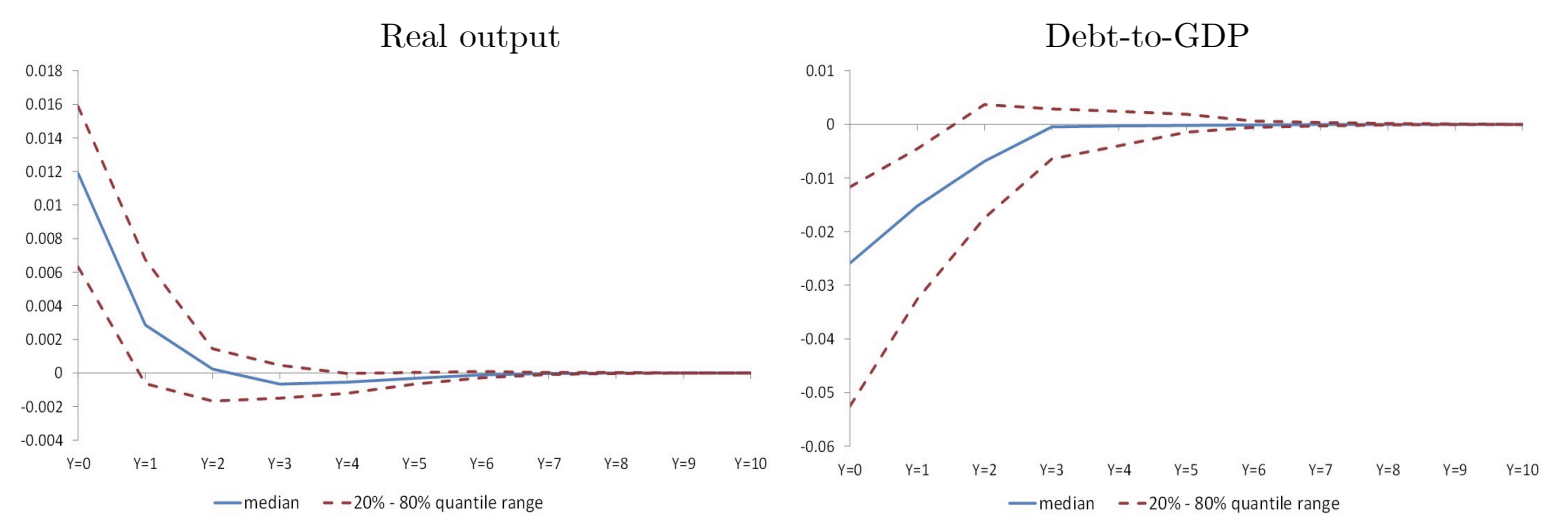

Positive one s.e. global fiscal shock
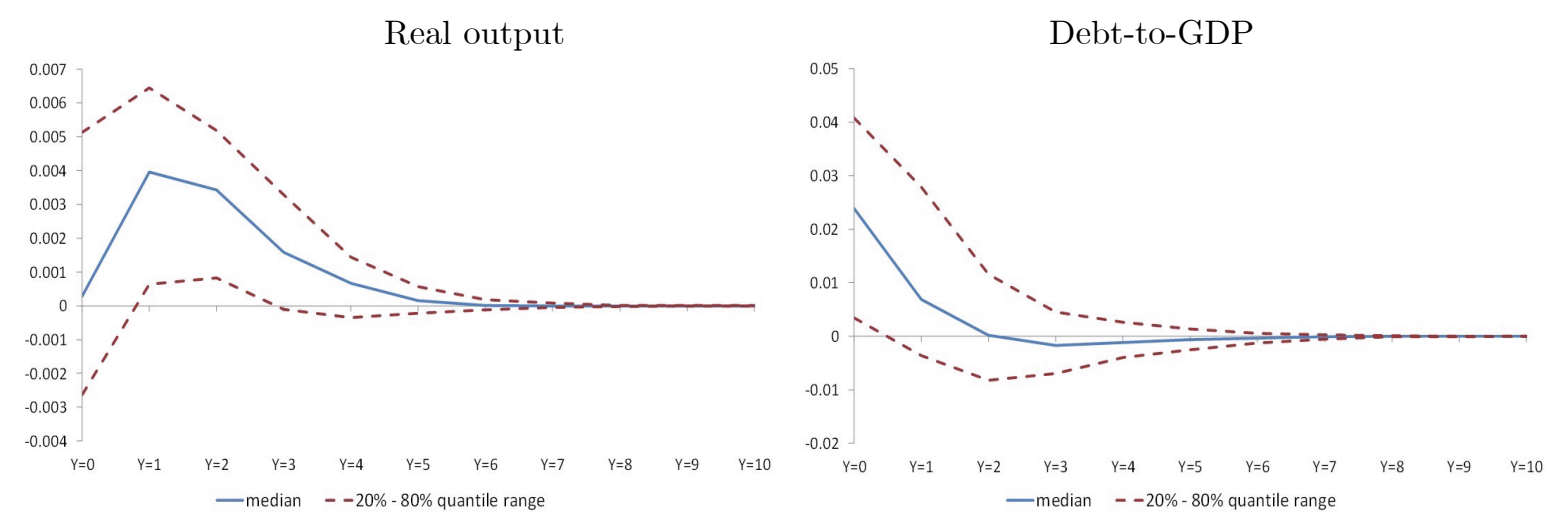

Notes: The plots in this figure show impulse responses of identified global shocks using the triangular ordering given by (12)-(13). Medians and 20-80 percent quantile ranges (across countries) are reported. 


\section{National shocks}

For identification of national shocks, it is useful to distinguish between identification of shocks within a given country, and identification of shocks across countries. The former problem has received a great deal of attention in the applied macro literature, some reviewed in Section 2, where a number of identification schemes have been considered and discussed. In contrast, the latter identification problem has received little attention. Notable exceptions are spatial econometric models, where origins of shocks are identified using geographic or economic distance often embodied in a priori specified spatial weight matrix.

Our modelling approach allows idiosyncratic shocks to correlate across countries, so long as this correlation is weak. To shed light on this correlation, we computed regularized reduced-form error covariance matrix estimate of $\boldsymbol{\Sigma}=E\left(\varepsilon_{t} \varepsilon_{t}^{\prime}\right)$ proposed by Bailey, Pesaran, and Smith (2018), and found that only a few of these pair-wise covariances (over $i$ and $j$ ) are non-zero. In particular, we find nonzero covariances in only 4 out of 2964 possible country-variable pairs! The country-pairs with nonzero correlations are given in Table A4 in the Appendix. Given the evidence of almost no correlation of $\varepsilon_{i t}$ across countries, in what follows we only allow for within country non-zero covariances, and assume that idiosyncratic errors are not correlated across countries. In effect, we are assuming that the common shocks, $\mathbf{v}_{t}$, capture almost all important cross country error correlations.

We are thus left with the problem of identifying the different types of shocks within a given country $i$, namely finding $\mathbf{A}_{i}$ such that $\boldsymbol{\eta}_{i t}=\mathbf{A}_{i} \boldsymbol{\varepsilon}_{i t}$, where $\boldsymbol{\eta}_{i t}$ can be viewed as national 'structural' shocks. Any identification scheme proposed in the (standard) VAR literature could be employed for this purpose. Here we follow the approach by Baumeister and Hamilton (2015) which uses sign restrictions in a Bayesian context to identify $\boldsymbol{\eta}_{i t}$.

Our identifying assumptions are based on the following premise. We view national shocks that result in:

- negative contemporaneous correlation between $\Delta y_{i t}$ and $\Delta b_{i t}$ as a technology shock,

- positive contemporaneous correlation between $\Delta y_{i t}$ and $\Delta b_{i t}$ as a fiscal policy shock.

Hence, a technology shock increases output and decreases debt-to-GDP ratio. A fiscal policy shock increases output as well as debt-to-GDP ratio. Given our assumption that $\boldsymbol{\varepsilon}_{i t}$ (and hence $\boldsymbol{\eta}_{i t}$ ) 
are uncorrelated over $i$, we only need to consider identification of $\boldsymbol{\eta}_{i t}$ for each $i$, separately. In what follows we simplify the notations by dropping the subscript $i$, and abstracting from global shocks and dynamics which are not essential to the identification problem under consideration.

According to the above identification scheme, we write the corresponding 'structural' model as,

$$
\begin{aligned}
& \Delta b_{t}=-\alpha \Delta y_{t}+\eta_{b t}, \\
& \Delta b_{t}=\beta \Delta y_{t}+\eta_{y t},
\end{aligned}
$$

where $\alpha, \beta>0$ and $\operatorname{Var}\left(\boldsymbol{\eta}_{t}\right)=\mathbf{D}, \mathbf{D}$ is diagonal with $\left(\sigma_{\eta b}^{2}, \sigma_{\eta y}^{2}\right)^{\prime}$ on the diagonal, and $\boldsymbol{\eta}_{t}=\left(\eta_{b t}, \eta_{y t}\right)^{\prime}$. The above system of equations can be rewritten equivalently in terms of debt and output, using $\Delta b_{t}=\Delta d_{t}-\Delta y_{t}$,

$$
\begin{aligned}
\Delta d_{t} & =(1-\alpha) \Delta y_{t}+\eta_{b t}, \\
\Delta d_{t} & =(1+\beta) \Delta y_{t}+\eta_{y t},
\end{aligned}
$$

in which $\epsilon_{\alpha}=(1-\alpha)$ is the elasticity of debt with respect to output when output expands due to a technology shock, and $\epsilon_{\beta}=(1+\beta)$ is the elasticity of debt with respect to output when output expands due to fiscal policy shock. In what follows we refer to $\epsilon_{\alpha}\left(\epsilon_{\alpha}<1\right)$ and $\epsilon_{\beta}\left(\epsilon_{\beta}>1\right)$ as debt elasticities corresponding to technology and fiscal policy shocks, respectively.

Let $\Delta \mathbf{x}_{t}=\left(\Delta b_{t}, \Delta y_{t}\right)^{\prime}$ and write (14) and (15) as

$$
\mathbf{A} \Delta \mathbf{x}_{t}=\boldsymbol{\eta}_{t} \text {, where } \mathbf{A}=\left(\begin{array}{cc}
1 & \alpha \\
1 & -\beta
\end{array}\right)
$$

which is similar to the textbook demand-supply model discussed recently within a Bayesian context by Baumeister and Hamilton $(\mathrm{BH})$. The corresponding reduced-form representation is

$$
\Delta \mathbf{x}_{t}=\underbrace{\mathbf{A}^{-1} \boldsymbol{\eta}_{t}}_{\boldsymbol{\varepsilon}_{t}} \text {, where } \mathbf{A}^{-1}=\frac{1}{\alpha+\beta}\left(\begin{array}{cc}
\beta & \alpha \\
1 & -1
\end{array}\right) \text {. }
$$

Hence, $\eta_{b t}$ (expansionary fiscal policy shock) gives rise to a positive correlation between $\Delta y_{t}$ and $\Delta b_{t}$, and $\eta_{y t}$ (contractionary technology shock) gives rise to a negative correlation between $\Delta y_{t}$ and $\Delta b_{t}$. 
Consider the variance of the reduced-form shocks defined by $\varepsilon_{t}=\mathbf{A}^{-1} \boldsymbol{\eta}_{t}$,

$$
V\left(\varepsilon_{t}\right)=\mathbf{A}^{-1} \mathbf{D A}^{-1 \prime}=\boldsymbol{\Omega}=\left(\begin{array}{ll}
\omega_{11} & \omega_{12} \\
\omega_{21} & \omega_{22}
\end{array}\right)
$$

where $\boldsymbol{\Omega}$ can be consistently estimated using time series observations on $\Delta b_{t}$ and $\Delta y_{t}$. Let $\kappa^{2}=\frac{\omega_{11}}{\omega_{22}}>$ 0 , and $\rho=\frac{\omega_{12}}{\sqrt{\omega_{11} \omega_{22}}}$, and note that $\mathbf{A}^{-1} \mathbf{D} \mathbf{A}^{-1 \prime}=\boldsymbol{\Omega}$ defines the estimable function $f(\alpha, \beta, \kappa, \rho)=$ 0 , which links $\alpha$ and $\beta$ in terms of $\kappa$ and $\rho$. Hence, for given population values of the reducedform parameters $\kappa$ and $\rho$, the structural parameters $\alpha$ and $\beta$ can take any point on the function $f(\alpha, \beta, \kappa, \rho)=0$. After some algebra, we obtain (similarly to eq. (51) of $\mathrm{BH}$ )

$$
\beta=\frac{\kappa^{2}+\alpha \rho \kappa}{\alpha+\rho \kappa}, \text { or } \alpha=\frac{\kappa^{2}-\rho \kappa \beta}{\beta-\rho \kappa} \text {. }
$$

It is now easy to see that if $\rho>0$, then $\alpha>0$ is unrestricted, and $\beta$ is restricted to lie within $\rho<\beta<\kappa / \rho$. On the other hand, if $\rho<0$, then $\beta>0$ is unrestricted, and $\alpha$ is restricted to lie in the range $-\rho \kappa<\alpha<-\kappa / \rho$. In vast majority of countries (34 out of 39) the LS estimates of $\hat{\rho}$ is negative. Therefore, without imposing additional restrictions (e.g. in form of prior distributions on $\alpha, \beta), \alpha$ and $\beta$ are not point-identified. Sign restrictions only yield set identification. We shall follow the Bayesian approach of $\mathrm{BH}$ and impose priors on $\alpha$ and $\beta$ to estimate individual country-specific models in a Bayesian framework, imposing priors on the reduced-form parameters. ${ }^{14}$ After conditioning on global shocks, we identify national shocks by considering each country separately. We use the same types of priors as in BH. For $\beta$ we use a truncated student $t$ distribution with location $c_{\beta}=0.6$, scale $\sigma_{\beta}=0.6$ and degrees of freedom $\nu_{\beta}=3$, such that $\beta>0$. This ensures that $\operatorname{Pr}(0.1<\beta<2.2)=90$ percent, prior mean is 0.91 , prior median is 0.76 , and prior interquartile range is $[0.43,1.18]$. The same prior distribution is also used for $\alpha$.

\subsection{Debt elasticities}

As discussed above, the elasticity of debt with respect to output is $\epsilon_{\alpha}=(1-\alpha)$ when output expands due to technology shock, and $\epsilon_{\beta}=(1+\beta)$ when output expands due to fiscal policy shock. Summary measures of posterior distributions of $\alpha$ and $\beta$ are presented in Table 5. With the exception of Belgium, posterior means and medians are smaller than the priors. Averaged across countries, the posterior medians of $\alpha$ and $\beta$, reported in the last row of Table 5 , give an average estimate of 0.75 for the

\footnotetext{
${ }^{14}$ The full description of priors is provided in the Appendix A.4.
} 
median debt elasticity when the output rise is due to a technology shock, and 1.4 when the output rise is due to a fiscal policy shock. ${ }^{15}$ These estimates provide some quantitative guidelines for the relative effects of technology and fiscal policy shocks on debt-to-GDP ratio, and suggest that undue reliance on fiscal policy shocks to simulate the economy can very quickly lead to higher levels of public debt to GDP. Supply-side policies that improve the rate of technical progress would also be needed if such a scenario is to be avoided.

Posterior interquartile ranges for $\alpha$ in majority countries (31 out of 39) are smaller than posterior interquartile range of $\beta$. However, these intervals are still quite wide as compared to the priors for most of the countries, which is reflective of both estimation uncertainty as well as weak prior identification. Figure A1 in the Appendix compares the posterior medians of $\alpha$ and $\beta$ with the standard VAR models without augmentation by global shocks and lagged cross section averages. The differences between the posterior medians of $\alpha$ and $\beta$ in country-specific models with and without CS augmentation are in the range of -0.1 to 0.07 in the case of $\alpha$ and in the range of -0.17 to 0.27 in the case of $\beta$. Hence omission of global shocks tends to lead to larger differences in the case of debt elasticities following a fiscal policy shock.

Figure 3 plots priors and posteriors for $\alpha$ and $\beta$ in the case of four selected countries: U.S., Brazil, Germany, and Italy. Full set of results is provided in the online supplement (Figures S1-S39). The posterior distributions of $\alpha$ and $\beta$ are much more skewed than the priors, with significant mass close to zero in the case of some countries.

\footnotetext{
${ }^{15}$ If we use the median of the country-specific posterior medians we obtain the estimates 0.20 and 0.42 for $\alpha$ and $\beta$, respectively, which are very close to the mean estimates of 0.25 and 0.40 that we use in our analysis.
} 
Table 5: Posterior mean, median, and interquartile range for parameters $\alpha$ and $\beta$ across

\section{countries}

\begin{tabular}{|c|c|c|c|c|c|c|}
\hline & \multicolumn{3}{|c|}{$\alpha$} & \multicolumn{3}{|c|}{$\beta$} \\
\hline & mean & median & range & mean & median & range \\
\hline Argentina & 0.16 & 0.09 & {$[0.07,0.15]$} & 0.74 & 0.58 & {$[0.16,1.03]$} \\
\hline Australia & 0.43 & 0.16 & {$[0.04,0.69]$} & 0.46 & 0.15 & {$[0.04,0.68]$} \\
\hline Austria & 0.47 & 0.31 & {$[0.18,0.64]$} & 0.68 & 0.38 & {$[0.14,0.83]$} \\
\hline Belgium & 1.07 & 0.93 & {$[0.64,1.32]$} & 1.11 & 1.00 & {$[0.75,1.32]$} \\
\hline Brazil & 0.30 & 0.05 & {$[0.03,0.45]$} & 0.59 & 0.28 & {$[0.02,0.81]$} \\
\hline Canada & 0.39 & 0.20 & {$[0.10,0.55]$} & 0.55 & 0.33 & {$[0.08,0.83]$} \\
\hline Chile & 0.27 & 0.16 & {$[0.11,0.32]$} & 0.57 & 0.48 & {$[0.12,0.96]$} \\
\hline China & 0.69 & 0.55 & {$[0.15,1.01]$} & 0.20 & 0.11 & {$[0.08,0.19]$} \\
\hline Ecuador & 0.33 & 0.20 & {$[0.14,0.42]$} & 0.60 & 0.44 & {$[0.11,0.92]$} \\
\hline Egypt & 0.51 & 0.24 & {$[0.04,0.77]$} & 0.38 & 0.11 & {$[0.04,0.56]$} \\
\hline Finland & 0.19 & 0.17 & {$[0.14,0.21]$} & 0.78 & 0.64 & {$[0.28,1.07]$} \\
\hline France & 0.38 & 0.08 & {$[0.02,0.63]$} & 0.48 & 0.13 & {$[0.02,0.70]$} \\
\hline Germany & 0.44 & 0.35 & {$[0.25,0.55]$} & 0.64 & 0.49 & {$[0.19,0.93]$} \\
\hline India & 0.55 & 0.42 & {$[0.27,0.70]$} & 0.63 & 0.47 & {$[0.20,0.88]$} \\
\hline Indonesia & 0.33 & 0.11 & {$[0.06,0.47]$} & 0.58 & 0.32 & {$[0.05,0.82]$} \\
\hline Iran & 0.20 & 0.05 & {$[0.03,0.17]$} & 0.60 & 0.48 & {$[0.05,0.95]$} \\
\hline Italy & 0.43 & 0.38 & {$[0.30,0.51]$} & 0.71 & 0.56 & {$[0.23,0.99]$} \\
\hline Japan & 0.52 & 0.31 & {$[0.13,0.75]$} & 0.50 & 0.30 & {$[0.13,0.74]$} \\
\hline Korea & 0.16 & 0.11 & {$[0.09,0.16]$} & 0.68 & 0.60 & {$[0.22,1.04]$} \\
\hline Malaysia & 0.38 & 0.27 & {$[0.19,0.48]$} & 0.67 & 0.47 & {$[0.15,0.92]$} \\
\hline Mexico & 0.31 & 0.09 & {$[0.04,0.46]$} & 0.52 & 0.30 & {$[0.04,0.82]$} \\
\hline Morocco & 0.62 & 0.57 & {$[0.46,0.72]$} & 0.78 & 0.64 & {$[0.32,1.05]$} \\
\hline Netherlands & 0.50 & 0.28 & {$[0.13,0.69]$} & & 0.32 & {$[0.12,0.78]$} \\
\hline New Zealand & 0.43 & 0.35 & {$[0.27,0.52]$} & 0.68 & 0.52 & {$[0.20,0.95]$} \\
\hline Nigeria & 0.38 & 0.16 & {$[0.08,0.56]$} & 0.49 & 0.29 & {$[0.06,0.80]$} \\
\hline Norway & 0.35 & 0.05 & {$[0.02,0.56]$} & 0.41 & 0.18 & {$[0.02,0.76]$} \\
\hline Peru & 0.23 & 0.14 & {$[0.10,0.25]$} & 0.63 & 0.53 & {$[0.14,1.00]$} \\
\hline Philippines & 0.60 & 0.40 & {$[0.10,0.88]$} & 0.36 & 0.21 & {$[0.13,0.47]$} \\
\hline Singapore & 0.46 & 0.29 & {$[0.17,0.61]$} & 0.59 & 0.41 & {$[0.14,0.86]$} \\
\hline South Africa & 0.37 & 0.23 & {$[0.15,0.48]$} & 0.59 & 0.42 & {$[0.11,0.89]$} \\
\hline Spain & 0.27 & 0.17 & {$[0.12,0.32]$} & 0.60 & 0.49 & {$[0.13,0.95]$} \\
\hline Sweden & 0.32 & 0.21 & {$[0.14,0.40]$} & 0.60 & 0.46 & {$[0.12,0.93]$} \\
\hline Switzerland & 0.34 & 0.11 & {$[0.06,0.50]$} & 0.54 & 0.29 & {$[0.05,0.81]$} \\
\hline Thailand & 0.14 & 0.12 & {$[0.10,0.15]$} & 0.71 & 0.64 & {$[0.28,1.06]$} \\
\hline Tunisia & 0.41 & 0.30 & {$[0.20,0.51]$} & 0.64 & 0.46 & {$[0.16,0.91]$} \\
\hline Turkey & 0.61 & 0.43 & {$[0.12,0.90]$} & 0.37 & 0.23 & {$[0.15,0.48]$} \\
\hline UK & 0.44 & 0.18 & {$[0.04,0.71]$} & 0.39 & 0.15 & {$[0.05,0.65]$} \\
\hline USA & 0.55 & 0.44 & {$[0.31,0.69]$} & 0.66 & 0.51 & {$[0.22,0.92]$} \\
\hline Venezuela & 0.35 & 0.16 & {$[0.09,0.49]$} & 0.52 & 0.34 & {$[0.07,0.83]$} \\
\hline Average & 0.41 & 0.25 & & 0.58 & 0.40 & \\
\hline
\end{tabular}

Notes: Prior mean for $\alpha$ and $\beta$ is 0.91 , prior median is 0.76 , and prior interquartile range is $[0.43,1.18] . \epsilon_{\alpha}=(1-\alpha)$ is the elasticity of debt with respect to output when output expands due to a technology shock, and $\epsilon_{\beta}=(1+\beta)$ is the elasticity of debt with respect to output when output expands due to a fiscal policy shock. 
Figure 3: Posterior distributions of parameters $\alpha$ and $\beta$ for selected countries

\section{United States}
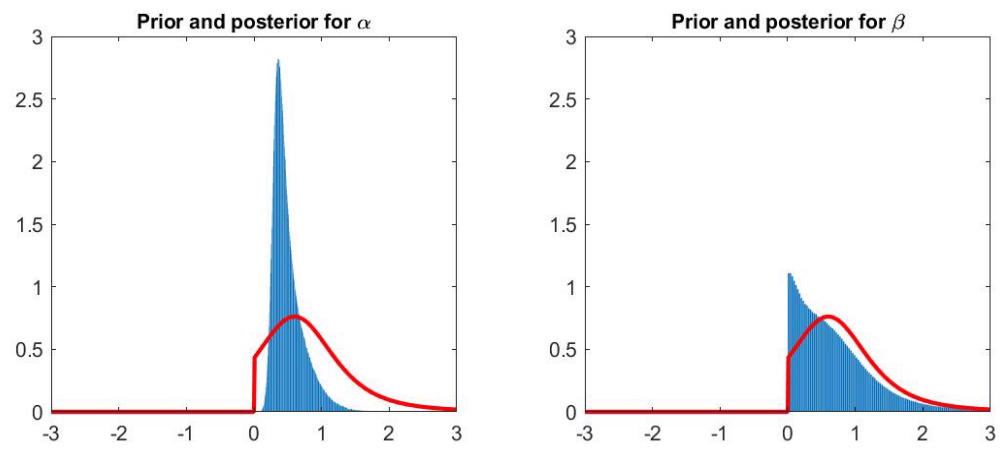

Brazil
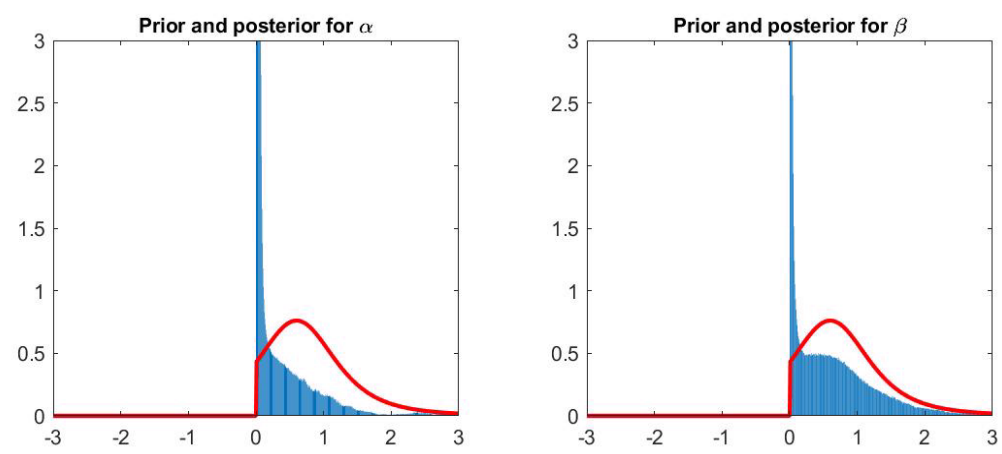

\section{Germany}
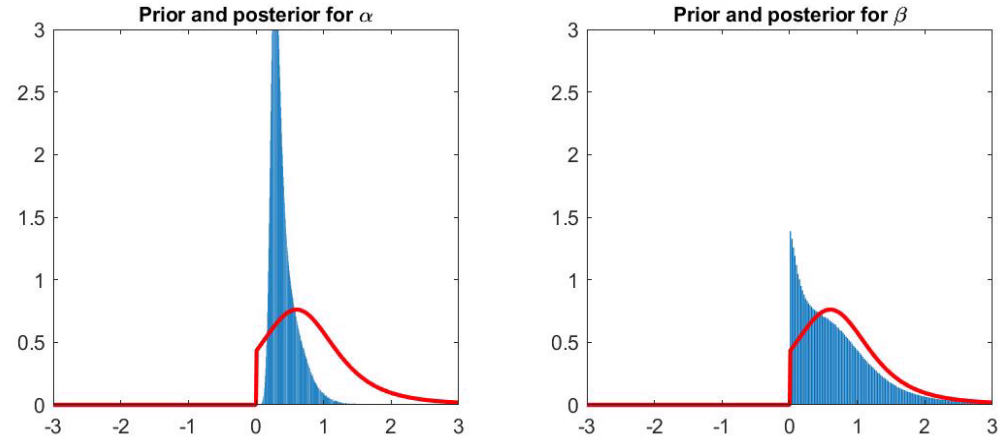

Italy
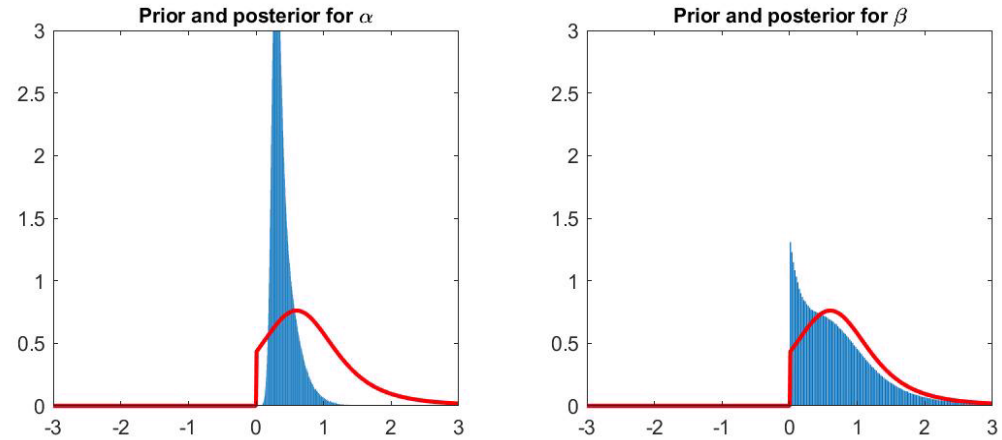

Notes: $\epsilon_{\alpha}=(1-\alpha)$ is the elasticity of debt with respect to output when output expands due to technology shock, and $\epsilon_{\beta}=(1+\beta)$ is the elasticity of debt with respect to output when output expands due to fiscal policy shock. 


\subsection{Effects of fiscal and technology shocks}

The corresponding impulse response functions for national technology and fiscal shocks are provided in Figure 4 for the four selected countries and in the online supplement for the remaining economies. Similarly to the effects of global shocks, the effects of national shocks dissipate rather quickly, within 2-3 years.

Using country-specific models without augmentation by global shocks and lagged cross section averages (or CS augmentation for short), will lead to miss-specified estimates. Figure 5 compares the contemporaneous effects of one standard error (s.e.) country shocks identified from VAR models with or without the augmentation. The contemporaneous effects of technology shock on output are, on average, about 20 percent smaller, and the contemporaneous effects of fiscal shocks on output are about 18 percent smaller. Larger differences are seen for countries, where global shocks explain larger share of the business cycle fluctuations. Since reduced-form shocks in models without CS augmentation are (by construction) always larger than the reduced-form errors in models with CS augmentation, estimated impacts of identified country shocks in the models without CS augmentation are in general over-estimated. In few cases (e.g. for some shock-variable combinations in Nigeria or Australia), the reported impact effects are smaller due to consequences of CS augmentation for the identification (rotation of reduced-form errors).

The CS augmentation does not affect only the variance of the reduced-form shocks, but also their covariances, and the autoregressive reduced-form coefficients. Hence, the CS augmentation can have consequences for all horizons of the IRFs. Posterior medians of the IRFs of national fiscal and technology shocks in models with and without CS augmentation are compared for all countries in the dataset in Figures S40-S78 in the online supplement. For countries with marginal increase in fit from the CS augmentation (i.e. countries with the lowest standard error ratios reported in the last two columns of Table A3 in Appendix, such as Iran or Egypt), there is a little difference between these two estimates, as to be expected. However, there are differences beyond the contemporaneous period for a number of countries where the global shocks explain nonnegligible fraction of the variance of domestic variables. 
Figure 4: Posterior median (solid line) and 95 percent posterior credibility sets for the effects of 1 percent technology and fiscal policy shocks for selected countries

\section{United States}
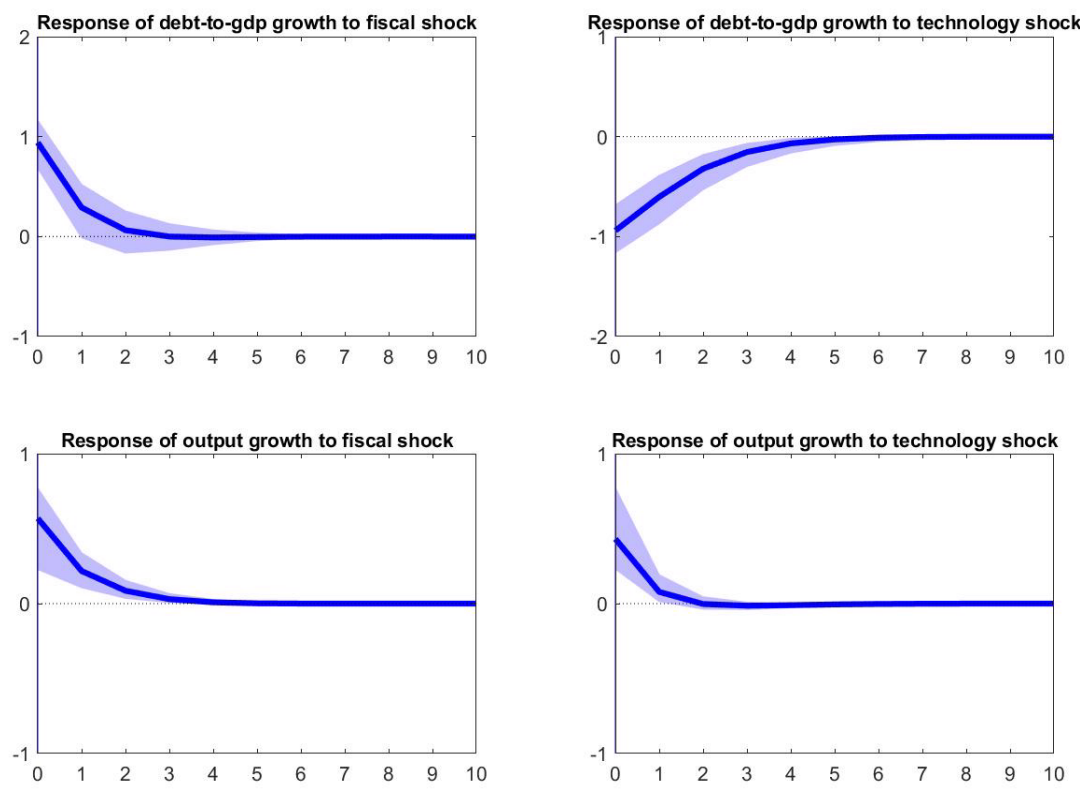

\section{Brazil}
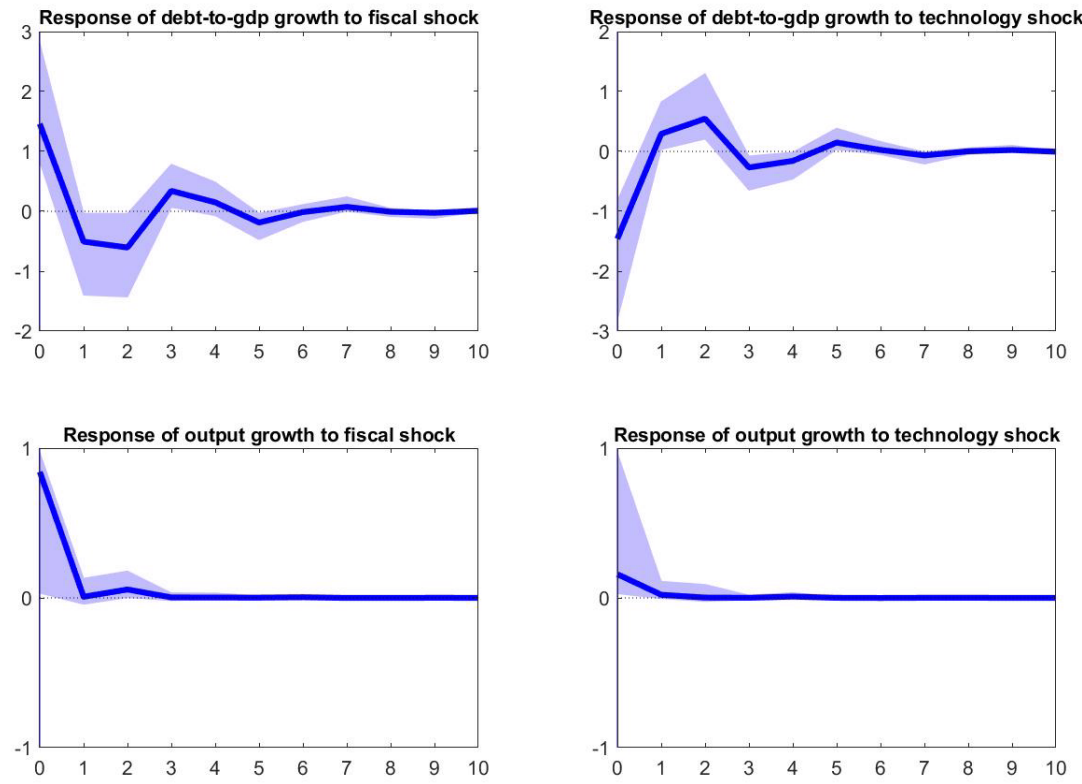
Figure 4 (Continued): Posterior median (solid line) and 95 percent posterior credibility sets for the effects of 1 percent technology and fiscal policy shocks

\section{Germany}
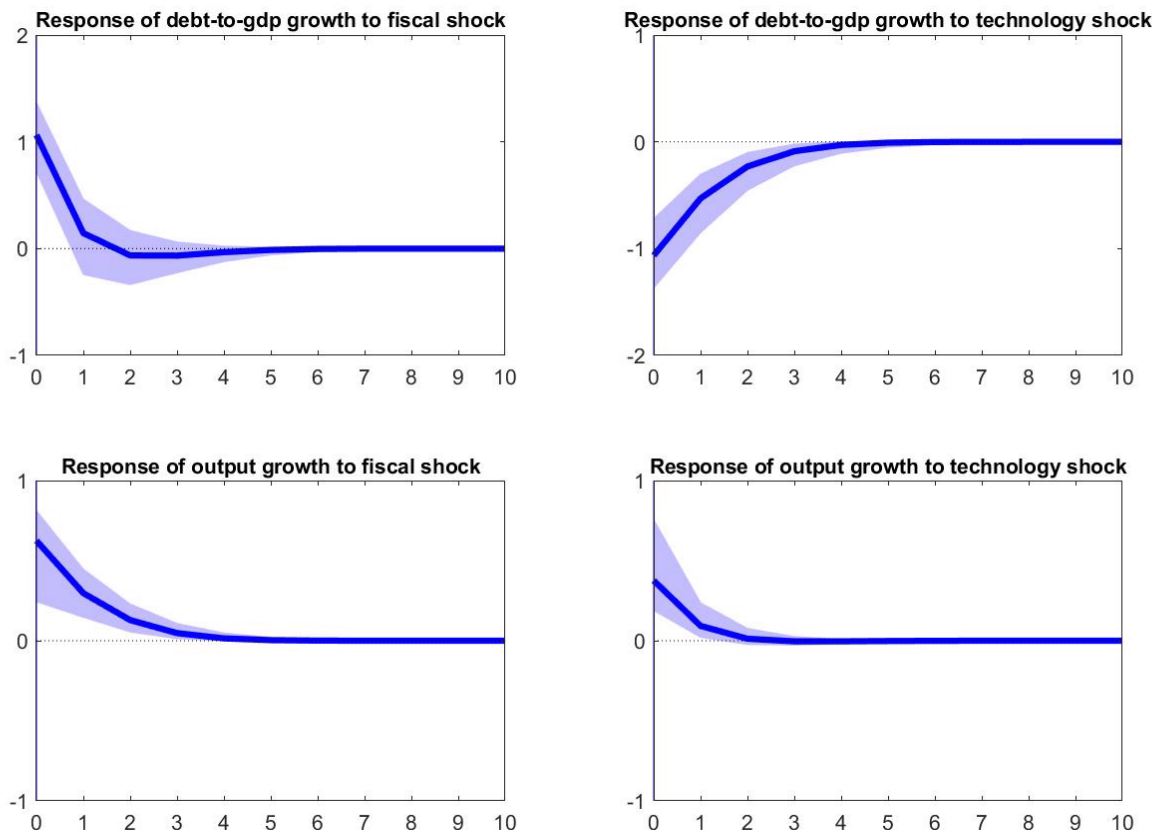

\section{Italy}
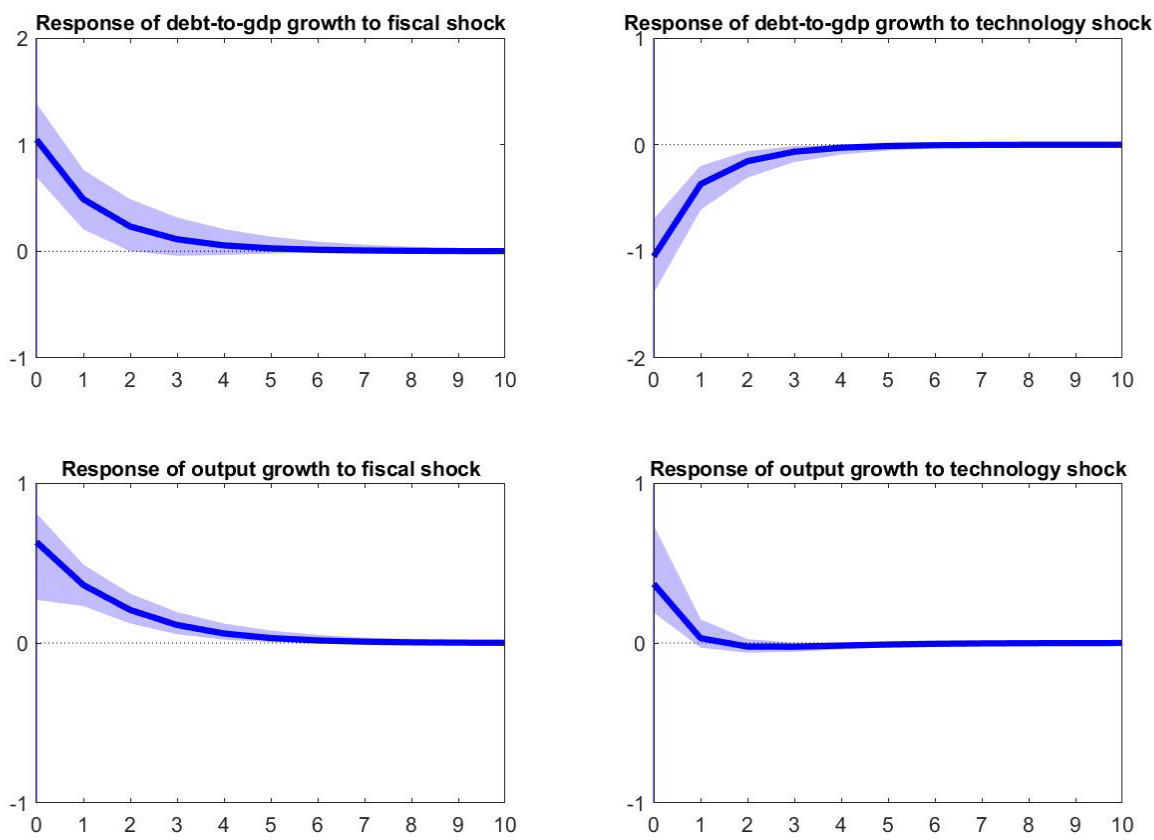

Notes: The plots in this figure show impulse responses of identified national one percent expansionary fiscal policy and technology shocks. Hence, the magnitudes on impact are given by the posterior distribution of $\frac{1}{\alpha_{i}+\beta_{i}}\left(\begin{array}{cc}\beta_{i} & -\alpha_{i} \\ 1 & 1\end{array}\right)=\mathbf{A}_{i} \mathbf{S}$, where $\mathbf{S}=\left(\begin{array}{cc}1 & 0 \\ 0 & -1\end{array}\right)$ defines the expansionary shocks. 
Figure 5: Impact effects of unit (one s.e.) national shocks in models with and without global shocks (median of posterior distribution)

Expansionary fiscal shock on output

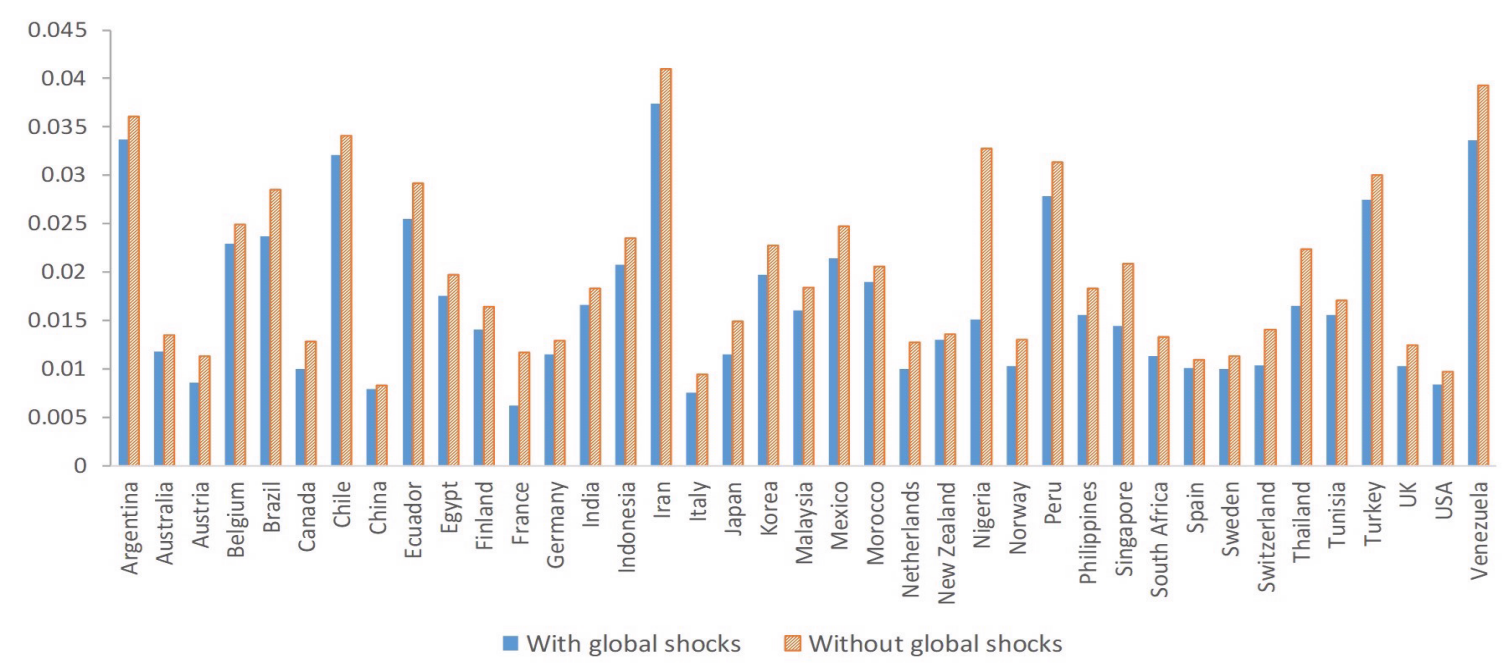

Positive technology shock on output

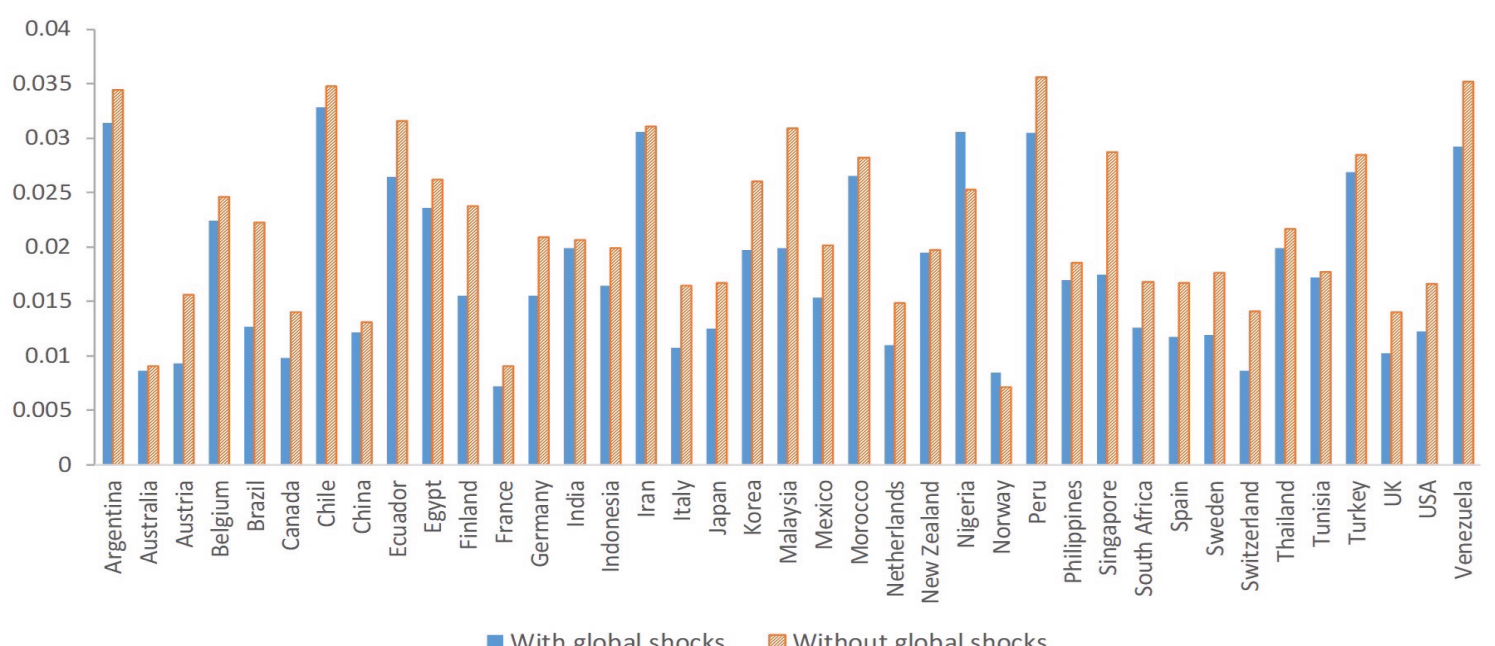


Figure 5 (Ctd.): Impact effects of unit (one s.e.) national shocks in models with and without global shocks (median of posterior distribution)

Expansionary fiscal shock on debt-to-GDP

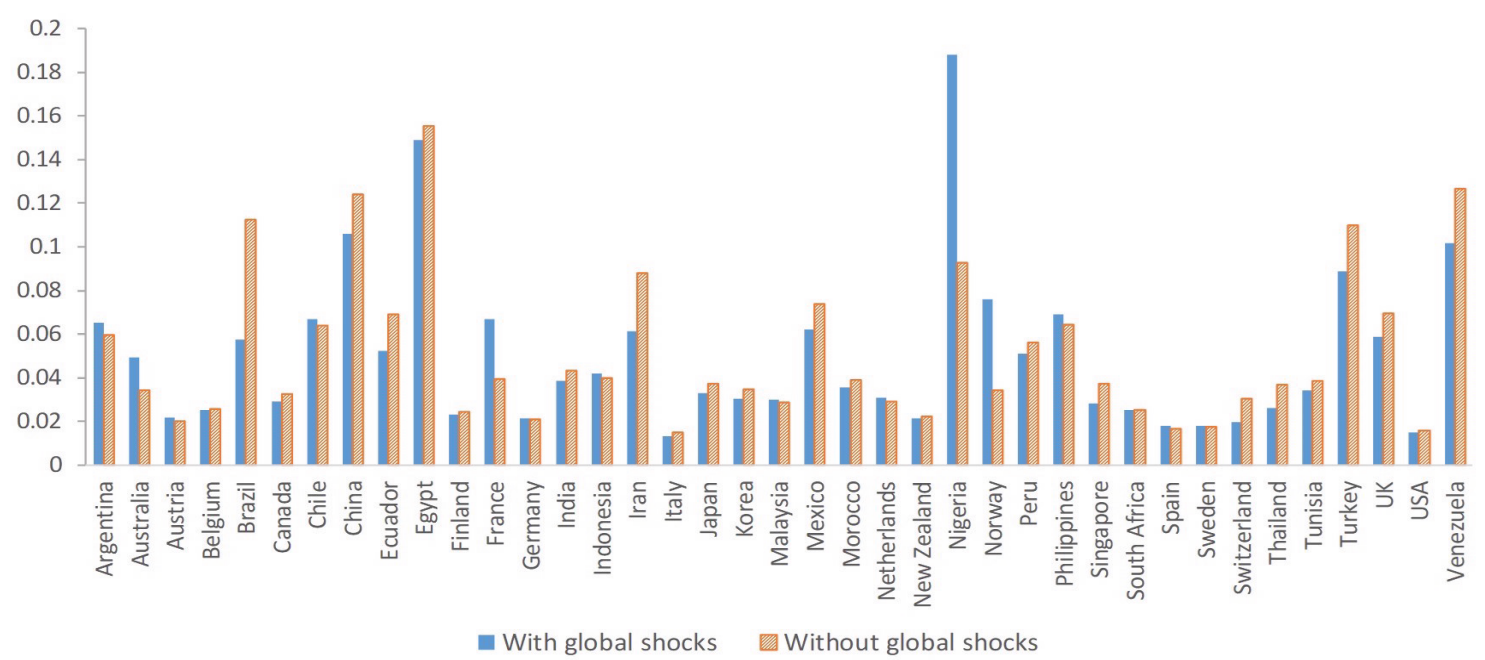

Positive technology shock on debt-to-GDP

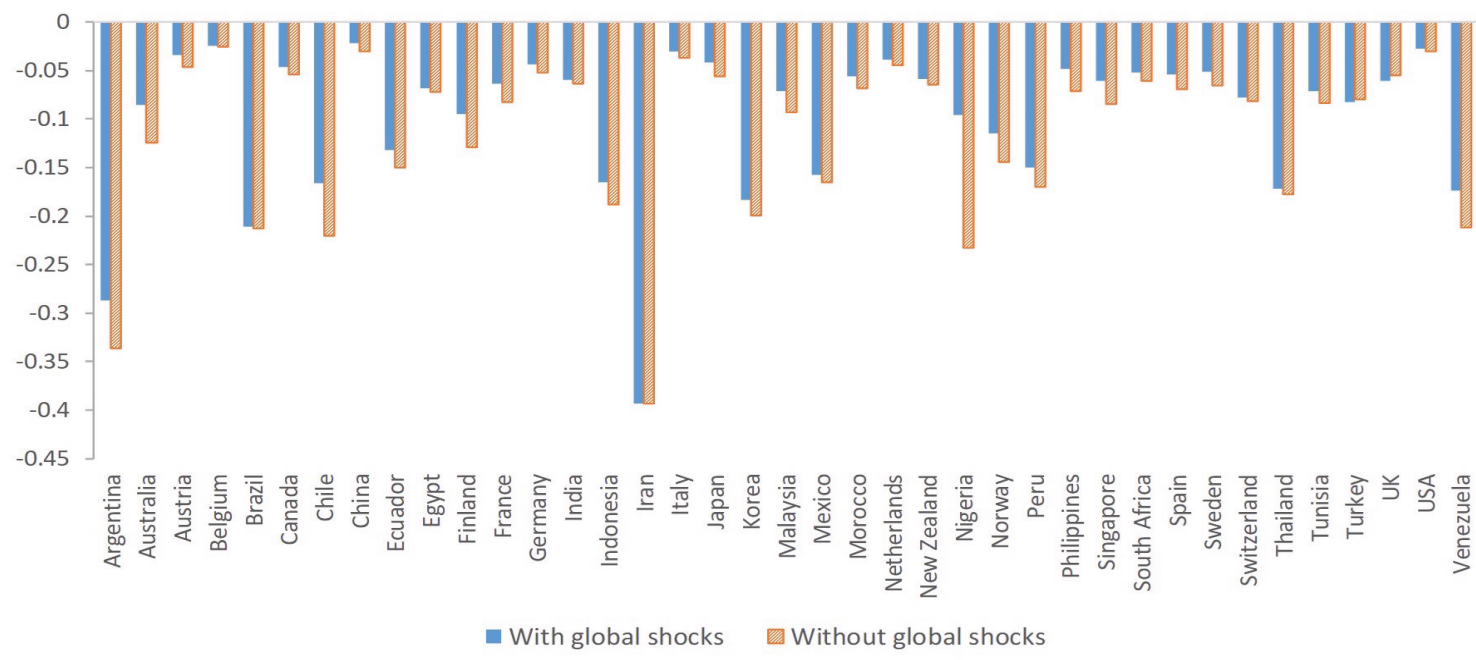

Notes: The plots in this figure show contemporaneous impulse responses of identified national one standard error (s.e.) expansionary fiscal and technology shocks in models with and without CS augmentation. The magnitudes on impact are therefore given by the posterior distribution of $\mathbf{A}_{i} \mathbf{D}_{i}^{1 / 2} \mathbf{S}$, where $\mathbf{A}_{i}$ is given by (18), $\mathbf{D}_{i}$ is posterior variance of fiscal and technology shocks, and $\mathbf{S}=\left(\begin{array}{cc}1 & 0 \\ 0 & -1\end{array}\right)$ defines the expansionary shocks. 


\section{Conclusion}

This paper builds on earlier contributions in the GVAR literature and considers the problem of identification of global and national shocks. To this end it first provides a general GVAR representation of a multi-country error correcting model with unobserved common factors, and shows that such a model can be written in terms of (reduced-form) global shocks computed as residuals from a VAR in observed global variables estimated either as cross section averages of the country-specific variables or their first principal components (as compared to using a pre-selected number of PCs from all the country-specific variables pooled together).

The proposed approach is applied to analyze the interactions between public debt and real output growth in a multicountry setting, and the results are compared to those obtained from single country VARs. We find strong evidence in support of allowing for global shocks in country-specific VARs, which contribute to between one-fifth and one-third of total variance of country-specific variables at long horizons. Similarly to Cesa-Bianchi, Pesaran, and Rebucci (2018), we find that a triangular ordering of the global variables is justified for identification of global output and fiscal shocks. Finally, we follow Baumeister and Hamilton (2015) and implemented weak identification restrictions in form of priors to identify national technology and fiscal policy shocks using a Bayesian approach. The results from our multicountry analysis are compared to standard single country VAR analyses and their differences highlighted. It is found that posterior median debt elasticity with respect to output is much larger when the rise in output is due to a fiscal policy shock, as compared to when the rise in output is due to a positive technology shock. The cross country average of the median debt elasticity is 1.58 when the rise in output is due to a fiscal expansion as compared to 0.75 when the rise in output follows from a favorable technological advance. 


\section{A Appendix}

This Appendix is organized as follows. Section A.1 derives GVAR representation for a global factoraugmented VECM model. Section A.2 provides the expressions for forecast error variance decompositions used to decompose the forecast error variance into the contributions from the sets of global and national shocks. Section A.3 describes the bootstrapping procedure for the calculation of confidence intervals for the effects of global shocks. Section A.4 sets out the priors used for estimating the effects of national fiscal and technology shocks. Section A.5 gives details of data sources. Section A.6 provides additional estimates.

\section{A.1 Derivation of GVAR representation using global factor-augmented error- correcting model.}

Suppose there are $N$ countries, let $\mathbf{x}_{i t}$ be a $k \times 1$ vector of domestic (country-specific) variables in country $i=1,2, \ldots, N$, and collect all $n=N k$ variables in the $n \times 1$ vector $\mathbf{x}_{t}=\left(\mathbf{x}_{1 t}^{\prime}, \mathbf{x}_{2 t}^{\prime}, \ldots, \mathbf{x}_{N t}^{\prime}\right)^{\prime}$. Further suppose that $\mathbf{x}_{t}$ is affected by an $m \times 1$ vector of unobserved common factors, denoted by $\mathbf{g}_{t}$, and the combined $(n+m) \times 1$ vector of observed and unobserved variables, $\mathbf{z}_{t}=\left(\mathbf{x}_{t}^{\prime}, \mathbf{g}_{t}^{\prime}\right)^{\prime}$, follows the vector error correction (VECM) model

$$
\Delta \mathbf{z}_{t}=-\Pi \mathbf{z}_{t-1}+\sum_{\ell=1}^{p-1} \boldsymbol{\Gamma}_{\ell} \Delta \mathbf{z}_{t-\ell}+\mathbf{u}_{t},
$$

where we abstracted from deterministic components to simplify the exposition. This is a general high-dimensional, multicountry VAR model which involves a large number of unknown parameters even for moderate values of $k, N$ and $m$. Partition the vector of innovations as $\mathbf{u}_{t}=\left(\mathbf{e}_{t}^{\prime}, \mathbf{v}_{g t}^{\prime}\right)^{\prime}$, $\mathbf{e}_{t}^{\prime}=\left(\mathbf{e}_{1 t}^{\prime}, \mathbf{e}_{2 t}^{\prime}, \ldots, \mathbf{e}_{N t}^{\prime}\right)^{\prime}$, in which $\mathbf{e}_{i t}$, for $i=1,2, \ldots N$, are $k \times 1$ vectors of country-specific reduced-form innovations, possibly correlated with $\mathbf{v}_{g t}$, and $\mathbf{v}_{g t}$ is an $m \times 1$ vector of (common) global shocks. Let $E\left(\mathbf{e}_{i t} \mid \mathbf{v}_{g t}\right)=\boldsymbol{\Gamma}_{v i} \mathbf{v}_{g t}$, in which $\boldsymbol{\Gamma}_{v i}$, for $i=1,2, \ldots, N$ and $k \times m$ loading matrices. Then, $\mathbf{e}_{i t}$ can be written as $\mathbf{e}_{i t}=\boldsymbol{\Gamma}_{v i} \mathbf{v}_{g t}+\boldsymbol{\varepsilon}_{i t}$ (also see (3)).

We consider the following assumptions on the coefficients and errors of the multicountry VECM model (A.1).

Assumption 1 (Coefficients) Let $\mathbf{\Phi}(z)=\mathbf{I}_{n+m}-\sum_{\ell=1}^{p} \boldsymbol{\Phi}_{\ell} z^{\ell}$, where $z \in \mathbb{C}, \boldsymbol{\Phi}_{1}=\mathbf{I}_{n+m}-\boldsymbol{\Pi}+\boldsymbol{\Gamma}_{1}$, $\boldsymbol{\Phi}_{\ell}=\boldsymbol{\Gamma}_{\ell}-\boldsymbol{\Gamma}_{\ell-1}$ for $\ell=2,3, \ldots, k-1$ and $\boldsymbol{\Phi}_{p}=-\boldsymbol{\Gamma}_{p-1}$.

(i) The roots of the determinantal equation $\operatorname{det}[\mathbf{\Phi}(z)]=0$ satisfy $z=1$ or $z>1+\epsilon$ for some $\epsilon>0$ that does not depend on $N$.

(ii) The matrix $\boldsymbol{\Pi}$ has reduced rank $r<N k+m$, i.e. we can write $\boldsymbol{\Pi}=\boldsymbol{\alpha}_{\pi} \boldsymbol{\beta}_{\pi}^{\prime}$, where $\boldsymbol{\alpha}_{\pi}$ and $\boldsymbol{\beta}_{\pi}$ are $N k+m \times r$ matrices of full column rank.

(iii) The $(N k+m-r) \times(N k+m-r)$ matrix $\boldsymbol{\alpha}_{\perp} \boldsymbol{\Gamma} \boldsymbol{\beta}_{\perp}$ has full rank, where $\boldsymbol{\Gamma}=\mathbf{I}_{n+m}-\sum_{\ell=1}^{p-1} \boldsymbol{\Gamma}_{\ell}$, and $\boldsymbol{\alpha}_{\perp}$ and $\boldsymbol{\beta}_{\perp}$ are the orthogonal complements of $\boldsymbol{\alpha}_{\pi}$ and $\boldsymbol{\beta}_{\pi}$, respectively.

Assumption 2 (Innovations) $\mathbf{e}_{i t}$ is given by factor representation (3), where $\sup _{i}\left\|\boldsymbol{\Gamma}_{v i}\right\|<K$, $\mathbf{v}_{g t}=\left(v_{g 1 t}, v_{g 2 t}, \ldots, v_{g m t}\right)^{\prime} \sim \operatorname{IID}\left(\mathbf{0}, \boldsymbol{\Omega}_{v}\right)$, and $\boldsymbol{\varepsilon}_{t}=\left(\varepsilon_{1 t}^{\prime}, \boldsymbol{\varepsilon}_{2 t}^{\prime}, \ldots, \boldsymbol{\varepsilon}_{N t}^{\prime}\right)^{\prime} \sim \operatorname{IID}\left(\mathbf{0}, \boldsymbol{\Omega}_{e}\right)$, where $\varepsilon_{i t}=$ 
$\mathbf{e}_{i t}-E\left(\mathbf{e}_{i t} \mid \mathbf{v}_{g t}\right)$. The row-norm of $\boldsymbol{\Omega}_{e}$ is bounded in $N \sup _{s, t} E\left|v_{g s t}\right|^{4+\epsilon}<K, \sup _{i, s, t} E\left|\varepsilon_{i s t}\right|^{4+\epsilon}<K$, where $\varepsilon_{i s t}$ are individual elements of $\varepsilon_{i t}=\left(\varepsilon_{i, 1, t}, \varepsilon_{i, 2, t}, \ldots, \varepsilon_{i k t}\right)^{\prime} . \mathbf{v}_{g t}$ is independently distributed of $\varepsilon_{t^{\prime}}$ for all $t$ and $t^{\prime}$. In addition, $\left(\mathbf{v}_{g t}^{\prime}, \varepsilon_{t}^{\prime}\right)^{\prime}$ is independently distributed of $\left(\mathbf{v}_{g t^{\prime}}^{\prime}, \varepsilon_{t^{\prime}}^{\prime}\right)^{\prime}$ for any $t \neq t^{\prime}$.

Assumption 1 is the standard assumption for VECM models featuring $I(1)$ variables. Condition (i) rules out the possibility of explosive or seasonal unit roots. Conditions (ii) and (iii) rule out $I(2)$ processes, and ensure that there are exactly $N k+m-r$ unit root variables in the model. Assumption 2 rules out strong cross-sectional dependence in the innovations, $\boldsymbol{\varepsilon}_{i t}$, but allows the reduced-form country-specific shocks $\mathbf{e}_{i t}$ to be strongly cross sectionally dependent via the global shocks, $\mathbf{v}_{g t}$.

Under the above assumptions, stochastic decomposition of $\mathbf{z}_{t}$ given by VECM model (A.1) directly follows from results in Section 22.15 of Pesaran (2015b). We have:

$$
\mathbf{z}_{t}=\mathbf{z}_{0}^{\star}+\mathbf{C} \sum_{\ell=1}^{t} \mathbf{u}_{t}+\mathbf{C}^{*}(L) \mathbf{u}_{t}
$$

where $\mathbf{z}_{0}^{\star}=\mathbf{C}\left(\mathbf{z}_{0}-\sum_{\ell=1}^{p-1} \Gamma_{\ell} \mathbf{z}_{-\ell}\right)$ is the contribution of the initial values $\left(\mathbf{z}_{0}, \mathbf{z}_{-1}, \ldots, \mathbf{z}_{-p+1}\right)$,

$$
\mathbf{C}=\boldsymbol{\beta}_{\perp}\left(\boldsymbol{\alpha}_{\perp}^{\prime} \boldsymbol{\Gamma} \boldsymbol{\beta}_{\perp}\right)^{-1} \boldsymbol{\alpha}_{\perp}^{\prime}
$$

and the coefficients of the matrix polynomial $\mathbf{C}^{*}(L)$ are recursively obtained using

$$
\mathbf{C}_{\ell}^{*}=-\boldsymbol{\Pi} \mathbf{C}_{\ell-\mathbf{1}}^{*}+\sum_{\ell=1}^{p-1} \boldsymbol{\Gamma}_{\ell} \Delta \mathbf{C}_{i-\ell}^{*}
$$

with $\mathbf{C}_{0}^{*}=\mathbf{I}_{n+m}-\mathbf{C}^{*}, \mathbf{C}_{-1}^{*}=\mathbf{C}_{-2}^{*}=\ldots=\mathbf{C}_{-k+1}^{*}=-\mathbf{C}$. Hence, using (3), partitioning $\mathbf{C}$ and $\mathbf{C}^{*}(L)$ conformably as

$$
\mathbf{C}=\left(\begin{array}{ll}
\mathbf{C}_{x x} & \mathbf{C}_{x g} \\
\mathbf{C}_{x g} & \mathbf{C}_{g g}
\end{array}\right), \mathbf{C}^{*}(L)=\left(\begin{array}{cc}
\mathbf{C}_{x x}^{*}(L) & \mathbf{C}_{x g}^{*}(L) \\
\mathbf{C}_{g x}^{*}(L) & \mathbf{C}_{g g}^{*}(L)
\end{array}\right),
$$

and partitioning further $\mathbf{C}_{x x}, \mathbf{C}_{x g}, \mathbf{C}_{x x}^{*}(L)$ and $\mathbf{C}_{x g}^{*}(L)$ conformably into $k \times k$ blocks denoted by additional subscripts $i$ or $i, j$, namely $\mathbf{C}_{x x, i j}, \mathbf{C}_{x g, i}, \mathbf{C}_{x x, i j}^{*}(L)$ and $\mathbf{C}_{x g, i}^{*}(L)$, we have

$$
\mathbf{x}_{i t}=\mathbf{x}_{i 0}^{\star}+\mathbf{C}_{x g, i} \boldsymbol{\zeta}_{v t}+\mathbf{C}_{\Gamma, i}(L) \mathbf{v}_{g t}+\sum_{j=1}^{N} \mathbf{C}_{x x, i j} \boldsymbol{\zeta}_{e, j t}+\sum_{j=1}^{N} \mathbf{C}_{x x, i j}^{*}(L) \varepsilon_{i t},
$$

for $i=1,2, \ldots, N$, where

$$
\boldsymbol{\zeta}_{e, j t}=\sum_{\ell=1}^{t} \mathbf{e}_{j \ell} \text { and } \boldsymbol{\zeta}_{v, t}=\sum_{\ell=1}^{t} \mathbf{v}_{g \ell}
$$

are stochastic trends, and $\mathbf{C}_{\Gamma, i}=\mathbf{C}_{x g, i}^{*}(L)+\sum_{j=1}^{N} \mathbf{C}_{x x, i j}^{*}(L) \boldsymbol{\Gamma}_{v i}$.

Without further restrictions, (A.5) is subject to the well-known curse of dimensionality problem. ${ }^{16}$

\footnotetext{
${ }^{16}$ The number of parameters of an unrestricted VAR grows at a quadratic rate with $n$, so restrictions are obviously needed when $n$ and $T$ grow at the same rate. Onatski and Wang (2018) recently considered Johansen's likelihood ratio framework when the number of variables $(n)$ is allowed to increase with $T$, but restrict the number of cointegrating vectors, $r$, to rise relatively slowly such that $r / n \rightarrow 0$. However, in practice, the number of cointegrating vectors is likely to increase with the number of variables (countries) and a more general set up is required.
} 
To avoid this problem, some researchers have focussed on a small number of countries using unrestricted VAR models, where cross-country interconnections, $\mathbf{C}_{x x}$ and $\mathbf{C}_{x x}^{*}(L)$, can be freely and directly estimated. This avenue has been followed, for example, by Dungey and Osborn (2013) who model Euro Area and U.S. macro variables in a cointegrating 7-variable VAR model. But this approach omits the influence of unobserved common factors and could lead to biased estimates.

An alternative approach, which we adopt here, is to consider a large number of countries but assume

$$
\mathbf{C}_{x x, i j}=\mathbf{0} \text { and } \mathbf{C}_{x x, i j}^{*}(L)=\mathbf{0} \text { for } i \neq j,
$$

that restricts $\mathbf{C}_{x x}$ and $\mathbf{C}_{x x}^{*}(L)$ to be block diagonal, and capture the cross cross-country interconnections via unobserved common factors. This set up can be further generalized, without any fundamental consequences to the large- $N$ representations derived below, by allowing coefficients of $\mathbf{C}_{x x, i j}$ and $\mathbf{C}_{x x, i j}^{*}(L)$ to be small, uniformly of order $O\left(N^{-1}\right)$, which can arise as an equilibrium outcome of multi-country structural macro models (Chudik and Straub (2017)), or could be motivated econometrically by noting that many of the off-diagonal coefficients must be small for variances to exist (Chudik and Pesaran (2011)). These restrictions do not allow for off-diagonal coefficients to be bounded away from zero in $N$, which arises in the presence of dominant unit(s) present (Chudik and Pesaran (2013)), or in the presence of local neighbor effects (Chudik and Pesaran (2011)). We abstract from such dominant or local effects, but we note that they could be accommodated if the identity of dominant unit(s) and/or the identities of local neighbor pairs were known.

In addition to condition (A.6), we assume $\mathbf{g}_{t}$ is causal for $\mathbf{x}_{t}$, namely

$$
\mathbf{C}_{x g}=\mathbf{0} \text { and } \mathbf{C}_{x g}(L)=\mathbf{0},
$$

and, for simplicity and without loss of generality, we set $\mathbf{C}_{g g}=\mathbf{I}_{m}$, which leads to the following representation

$$
\Delta \mathbf{g}_{t}=\sum_{\ell=1}^{p-1} \boldsymbol{\Gamma}_{g \ell} \Delta \mathbf{g}_{t-\ell}+\mathbf{v}_{g t} .
$$

Following Pesaran (2006), we use cross-section averages and their lags to obtain an approximation of common shocks $\mathbf{v}_{g t}$ and common stochastic trends $\boldsymbol{\zeta}_{v t}=\sum_{\ell=1}^{t} \mathbf{v}_{g t}$. Let $\mathbf{W}=\left(\mathbf{W}_{i}, \mathbf{W}_{2}, \ldots, \mathbf{W}_{N}\right)^{\prime}$ be an $n \times k$ weighting matrix that satisfies the granularity conditions (5) and define the $k \times 1$ vector of cross-section averages $\overline{\mathbf{x}}_{t}$ given by (4). To obtain an approximation of $\mathbf{v}_{g t}$, we first note that the moving average representation of $\Delta \mathbf{x}_{t}$ is given by

$$
\Delta \mathbf{x}_{t}=\mathbf{C}_{\Delta x v}(L) \mathbf{v}_{g t}+\mathbf{C}_{\Delta x \varepsilon}(L) \varepsilon_{t},
$$

where

$$
\mathbf{C}_{\Delta x v}(L)=\mathbf{S}_{x}^{\prime} \mathbf{C}_{\Delta}(L) \boldsymbol{\Gamma}_{z v}, \text { and } \mathbf{C}_{\Delta x \varepsilon}(L)=\mathbf{S}_{x}^{\prime} \mathbf{C}_{\Delta}(L) \mathbf{S}_{x}
$$

in which $\mathbf{S}_{x}$ is $(k N+m) \times k N$ selection matrix that selects $\mathbf{x}_{t}=\mathbf{S}_{x}^{\prime} \mathbf{z}_{t}, \boldsymbol{\Gamma}_{z v}=\left(\boldsymbol{\Gamma}_{v}^{\prime}, \mathbf{I}_{m}\right)^{\prime}, \boldsymbol{\Gamma}_{v}=$ $\left(\boldsymbol{\Gamma}_{v 1}^{\prime}, \boldsymbol{\Gamma}_{v 2}^{\prime}, \ldots, \boldsymbol{\Gamma}_{v N}^{\prime}\right)^{\prime}$, and

$$
\mathbf{C}_{\Delta}(L)=\sum_{\ell=0}^{\infty} \mathbf{C}_{\Delta \ell} L^{\ell}, \mathbf{C}_{\Delta \ell}=\mathbf{C}_{\ell}^{*}-\mathbf{C}_{\ell-1}^{*}, \text { for } \ell=0,1, \ldots
$$


First-differencing $\overline{\mathbf{x}}_{t}$ and using (A.8), we obtain

$$
\Delta \overline{\mathbf{x}}_{t}=\overline{\mathbf{\Theta}}_{w}(L) \mathbf{v}_{g t}+O_{p}\left(N^{-1 / 2}\right)
$$

where $\overline{\boldsymbol{\Theta}}_{w}(L)=\mathbf{W}^{\prime} \mathbf{C}_{\Delta x v}(L)$, and $\mathbf{W}^{\prime} \mathbf{C}_{\Delta x \varepsilon}(L) \boldsymbol{\varepsilon}_{t}=O_{p}\left(N^{-1 / 2}\right)$, since by Assumption $2 \boldsymbol{\varepsilon}_{i t}$ is weakly cross-sectionally dependent. We assume next that the left inverse of $\overline{\boldsymbol{\Theta}}_{w}(L)$ exists so that the space spanned by the shocks $\mathbf{v}_{g t}$ is recoverable from $\Delta \overline{\mathbf{x}}_{t}$ and their lags.

Assumption 3 (Recovering $\mathbf{v}_{g t}$ using cross section averages) The left inverses of $\overline{\mathbf{\Theta}}_{w}(L)$ and $\boldsymbol{\Theta}_{w}(L)=\lim _{N \rightarrow \infty} \overline{\boldsymbol{\Theta}}_{w}(L)$, denoted by

$$
\overline{\mathbf{B}}_{w}(L)=\overline{\mathbf{\Theta}}_{w}^{-}(L) \text { and } \mathbf{B}_{w}(L)=\mathbf{\Theta}_{w}^{-}(L),
$$

exist. $^{17}$

Remark 1 Let $\overline{\boldsymbol{\Theta}}_{w}(L)=\sum_{\ell=0}^{\infty} \overline{\boldsymbol{\Theta}}_{w, \ell} L^{\ell}$ and $\overline{\mathbf{B}}_{w}(L)=\sum_{\ell=0}^{\infty} \overline{\mathbf{B}}_{w, \ell} L^{\ell}$, and note that $\overline{\boldsymbol{\Theta}}_{w}(L)=\mathbf{W}^{\prime} \mathbf{C}_{\Delta x v}(L)=$ $\mathbf{W}^{\prime} \mathbf{S}_{x}^{\prime} \mathbf{C}_{\Delta}(L) \boldsymbol{\Gamma}_{z v}$, where $\mathbf{C}_{\Delta}(L)=\sum_{\ell=0}^{\infty} \mathbf{C}_{\Delta, \ell} L^{\ell}$, with $\mathbf{C}_{\Delta, 0}=\mathbf{I}_{n+m}$, and hence

$$
\begin{aligned}
\overline{\boldsymbol{\Theta}}_{w, 0} & =\sum_{i=1}^{N} \mathbf{W}_{i} \boldsymbol{\Gamma}_{v, i} \equiv \overline{\boldsymbol{\Gamma}}_{w, v} \\
\overline{\mathbf{B}}_{w, 0} & =\left(\overline{\boldsymbol{\Gamma}}_{w, v}^{\prime} \overline{\boldsymbol{\Gamma}}_{w, v}\right)^{-1} \overline{\boldsymbol{\Gamma}}_{w, v}^{\prime},
\end{aligned}
$$

and $\overline{\mathbf{B}}_{w, 0} \overline{\mathbf{\Theta}}_{w, 0}=\mathbf{I}_{m}$. Consequently, for Assumption 3 to hold it is necessary that the $k^{*} \times m$ matrices $\overline{\boldsymbol{\Gamma}}_{w, v}$ and $\boldsymbol{\Gamma}_{w, v}=\lim _{N \rightarrow \infty} \overline{\boldsymbol{\Gamma}}_{w, v}$ have full column ranks. These rank conditions resemble the rank conditions in the CCE literature (Pesaran (2006)) which deals with a simpler setting. Finally, it is necessary that $k^{*} \geq m$ for these rank conditions to hold.

Using (A.10) and Assumption 3, we obtain

$$
\mathbf{v}_{g t}=\overline{\mathbf{B}}_{w}(L) \Delta \overline{\mathbf{x}}_{t}+O_{p}\left(N^{-1 / 2}\right)
$$

Recalling (A.12), we can write (A.10) as

$$
\Delta \overline{\mathbf{x}}_{t}=\overline{\boldsymbol{\Gamma}}_{w, v} \mathbf{v}_{g t}+\sum_{\ell=1}^{\infty} \overline{\boldsymbol{\Theta}}_{w, \ell} \mathbf{v}_{g, t-\ell}+O_{p}\left(N^{-1 / 2}\right)
$$

and substituting (A.13) for the past values of $\mathbf{v}_{g t}$, we obtain the following large- $N$ representation for $\Delta \overline{\mathbf{x}}_{t}$,

$$
\Delta \overline{\mathbf{x}}_{t}=\sum_{\ell=1}^{\infty} \overline{\mathbf{\Psi}}_{w, \ell} \Delta \overline{\mathbf{x}}_{w, t-\ell}+\overline{\boldsymbol{\Gamma}}_{w, v} \mathbf{v}_{g t}+O_{p}\left(N^{-1 / 2}\right),
$$

where $\sum_{\ell=1}^{\infty} \overline{\mathbf{\Psi}}_{w, \ell} L^{\ell}=\left(\sum_{\ell=1}^{\infty} \overline{\boldsymbol{\Theta}}_{w, \ell} L^{\ell}\right) \overline{\mathbf{B}}_{w}(L)$.

To derive an approximation of the common stochastic trends, $\boldsymbol{\zeta}_{v t}$, we take the cross-section average of the MA representation of $\mathbf{x}_{t}$, and note that (under weak cross-sectional dependence of $\varepsilon_{i t}$ in

\footnotetext{
${ }^{17}$ Specifically, $\overline{\mathbf{B}}_{w}(L) \overline{\mathbf{\Theta}}_{w}(L)=\mathbf{I}_{m}$ and $\mathbf{B}_{w}(L) \boldsymbol{\Theta}_{w}(L)=\mathbf{I}_{m}$.
} 
Assumption 2), we have the following stochastic upper bound

$$
\mathbf{W}^{\prime} \mathbf{S}_{x}^{\prime} \mathbf{C S}_{x} \sum_{\ell=1}^{t} \varepsilon_{\ell}=O_{p}\left(N^{-1 / 2} t^{1 / 2}\right)
$$

for $t=1,2, \ldots, T$. Assuming that $\overline{\mathbf{D}}_{w}$ and $\mathbf{D}=\lim _{N \rightarrow \infty} \overline{\mathbf{D}}_{w}$ are full column rank, where $\overline{\mathbf{D}}_{w}=$ $\mathbf{W}^{\prime} \mathbf{S}_{x}^{\prime} \mathbf{C} \boldsymbol{\Gamma}_{z v}$, then, using (A.15) in the MA representation of $\mathbf{x}_{t}$, and noting that $\mathbf{W}^{\prime} \mathbf{S}_{x}^{\prime} \mathbf{C}^{*}(L) \mathbf{S}_{x} \varepsilon_{i t}=$ $O_{p}\left(N^{-1 / 2}\right)$, we obtain

$$
\boldsymbol{\zeta}_{v t}=\mathbf{b}_{\zeta x}^{\star}+\overline{\mathbf{A}}_{w} \overline{\mathbf{x}}_{t}-\overline{\mathbf{A}}_{w} \overline{\mathbf{D}}_{w}(L) \mathbf{v}_{g t}+O_{p}\left(N^{-1 / 2} t^{1 / 2}\right)+O_{p}\left(N^{-1 / 2}\right),
$$

for $t=1,2, \ldots, T$, where

$$
\overline{\mathbf{A}}_{w}=\left(\overline{\mathbf{D}}_{w}^{\prime} \overline{\mathbf{D}}_{w}\right)^{-1} \overline{\mathbf{D}}_{w}^{\prime}
$$

and $\overline{\mathbf{D}}_{w}(L)=\mathbf{W}^{\prime} \mathbf{S}_{x} \mathbf{C}(L) \boldsymbol{\Gamma}_{z v}$. Substituting (A.13) in (A.16) now yields

$$
\boldsymbol{\zeta}_{v t}=\mathbf{b}_{\zeta x}^{\star}+\overline{\mathbf{A}}_{w} \overline{\mathbf{x}}_{t}+\overline{\mathbf{A}}_{w}^{*}(L) \Delta \overline{\mathbf{x}}_{t}+O_{p}\left(N^{-1 / 2} t^{1 / 2}\right)+O_{p}\left(N^{-1 / 2}\right),
$$

for $t=1,2, \ldots, T$, where

$$
\overline{\mathbf{A}}_{w}^{*}(L)=-\overline{\mathbf{A}}_{w} \overline{\mathbf{D}}_{w}(L) \overline{\mathbf{B}}_{w}(L) .
$$

Finally, a large- $N$ ECM representations for individual country models can be obtained as follows: Using results in Section 22.15 of Pesaran (2015b) for $\mathbf{g}_{t}$ given by (A.7), we obtain

$$
\mathbf{g}_{t}=\mathbf{g}_{0}^{\star}+\boldsymbol{\zeta}_{v t}+\mathbf{C}_{g}^{*}(L) \mathbf{v}_{g t}
$$

and $\Delta \mathbf{g}_{t}=\mathbf{C}_{\Delta g}(L) \mathbf{v}_{g t}$, where $\mathbf{C}_{g}^{*}(L)$ and $\mathbf{C}_{\Delta g}(L)$ are defined in the same way as $\mathbf{C}^{*}(L)$ in (A.4) and $\mathbf{C}_{\Delta}(L)$ in (A.9), but with $\boldsymbol{\Pi}_{g}=\mathbf{0}$ and $\boldsymbol{\Gamma}_{g \ell}$ instead of $\boldsymbol{\Pi}$ and $\boldsymbol{\Gamma}_{\ell}$. Using (A.20) and substituting (A.16) for $\boldsymbol{\zeta}_{v t}$, we have

$$
\mathbf{g}_{t}=\mathbf{C}_{g} \overline{\mathbf{A}}_{w} \overline{\mathbf{x}}_{t}+\mathbf{C}_{g v}(L) \mathbf{v}_{g t}+O_{p}\left(N^{\theta / 2-1} T^{1 / 2}\right)+O_{p}\left(N^{-1 / 2}\right)
$$

where $\mathbf{C}_{g v}(L)=\mathbf{C}_{g}^{*}(L)-\overline{\mathbf{A}}_{w} \overline{\mathbf{D}}_{w}(L)$. Using (A.21) in the VECM representation for $\mathbf{x}_{i t}$, we obtain

$$
\Delta \mathbf{x}_{i t}=-\boldsymbol{\alpha}_{\pi, i} \widetilde{\boldsymbol{\beta}}_{i}^{\prime} \widetilde{\mathbf{x}}_{i, t-1}+\sum_{\ell=1}^{p-1} \boldsymbol{\Gamma}_{x x i \ell} \Delta \mathbf{x}_{i, t-\ell}+\mathbf{Q}_{i}(L) \mathbf{v}_{t}+\varepsilon_{i t}+O_{p}\left(N^{-1 / 2} t^{1 / 2}\right)+O_{p}\left(N^{-1 / 2}\right),
$$

where $\widetilde{\mathbf{x}}_{i t}=\left(\mathbf{x}_{i t}^{\prime}, \overline{\mathbf{x}}_{t}^{\prime}\right)^{\prime}, \widetilde{\boldsymbol{\beta}}_{i}=\left(\boldsymbol{\beta}_{\pi x i}^{\prime}, \boldsymbol{\beta}_{\pi g i}^{\prime} \overline{\mathbf{A}}_{w}\right)^{\prime}$,

$$
\mathbf{Q}_{i}(L)=\boldsymbol{\Gamma}_{v i}+\boldsymbol{\alpha}_{i} \widetilde{\boldsymbol{\beta}}_{i}^{\prime}\left[\mathbf{C}_{g}(L)-\overline{\mathbf{A}}_{w} \overline{\mathbf{D}}_{w}(L)\right]+\sum_{\ell=1}^{p-1} \mathbf{C}_{\Delta g}(L) L^{\ell},
$$

and $\boldsymbol{\Gamma}_{x g i \ell}$ is defined by the partitioned $\boldsymbol{\Gamma}_{x i \ell}=\left(\boldsymbol{\Gamma}_{x x i \ell}, \boldsymbol{\Gamma}_{x g i \ell}\right)$. Substituting now (A.13) for $\mathbf{v}_{g t}$, we obtain 
the following large- $N$ country ECM representations

$$
\Delta \mathbf{x}_{i t}=-\boldsymbol{\alpha}_{\pi i} \widetilde{\boldsymbol{\beta}}_{i}^{\prime} \widetilde{\mathbf{x}}_{i, t-1}+\sum_{\ell=1}^{p-1} \boldsymbol{\Gamma}_{x x i \ell} \Delta \mathbf{x}_{i, t-\ell}+\mathbf{\Xi}_{i}(L) \Delta \overline{\mathbf{x}}_{t}+\varepsilon_{i t}+O_{p}\left(N^{-1 / 2} t^{1 / 2}\right)+O_{p}\left(N^{-1 / 2}\right)
$$

for $t=1,2, \ldots, T$, where

$$
\boldsymbol{\Xi}_{i}(L)=\mathbf{Q}_{i}(L) \mathbf{B}_{w}^{-1}(L)=\sum_{\ell=0}^{\infty} \boldsymbol{\Xi}_{i \ell} L^{\ell}
$$

When $\boldsymbol{\alpha}_{\pi i}=0$, we have

$$
\Delta \mathbf{x}_{i t}=\sum_{\ell=1}^{p-1} \boldsymbol{\Gamma}_{x x i \ell} \Delta \mathbf{x}_{i, t-\ell}+\boldsymbol{\Xi}_{i}(L) \Delta \overline{\mathbf{x}}_{t}+\boldsymbol{\varepsilon}_{i t}+O_{p}\left(N^{-1 / 2}\right)
$$

To obtain the representation featuring the global and national error structure, we can substitute (A.14) in $\boldsymbol{\Xi}_{i, 0} \Delta \overline{\mathbf{x}}_{t}$.

\section{A.2 Forecast error variance decompositions for the sets of global and national shocks}

Consider the following moving average representation of the GVAR model,

$$
\Delta \mathbf{x}_{t}=\boldsymbol{\mu}+\mathbf{H}(L)\left(\mathbf{B}_{v} \mathbf{v}_{t}+\varepsilon_{t}\right)
$$

where $\mathbf{H}(L)=\mathbf{G}^{-1}(L), \mathbf{G}(L)=\mathbf{I}_{k N}-\sum_{\ell=1}^{p_{T}} \mathbf{G}_{\ell} L^{\ell}$ and $\boldsymbol{\mu}=\mathbf{G}^{-\mathbf{1}}(\mathbf{L}) \mathbf{a}$. Forecast error variance explained by the global and national shocks, at horizon $h=0,1,2, \ldots$, are given by

$$
\begin{aligned}
& F E V D_{c}(h)=\sum_{\ell=0}^{h} \mathbf{H}_{\ell} \boldsymbol{\Sigma}_{\varepsilon} \mathbf{H}_{\ell}^{\prime}, \\
& F E V D_{g}(h)=\sum_{\ell=0}^{h} \mathbf{H}_{\ell} \mathbf{B}_{v} \boldsymbol{\Sigma}_{v} \mathbf{B}_{v}^{\prime} \mathbf{H}_{\ell}^{\prime},
\end{aligned}
$$

respectively, where $\boldsymbol{\Sigma}_{\varepsilon}$ is the covariance matrix of $\varepsilon_{t}$ and $\boldsymbol{\Sigma}_{v}$ is the covariance matrix of $\mathbf{v}_{t}$. Note that regardless of rotation matrix $\mathbf{A}_{v}$, forecast error variance explained by the rotated global shocks, $\mathbf{A}_{v} \mathbf{v}_{t}$, is numerically identical to $F E V D_{g}(h)$. The total forecast error variance is $F E V D(h)=$ $F E V D_{g}(h)+F E V D_{c}(h)$, and the share of forecast error variance explained by the global shocks is given by $F E V D_{g}(h) / F E V D(h)$.

\section{A.3 Description of the bootstrapping procedure for the effects of global shocks}

Let $t_{0}$ denote the first time period where observations on residuals for all countries are available. Bootstrapping procedure is described in the following steps.

1. Let $\hat{\varepsilon}_{t}=\left(\hat{\varepsilon}_{1, t}^{\prime}, \hat{\varepsilon}_{2, t}^{\prime}, \ldots, \hat{\varepsilon}_{N t}^{\prime}\right)^{\prime}$, for $t=t_{0}, t_{0}+1, \ldots, T$, where $\hat{\varepsilon}_{i t}$ is the vector of LS residuals from conditional country models (8). Let $\mathbf{E}=\left(\hat{\varepsilon}_{t_{0}}, \hat{\varepsilon}_{t_{0}+1}, \ldots, \hat{\varepsilon}_{T}\right)$. For each bootstrap replication $r=1,2, \ldots, R$, we randomly draw with replacement $T-p_{T}$ column vectors from $\mathbf{E}$. The bootstrap 
draws are then re-centered to ensure that their temporal average is zero for each $i$. Denote these re-centered draws by $\hat{\varepsilon}_{i t}^{(r)}$, for $i=1,2, \ldots, N, t=p_{T}+1, p_{T}+2, \ldots, T$ and $r=1,2, \ldots, R$. For each bootstrap replication $r$, we also randomly draw with replacement $T-p_{T}$ vectors from the set $\left\{\hat{\mathbf{v}}_{t}\right\}_{t=t_{0}}^{T}$, and we re-center the draws to ensure that the temporal average of the draws is zero. The resulting re-centered vector draws are denoted as $\hat{\mathbf{v}}_{t}^{(r)}$.

2. We compute bootstrap replications $\Delta \overline{\mathbf{x}}_{t}^{(r)}$ based on the estimates of the GVAR marginal model (10), namely

$$
\Delta \mathbf{x}_{t}^{(r)}=\hat{\mathbf{a}}+\sum_{\ell=1}^{p_{T}} \hat{\mathbf{G}}_{\ell} \Delta \mathbf{x}_{t-\ell}^{(r)}+\hat{\mathbf{B}} \hat{\mathbf{v}}_{t}^{(r)}+\varepsilon_{t}^{(r)}
$$

for $t=p_{T}+1, p_{T}+2, \ldots, T, r=1,2, \ldots, R$, with the starting values $\Delta \overline{\mathbf{x}}_{\ell}^{(r)}=\Delta \overline{\mathbf{x}}_{\ell}$ for $\ell=1,2, \ldots, p_{T}$.

3. For each bootstrap replication $r=1,2, \ldots, R$, the bootstrapped data is trimmed from the beginning to match the available sample, and we then use the generated unbalanced panel data for estimation of the effects of global shocks and for FEVDs.

\section{A.4 Priors used for estimating the effects of national fiscal and technology shocks}

The structural representation of country-specific models (8) is given by

$$
\mathbf{A}_{i} \Delta \mathbf{x}_{i t}=\mathbf{A}_{i} \mathbf{a}_{x i}+\sum_{\ell=1}^{p_{i}}\left(\mathbf{A}_{i} \boldsymbol{\Lambda}_{x, i \ell}\right) \Delta \mathbf{x}_{i, t-\ell}+\sum_{\ell=1}^{q_{i}}\left(\mathbf{A}_{i} \boldsymbol{\Lambda}_{\bar{x}, i \ell}\right) \Delta \overline{\mathbf{x}}_{t-\ell}+\left(\mathbf{A}_{i} \mathbf{B}_{i}\right) \hat{\mathbf{v}}_{t}+\boldsymbol{\eta}_{i t}
$$

for $i=1,2, \ldots, N$. Let $\boldsymbol{\Lambda}_{x, i \ell}^{*}=\mathbf{A}_{i} \boldsymbol{\Lambda}_{x, i \ell}, \boldsymbol{\Lambda}_{\bar{x}, i \ell}^{*}=\mathbf{A}_{i} \boldsymbol{\Lambda}_{\bar{x}, i \ell}, \mathbf{B}_{i}^{*}=\mathbf{A}_{i} \mathbf{B}_{i}$, and $\mathbf{a}_{x i}^{*}=\mathbf{A}_{i} \mathbf{a}_{x i}$. In addition, define $\boldsymbol{\omega}_{i t}=\left(1, \hat{\mathbf{v}}_{t}, \Delta \mathbf{x}_{i, t-1}^{\prime}, \ldots, \Delta \mathbf{x}_{i, t-p_{i}}^{\prime}, \Delta \overline{\mathbf{x}}_{t-1}^{\prime}, \ldots, \Delta \overline{\mathbf{x}}_{t-q_{i}}^{\prime}\right)^{\prime}$ and $\mathbf{Q}_{i}=\left(\mathbf{a}_{x i}^{* \prime}, \mathbf{B}_{i}^{* \prime}, \boldsymbol{\Lambda}_{x, i 1}^{*}, \ldots, \boldsymbol{\Lambda}_{x, i p_{i}}^{*}, \boldsymbol{\Lambda}_{\bar{x}, i 1}^{*}, \ldots, \boldsymbol{\Lambda}_{\bar{x}, i q_{i}}^{*}\right)^{\prime}$. Then (A.23) can be compactly written as

$$
\mathbf{A}_{i} \Delta \mathbf{x}_{i t}=\mathbf{Q}_{i} \boldsymbol{\omega}_{i t}+\boldsymbol{\eta}_{i t}
$$

We assume $\boldsymbol{\eta}_{i t} \sim \operatorname{IID}\left(\mathbf{0}, \mathbf{D}_{i}\right)$, where $\mathbf{D}_{i}$ is diagonal. We impose priors on $\mathbf{A}_{i}, \mathbf{Q}_{i}, \mathbf{D}_{i}$ to estimate country-specific models (A.23), and to conduct IRF analysis for national shocks. We specify the same priors as in $\mathrm{BH}$,

$$
p\left(\mathbf{A}_{i}, \mathbf{Q}_{i}, \mathbf{D}_{i}\right)=p\left(\mathbf{A}_{i}\right) p\left(\mathbf{D}_{i} \mid \mathbf{A}_{i}\right) p\left(\mathbf{Q}_{i} \mid \mathbf{D}_{i}, \mathbf{A}_{i}\right) .
$$

For future reference, let $d_{i, j j}$ be the $j$-th diagonal element of $\mathbf{D}_{i}$, and $\mathbf{q}_{i j}^{\prime}$ be the $j$-th row of $\mathbf{Q}_{i}$. The natural conjugate priors for $\mathbf{Q}_{i}$, and $\mathbf{D}_{i}$ are considered as in $\mathrm{BH}$.

\section{Prior for $\mathbf{D}_{i}$}

Gamma distribution with the shape parameter $\kappa_{i}$ and the rate parameter (or the inverse scale parameter $) \tau_{i}$, denoted as $\Gamma\left(\kappa_{i}, \tau_{i}\right)$, is used as a prior for the reciprocals of the diagonal elements of 
$\mathbf{D}_{i}$ (taken to be independent across equations)

$$
p\left(d_{i, j j}^{-1} \mid \mathbf{A}_{i}\right)=\left\{\begin{array}{lc}
\frac{\tau_{i}^{\kappa_{i}}}{\Gamma\left(\kappa_{i}\right)}\left(d_{i, j j}^{-1}\right)^{\kappa_{i}-1} \exp \left(-\tau_{i} d_{i, j j}^{-1}\right) & \text { for } d_{i, j j}^{-1} \geq 0 \\
0 & \text { otherwise }
\end{array}\right.
$$

Hence, $\kappa_{i} / \tau_{i}$ is the prior mean and $\kappa_{i} / \tau_{i}^{2}$ is the variance of the prior. We set $\kappa_{i}=\tau_{i}=0$.

\section{Prior for $\mathbf{Q}_{i}$}

Coefficients in $\mathbf{Q}_{i}$ are taken to be independent across equations, $p\left(\mathbf{q}_{i j} \mid \mathbf{D}_{i}, \mathbf{A}_{i}\right)=\prod_{j=1}^{2} p\left(\mathbf{q}_{i j} \mid \mathbf{D}_{i}, \mathbf{A}_{i}\right)$. Normal priors $N\left(\mathbf{m}_{i j}, d_{i, j j} \mathbf{M}_{i j}\right)$ are used for $\mathbf{q}_{i j}$,

$$
\begin{aligned}
& p\left(\mathbf{q}_{i j} \mid \mathbf{D}_{i}, \mathbf{A}_{i}\right)=\frac{1}{(2 \pi)^{k / 2}\left|d_{i, j j} \mathbf{M}_{i j}\right|^{1 / 2}} \\
& \quad \times \exp \left[-(1 / 2)\left(\mathbf{q}_{i j}-\mathbf{m}_{i j}\right)^{\prime}\left(d_{i, j j} \mathbf{M}_{i j}\right)^{-1}\left(\mathbf{q}_{i j}-\mathbf{m}_{i j}\right)\right],
\end{aligned}
$$

where $k$ is the dimension of $\mathbf{q}_{i j} \cdot \mathbf{m}_{i j}$ is the prior mean and $d_{i, j j} \mathbf{M}_{i j}$ is the prior variance. We set $\mathbf{M}_{i j}^{-1}=\mathbf{0}$.

\section{Prior for $\mathbf{A}_{i}$}

Recall that

$$
\mathbf{A}_{i}=\left(\begin{array}{cc}
1 & \alpha_{i} \\
1 & -\beta_{i}
\end{array}\right) \text { and } \mathbf{A}_{i}^{-1}=\frac{1}{\alpha_{i}+\beta_{i}}\left(\begin{array}{cc}
\beta_{i} & \alpha_{i} \\
1 & -1
\end{array}\right) .
$$

For $\beta_{i}$, we use student $t$ distribution with location parameter $c_{\beta i}=0.6$, scale parameter $\sigma_{\beta i}=0.6$ and degrees of freedom $\nu_{\beta i}=3$, truncated to be positive. This ensures that $\operatorname{Pr}\left(0.1<\beta_{i}<2.2\right.$. $)=$ 90 percent, prior mean is 0.91 , prior median is 0.76 , and prior interquartile range is $[0.43,1.18]$. The same prior distribution is used for $\alpha_{i}$.

\section{A.5 Data}

Output growth is computed using real gross domestic product (GDP) data series obtained from the International Monetary Fund (IMF) International Financial Statistics database. The gross government deb-to-GDP data series for the majority of the countries are downloaded from http://www.carmenreinhart.com/data/browse-by-topic/topics/9/ which are the updates of those discussed in Reinhart and Rogoff (2011). For Iran, Morocco, and Nigeria the debt-to-GDP series are obtained from the IMF FAD Historical Public Debt database. We focus on gross debt data due to difficulty of collecting net debt data on a consistent basis over time and across countries. Moreover, we use public debt at the general government level for as many countries as possible (Austria, Belgium, Germany, Italy, Netherlands, New Zealand, Singapore, Spain, Sweden, and Tunisia), but given the lack of general public debt data for many countries, central government debt data is used as an alternative. 


\section{A.6 Additional result tables and figures}

Table A1: Maximum eigenvalue and trace statistics for testing cointegration in VAR(4) models in $\left(y_{i t}, d_{i t}\right)^{\prime}$.

Deterministics: unrestricted intercepts and no linear trends.

\begin{tabular}{|c|c|c|c|c|c|c|c|c|}
\hline$H_{0} \quad H_{1}$ & Argentina & Australia & Austria & Belgium & Brazil & Canada & Chile & China \\
\hline \multicolumn{9}{|c|}{ (a) Maximal eigenvalue statistic } \\
\hline$r=0 r=1$ & 7.88 & 3.89 & $17.81^{*}$ & 7.10 & $17.06^{*}$ & 7.35 & 6.56 & 5.58 \\
\hline$r \leq 1 r=2$ & 0.31 & 2.04 & 5.05 & 2.79 & 2.07 & 5.79 & 0.27 & 0.00 \\
\hline \multicolumn{9}{|c|}{ (b) Trace statistic } \\
\hline$r=0 r=1$ & 8.19 & 5.93 & $22.86^{*}$ & 9.89 & $19.13^{*}$ & 13.14 & 6.82 & 5.58 \\
\hline$r \leq 1 r=2$ & 0.31 & 2.04 & 5.05 & 2.79 & 2.07 & 5.79 & 0.27 & 0.00 \\
\hline$H_{0} \quad H_{1}$ & Ecuador & Egypt & Finland & France & Germany & India & Indonesia & Iran \\
\hline \multicolumn{9}{|c|}{ (a) Maximal eigenvalue statistic } \\
\hline$r=0 r=1$ & $15.02^{*}$ & 14.77 & $16.20^{*}$ & $27.51^{*}$ & 16.86 & 11.52 & $17.57^{*}$ & $17.67^{*}$ \\
\hline$r \leq 1 r=2$ & 1.22 & 6.20 & 6.68 & $11.09^{*}$ & 5.11 & $8.58^{*}$ & 1.57 & 0.84 \\
\hline \multicolumn{9}{|c|}{ (b) Trace statistic } \\
\hline$r=0 r=1$ & 16.24 & 20.97 & $22.88^{*}$ & $38.60^{*}$ & $21.96^{*}$ & $20.10^{*}$ & $19.13^{*}$ & $18.51^{*}$ \\
\hline$r \leq 1 r=2$ & 1.22 & 6.20 & 6.68 & $11.09^{*}$ & 5.11 & $8.58^{*}$ & 1.57 & 0.84 \\
\hline
\end{tabular}

\begin{tabular}{|c|c|c|c|c|c|c|c|c|}
\hline$H_{1}$ & Italy & Japan & Korea & Malaysia & Mexico & Morocco & Netherlands & New Zealand \\
\hline \multicolumn{9}{|c|}{ (a) Maximal eigenvalue statistic } \\
\hline$r=0 r=1$ & 12.62 & $23.85^{*}$ & $20.98^{*}$ & 12.38 & 10.20 & 6.66 & 10.75 & 4.12 \\
\hline$r \leq 1 r=2$ & 4.90 & 4.63 & 3.91 & 4.64 & 1.24 & 0.08 & 6.55 & 0.23 \\
\hline \multicolumn{9}{|c|}{ (b) Trace statistic } \\
\hline$r=0 r=1$ & 17.52 & $28.49^{*}$ & $24.89^{*}$ & 17.02 & 11.45 & 6.74 & 17.30 & 4.34 \\
\hline$r \leq 1 r=2$ & 4.90 & 4.63 & 3.91 & 4.64 & 1.24 & 0.08 & 6.55 & 0.23 \\
\hline
\end{tabular}

\begin{tabular}{|c|c|c|c|c|c|c|c|c|}
\hline$H_{0} \quad H_{1}$ & Nigeria & Norway & Peru & Philippines & Singapore & South Africa & Spain & Sweden \\
\hline \multicolumn{9}{|c|}{ (a) Maximal eigenvalue statistic } \\
\hline$r=0 r=1$ & 9.44 & 11.69 & $15.85^{*}$ & 10.43 & $21.18^{*}$ & 6.72 & $19.00^{*}$ & 6.41 \\
\hline$r \leq 1 r=2$ & 0.00 & $8.13^{*}$ & 1.40 & 0.00 & 6.38 & 0.23 & 6.49 & 0.69 \\
\hline \multicolumn{9}{|c|}{ (b) Trace statistic } \\
\hline$r=0 r=1$ & 9.44 & $19.82^{*}$ & 17.25 & 10.43 & $27.56^{*}$ & 6.95 & $25.49^{*}$ & 7.10 \\
\hline$r \leq 1 r=2$ & 0.00 & $8.13^{*}$ & 1.40 & 0.00 & 6.38 & 0.23 & 6.49 & 0.69 \\
\hline
\end{tabular}

\begin{tabular}{|c|c|c|c|c|c|c|c|}
\hline$H_{1}$ & Switzerland & Thailand & Tunisia & Turkey & UK & USA & Venezu \\
\hline \multicolumn{8}{|c|}{ (a) Maximal eigenvalue statistic } \\
\hline$r=0 r=1$ & 10.66 & 13.84 & 14.28 & 5.41 & 10.70 & 10.63 & 9.05 \\
\hline$r \leq 1 r=2$ & 5.26 & $8.83^{*}$ & 2.01 & 0.01 & 0.60 & 2.65 & 2.36 \\
\hline \multicolumn{8}{|c|}{ (b) Trace statistic } \\
\hline$r=0 r=1$ & 15.92 & $22.67^{*}$ & 16.29 & 5.42 & 11.30 & 13.28 & 11.41 \\
\hline$r \leq 1 r=2$ & 5.26 & $8.83^{*}$ & 2.01 & 0.01 & 0.60 & 2.65 & 2.36 \\
\hline
\end{tabular}


Table A1(Ctd.): Cointegration tests statistics for the VAR(4) models in $\left(y_{i t}, d_{i t}\right)^{\prime}$.

Deterministics: unrestricted intercepts and restricted linear trends.

\begin{tabular}{|c|c|c|c|c|c|c|c|c|}
\hline$H_{1}$ & Argentina & Australia & Austria & Belgium & Brazil & Canada & Chile & China \\
\hline \multicolumn{9}{|c|}{ (a) Maximal eigenvalue statistic } \\
\hline$r=0 r=1$ & 10.14 & 12.06 & 17.85 & 8.93 & 18.22 & 9.41 & 9.24 & $19.63^{*}$ \\
\hline$r \leq 1 r=2$ & 4.54 & 3.89 & 6.09 & 4.61 & 11.14 & 7.34 & 4.30 & 5.57 \\
\hline \multicolumn{9}{|c|}{ (b) Trace statistic } \\
\hline$r=0 r=1$ & 14.69 & 15.95 & 23.94 & 13.53 & $29.36^{*}$ & 16.74 & 13.54 & 25.20 \\
\hline$r \leq 1 r=2$ & 4.54 & 3.89 & 6.09 & 4.61 & 11.14 & 7.34 & 4.30 & 5.57 \\
\hline$H_{0} \quad H_{1}$ & Ecuador & Egypt & Finland & France & Germany & India & Indonesia & Iran \\
\hline \multicolumn{9}{|c|}{ (a) Maximal eigenvalue statistic } \\
\hline$r=0 r=1$ & 18.69 & 16.50 & 16.20 & $27.55^{*}$ & $20.33^{*}$ & 14.87 & $23.53^{*}$ & 18.17 \\
\hline$r \leq 1 r=2$ & 11.09 & $13.32^{*}$ & 7.39 & 11.52 & 5.16 & 10.65 & 4.33 & $15.99^{*}$ \\
\hline \multicolumn{9}{|c|}{ (b) Trace statistic } \\
\hline$r=0 r=1$ & $29.78^{*}$ & $29.83^{*}$ & 23.59 & $39.07^{*}$ & 25.49 & 25.52 & $27.86^{*}$ & $34.16^{*}$ \\
\hline$r \leq 1 r=2$ & 11.09 & $13.32^{*}$ & 7.39 & 11.52 & 5.16 & 10.65 & 4.33 & $15.99^{*}$ \\
\hline
\end{tabular}

$\begin{array}{llllllll}H_{0} & H_{1} & \text { Italy } & \text { Japan } & \text { Korea } & \text { Malaysia } & \text { Mexico } & \text { Morocco Netherlands New Zealand }\end{array}$

\begin{tabular}{|c|c|c|c|c|c|c|c|c|}
\hline \multicolumn{9}{|c|}{ (a) Maximal eigenvalue statistic } \\
\hline$r=0 r=1$ & $25.77^{*}$ & $23.91^{*}$ & $20.98^{*}$ & 17.02 & 11.23 & 10.76 & $20.51^{*}$ & 17.31 \\
\hline$r \leq 1 r=2$ & 4.92 & 6.47 & 6.46 & 6.41 & 8.99 & 5.86 & 6.76 & 3.81 \\
\hline
\end{tabular}

(b) Trace statistic

\begin{tabular}{|c|c|c|c|c|c|c|c|c|}
\hline$r=0 r=1$ & $30.69^{*}$ & $30.38^{*}$ & $27.44^{*}$ & 23.44 & 20.22 & 16.62 & $27.26^{*}$ & 21.11 \\
\hline$r \leq 1 r=2$ & 4.92 & 6.47 & 6.46 & 6.41 & 8.99 & 5.86 & 6.76 & 3.81 \\
\hline
\end{tabular}

\begin{tabular}{|c|c|c|c|c|c|c|c|c|}
\hline$H_{1}$ & Nigeria & Norway & Peru & Philippines & Singapore & South Africa & Spain & Sweden \\
\hline \multicolumn{9}{|c|}{ (a) Maximal eigenvalue statistic } \\
\hline$r=0 r=1$ & $26.40^{*}$ & 11.93 & $20.34^{*}$ & 17.58 & $21.27^{*}$ & 6.77 & 19.10 & 8.84 \\
\hline$r \leq 1 r=2$ & 6.29 & 8.32 & 8.55 & 9.97 & 6.78 & 2.36 & 7.00 & 4.67 \\
\hline \multicolumn{9}{|c|}{ (b) Trace statistic } \\
\hline$r=0 r=1$ & $32.69^{*}$ & 20.25 & $28.89^{*}$ & $27.55^{*}$ & $28.05^{*}$ & 9.13 & 26.10* & 13.51 \\
\hline$r \leq 1 r=2$ & 6.29 & 8.32 & 8.55 & 9.97 & 6.78 & 2.36 & 7.00 & 4.67 \\
\hline
\end{tabular}

\begin{tabular}{|c|c|c|c|c|c|c|c|}
\hline$H_{1}$ & Switzerland & Thailand & Tunisia & Turkey & UK & USA & Venezuela \\
\hline \multicolumn{8}{|c|}{ (a) Maximal eigenvalue statistic } \\
\hline$r=0 r=1$ & $29.95^{*}$ & 17.04 & 15.08 & $22.39^{*}$ & 14.26 & 10.71 & 11.48 \\
\hline$r \leq 1 r=2$ & 9.57 & 10.00 & 6.27 & 5.39 & 5.59 & 2.65 & 7.96 \\
\hline \multicolumn{8}{|c|}{ (b) Trace statistic } \\
\hline$r=0 r=1$ & $39.52^{*}$ & $27.05^{*}$ & 21.35 & $27.78^{*}$ & 19.85 & 13.36 & 19.44 \\
\hline$r \leq 1 r=2$ & 9.57 & 10.00 & 6.27 & 5.39 & 5.59 & 2.65 & 7.96 \\
\hline
\end{tabular}


Table A2: Estimates of long-run relationships between real GDP and public debt (in logs)

\begin{tabular}{|c|c|c|c|c|c|c|c|c|c|c|c|}
\hline \multirow{6}{*}{ Country } & \multicolumn{4}{|c|}{ Unrestricted intercepts and no linear trends } & \multicolumn{7}{|c|}{ Unrestricted intercepts and restricted linear trends } \\
\hline & \multirow{5}{*}{$\begin{array}{c}\text { Exactly } \\
\text { identified } \\
\widehat{\theta} \\
\end{array}$} & \multicolumn{3}{|c|}{ Theory restriction } & \multicolumn{4}{|c|}{ Co-trending restriction } & \multicolumn{3}{|c|}{ Co-trending \& theory } \\
\hline & & \multicolumn{3}{|c|}{$(\theta=1)$} & \multicolumn{4}{|c|}{$(\xi=0)$} & \multicolumn{3}{|c|}{ restriction $(\theta=1)$} \\
\hline & & \multicolumn{3}{|c|}{ Bootstrapped } & \multicolumn{4}{|c|}{ Bootstrapped } & \multirow{2}{*}{\multicolumn{3}{|c|}{$\begin{array}{ll} & \text { Bootstrapped } \\
\text { LR } & \text { Critical Values }\end{array}$}} \\
\hline & & LR & Critic & l Values & & LR & Critical & l Values & & & \\
\hline & & $(d . f .=1)$ & $1 \%$ & $5 \%$ & $\widehat{\theta}$ & $(d . f .=1)$ & $1 \%$ & $5 \%$ & $(d . f .=2)$ & $1 \%$ & $5 \%$ \\
\hline Austria & $\begin{array}{c}3.8674 \\
(13.6969)\end{array}$ & 1.1653 & 11.2627 & 6.0984 & -—— & $-\mathrm{N} / \mathrm{A}$ & -—— - & & -—- & $-\mathrm{N} / \mathrm{A}-$ & - \\
\hline Brazil & $\begin{array}{c}1.5362 \\
(0.94641)\end{array}$ & 1.3339 & 9.3370 & 6.2584 & $\begin{array}{c}1.5362 \\
(0.94561)\end{array}$ & 1.1628 & 11.3256 & 6.6432 & 2.4966 & 14.3109 & 10.2205 \\
\hline China & - & $-\mathrm{N} /$ & $\mathrm{A}$ & - - & $\begin{array}{c}0.53352 \\
(0.024718)\end{array}$ & 14.1378 & 19.8391 & 13.8566 & 19.6136 & 27.6080 & 22.9566 \\
\hline Ecuador & $\begin{array}{c}8.4008 \\
(27.0542)\end{array}$ & 7.0627 & 13.1067 & 9.0936 & $\begin{array}{c}8.3994 \\
(26.4435)\end{array}$ & 3.6719 & 13.7931 & 8.0240 & 10.7346 & 19.7259 & 14.9056 \\
\hline Egypt & $\begin{array}{c}0.76555 \\
(0.10471)\end{array}$ & 1.3094 & 11.203 & 6.4050 & $\begin{array}{c}0.76555 \\
(0.10471)\end{array}$ & 1.7294 & 13.8929 & 8.0832 & 3.0388 & 17.6195 & 11.3400 \\
\hline Finland & $\begin{array}{c}0.21752 \\
(0.049579)\end{array}$ & 9.4161 & 16.8036 & 10.6689 & - - & $-\mathrm{N} / \mathrm{A}$ & - & & - - & $-\mathrm{N} / \mathrm{A}-$ & - - \\
\hline France & $\begin{array}{c}0.31725 \\
(0.018467)\end{array}$ & 16.3753 & 13.5892 & 8.0999 & $\begin{array}{c}0.31720 \\
(0.018469)\end{array}$ & 0.039077 & 9.9713 & 6.1465 & 16.4144 & 18.0087 & 12.8632 \\
\hline Germany & $\begin{array}{c}0.41423 \\
(0.016329)\end{array}$ & 11.6382 & 16.1652 & 12.2464 & $\begin{array}{c}0.41470 \\
(0.016334)\end{array}$ & 3.4684 & 11.6633 & 6.5882 & 15.1058 & 23.6078 & 17.3975 \\
\hline India & $\begin{array}{c}0.96127 \\
(0.11059)\end{array}$ & 0.10157 & 10.3836 & 7.1798 & - & $-\mathrm{N} / \mathrm{A}$ & - — & & —— & $-\mathrm{N} / \mathrm{A}-$ & - - \\
\hline Indonesia & $\begin{array}{c}1.0555 \\
(0.12972)\end{array}$ & 0.20668 & 11.8274 & 6.9002 & $\begin{array}{c}1.0555 \\
(0.12972)\end{array}$ & 5.9685 & 14.3651 & 8.5834 & 6.1752 & 17.6587 & 11.8289 \\
\hline Iran & $\begin{array}{c}4.1026 \\
(1.6480)\end{array}$ & 12.3382 & 13.9755 & 8.6277 & $\begin{array}{c}4.1026 \\
(1.6480)\end{array}$ & 0.49545 & 12.9670 & 7.3050 & 12.8337 & 20.4609 & 15.4487 \\
\hline Italy & - & $-\mathrm{N} /$ & $\mathrm{A}$ & & $\begin{array}{c}0.14005 \\
(0.13172)\end{array}$ & 13.1499 & 15.2560 & 8.4779 & 17.0032 & 19.7953 & 15.2036 \\
\hline
\end{tabular}

Notes: LR is the log-likelihood ratio statistic for testing the long-run relations, with the number of over-identifying restrictions being 1 when imposing the co-trending restriction and 2 when imposing the co-trending and theory restriction, $\theta=1$. The bootstrapped upper five and one percent critical values of the LR statistics are provided in the columns succeeding the LR statistic and are based on 1,000 replications. Absence of cointegration is denoted by N/A. 
Table A2 (Ctd.): Estimates of long-run relationships between real GDP and public debt (in logs)

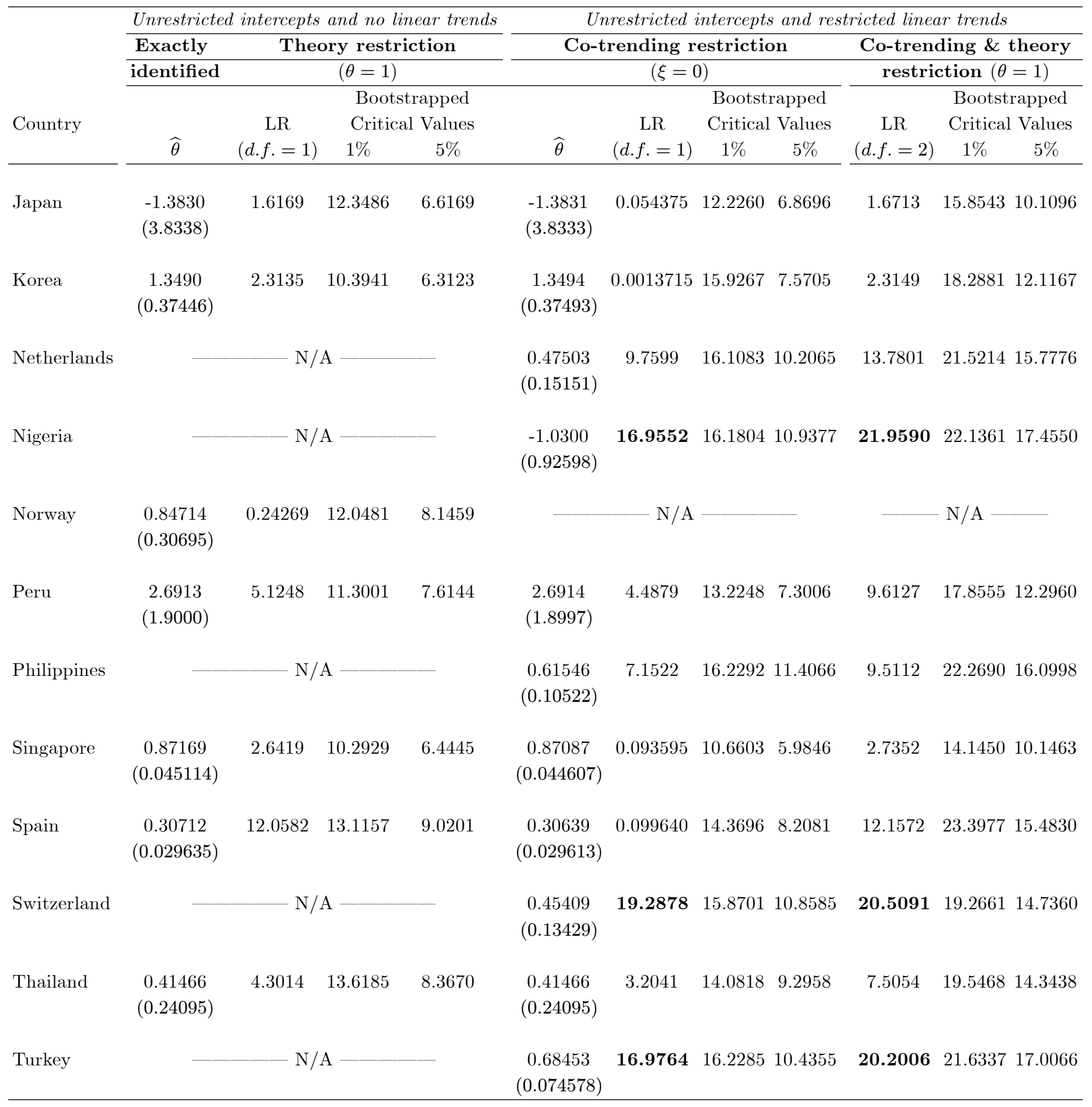

Notes: LR is the log-likelihood ratio statistic for testing the long-run relations, with the number of over-identifying restrictions being 1 when imposing the co-trending restriction and 2 when imposing the co-trending and theory restriction, $\beta=1$. The bootstrapped upper five and one percent critical values of the LR statistics are provided in the columns succeeding the LR statistic and are based on 1,000 replications. Absence of cointegration is denoted by N/A. 
Table A3: Standard errors of reduced-form shocks in models with and without global

shocks

\begin{tabular}{|c|c|c|c|c|c|c|}
\hline & \multicolumn{2}{|c|}{ Single country VARs } & \multicolumn{2}{|c|}{ With global shocks } & \multicolumn{2}{|c|}{ Ratio (without/with) } \\
\hline & $\Delta y_{i t}$ equation & $\Delta b_{i t}$ equation & $\Delta y_{i t}$ equation & $\Delta b_{i t}$ equation & $\Delta y_{i t}$ equation & $\Delta b_{i t}$ equation \\
\hline Argentina & 0.049 & 0.353 & 0.045 & 0.306 & 1.084 & 1.154 \\
\hline Australia & 0.016 & 0.138 & 0.015 & 0.104 & 1.114 & 1.326 \\
\hline Austria & 0.019 & 0.053 & 0.012 & 0.042 & 1.537 & 1.261 \\
\hline Belgium & 0.035 & 0.036 & 0.032 & 0.035 & 1.098 & 1.022 \\
\hline Brazil & 0.036 & 0.257 & 0.027 & 0.236 & 1.315 & 1.090 \\
\hline Canada & 0.018 & 0.066 & 0.014 & 0.058 & 1.356 & 1.139 \\
\hline Chile & 0.048 & 0.243 & 0.045 & 0.188 & 1.070 & 1.293 \\
\hline China & 0.016 & 0.144 & 0.015 & 0.119 & 1.109 & 1.211 \\
\hline Ecuador & 0.042 & 0.174 & 0.036 & 0.149 & 1.166 & 1.165 \\
\hline Egypt & 0.033 & 0.184 & 0.029 & 0.177 & 1.119 & 1.041 \\
\hline Finland & 0.029 & 0.136 & 0.022 & 0.102 & 1.297 & 1.332 \\
\hline France & 0.015 & 0.097 & 0.009 & 0.095 & 1.572 & 1.025 \\
\hline Germany & 0.024 & 0.059 & 0.019 & 0.051 & 1.276 & 1.151 \\
\hline India & 0.027 & 0.079 & 0.025 & 0.073 & 1.064 & 1.080 \\
\hline Indonesia & 0.030 & 0.210 & 0.026 & 0.184 & 1.159 & 1.138 \\
\hline Iran & 0.051 & 0.431 & 0.048 & 0.414 & 1.065 & 1.040 \\
\hline Italy & 0.019 & 0.041 & 0.013 & 0.034 & 1.458 & 1.216 \\
\hline Japan & 0.022 & 0.073 & 0.017 & 0.056 & 1.326 & 1.301 \\
\hline Korea & 0.034 & 0.209 & 0.027 & 0.192 & 1.238 & 1.088 \\
\hline Malaysia & 0.035 & 0.101 & 0.025 & 0.081 & 1.422 & 1.246 \\
\hline Mexico & 0.031 & 0.193 & 0.026 & 0.182 & 1.198 & 1.062 \\
\hline Morocco & 0.034 & 0.082 & 0.032 & 0.070 & 1.069 & 1.177 \\
\hline Netherlands & 0.019 & 0.056 & 0.014 & 0.051 & 1.315 & 1.083 \\
\hline New Zealand & 0.024 & 0.071 & 0.023 & 0.064 & 1.021 & 1.098 \\
\hline Nigeria & 0.041 & 0.269 & 0.035 & 0.227 & 1.161 & 1.184 \\
\hline Norway & 0.015 & 0.160 & 0.013 & 0.145 & 1.146 & 1.105 \\
\hline Peru & 0.046 & 0.188 & 0.040 & 0.169 & 1.153 & 1.111 \\
\hline Philippines & 0.026 & 0.099 & 0.023 & 0.090 & 1.123 & 1.105 \\
\hline Singapore & 0.035 & 0.099 & 0.022 & 0.072 & 1.570 & 1.364 \\
\hline South Africa & 0.021 & 0.068 & 0.016 & 0.061 & 1.268 & 1.129 \\
\hline Spain & 0.020 & 0.073 & 0.015 & 0.059 & 1.298 & 1.240 \\
\hline Sweden & 0.021 & 0.070 & 0.015 & 0.057 & 1.357 & 1.224 \\
\hline Switzerland & 0.019 & 0.092 & 0.013 & 0.085 & 1.462 & 1.085 \\
\hline Thailand & 0.035 & 0.188 & 0.028 & 0.179 & 1.219 & 1.050 \\
\hline Tunisia & 0.024 & 0.097 & 0.023 & 0.084 & 1.062 & 1.159 \\
\hline Turkey & 0.040 & 0.141 & 0.037 & 0.125 & 1.076 & 1.127 \\
\hline UK & 0.018 & 0.091 & 0.014 & 0.087 & 1.294 & 1.049 \\
\hline USA & 0.019 & 0.035 & 0.015 & 0.032 & 1.307 & 1.088 \\
\hline Venezuela & 0.052 & 0.259 & 0.044 & 0.211 & 1.182 & 1.227 \\
\hline \multicolumn{7}{|l|}{ Averages } \\
\hline Advanced & 0.022 & 0.087 & 0.017 & 0.075 & 1.318 & 1.168 \\
\hline Emerging & 0.036 & 0.188 & 0.031 & 0.166 & 1.154 & 1.139 \\
\hline All countries & 0.029 & 0.139 & 0.024 & 0.122 & 1.234 & 1.153 \\
\hline
\end{tabular}

Note: This table reports the estimates of standard errors of the reduced-form shocks in country-specific models with and without CS augmentation. The last two columns report the ratio of standard error estimates in the models without the CS augmentation (in the numerator) and with CS augmentation (denominator). By construction, this ratio $\geq 1$. 
Table A4: Country pairs with statistically significant correlations between their national shocks

\begin{tabular}{lll}
\hline \hline Country and variable pairs & $\hat{\rho}$ \\
\hline (1) Indonesia $(\Delta y)$ & Malaysia $(\Delta y)$ & 0.71 \\
$(2)$ Sweden $(\Delta y)$ & Finland $(\Delta y)$ & 0.71 \\
$(3)$ USA $(\Delta b)$ & New Zealand $(\Delta b)$ & 0.60 \\
$(4)$ USA $(\Delta y)$ & Canada $(\Delta y)$ & 0.71 \\
\hline \hline
\end{tabular}

Notes: We estimated the covariance matrix of the reduced-form national errors using the regularized reduced-form error covariance matrix estimate proposed by Bailey, Pesaran, and Smith (2018). The pairs with nonzero correlations are reported in this table, together with the correlation coefficients. 
Figure A1: Comparison of parameters $\alpha$ and $\beta$ across countries in models with and without global shocks

(medians of posterior distributions)

Parameter $\alpha$

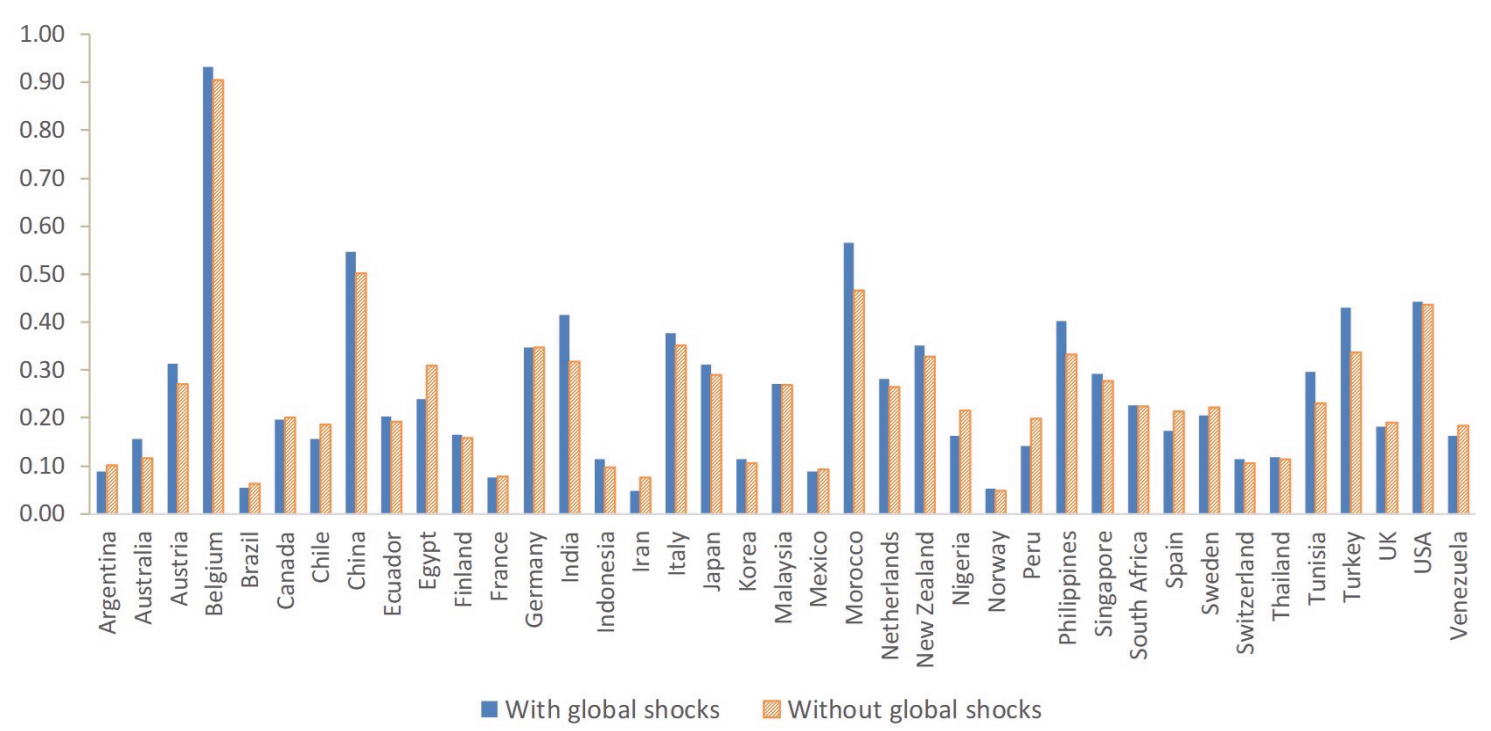

Parameter $\beta$

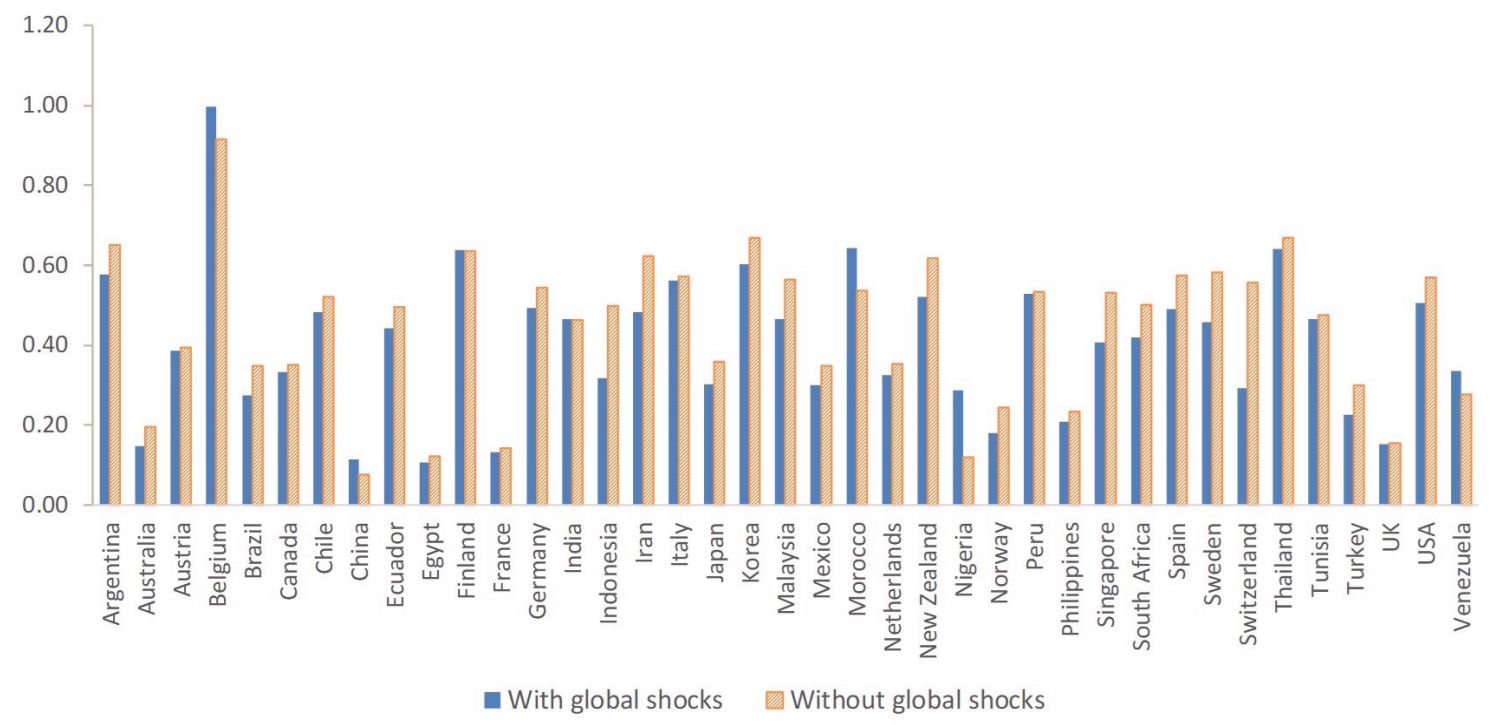

Notes: This figure plots posterior medians of $\alpha$ and $\beta$ in country-specific models with and without CS augmentation. $\epsilon_{\alpha}=(1-\alpha)$ is the elasticity of debt with respect to output when output expands due to technology shock, and $\epsilon_{\beta}=(1+\beta)$ is the elasticity of debt with respect to output when output expands due to fiscal policy shock. 


\section{References}

Bai, J., K. Li, and L. Lu (2016). Estimation and inference of favar models. Journal of Business 83 Economic Statistics 34, 620-641. https://doi.org/10.1080/07350015.2015.1111222.

Bailey, N., G. Kapetanios, and M. H. Pesaran (2016). Exponent of cross-sectional dependence: Estimation and inference. Journal of Applied Econometrics 31, 929-1196. https://doi.org/10.1002/jae.2476.

Bailey, N., M. H. Pesaran, and L. V. Smith (2018). A multiple testing approach to the regularisation of large sample correlation matrices. forthcoming in Journal of Econometrics. https://doi.org/10.1016/j.jeconom.2018.10.006.

Baumeister, C. and J. D. Hamilton (2015). Sign restrictions, structural vector autoregressions, and useful prior information. Econometrica 83, 1963-1999. https://doi.org/10.3982/ecta12356.

Bernanke, B. S., J. Bovian, and P. Eliasz (2005). Measuring the effects of monetary policy: A factoraugmented vector autoregressive (FAVAR) approach. Quarterly Journal of Economics 120, 387422. https://www.jstor.org/stable/25098739.

Blanchard, O. J. (1985). Debt, deficits, and finite horizons. Journal of Political Economy 93, 223247. https://doi.org/10.1086/261297.

Cesa-Bianchi, A., M. H. Pesaran, and A. Rebucci (2018). Uncertainty and economic activity: A multi-country perspective. NBER Working Paper No. 24325, https://doi.org/10.3386/w24325.

Checherita-Westphal, C. and P. Rother (2012). The impact of high government debt on economic growth and its channels: An empirical investigation for the Euro Area. European Economic Review 56, 1392 - 1405. https://doi.org/10.1016/j.euroecorev.2012.06.007.

Chudik, A., V. Grossman, and M. H. Pesaran (2016). A multi-country approach to forecasting output growth using PMIs. Journal of Econometrics 192, 349-365. https://doi.org/10.1016/j.jeconom.2016.02.003.

Chudik, A., K. Mohaddes, M. H. Pesaran, and M. Raissi (2017). Is there a debtthreshold effect on output growth? Review of Economics and Statistics 99, 135-150. https://dx.doi.org/10.1162/REST_a_00593.

Chudik, A. and M. H. Pesaran (2011). Infinite dimensional VARs and factor models. Journal of Econometrics 163, 4-22. https://doi.org/10.1016/j.jeconom.2010.11.002.

Chudik, A. and M. H. Pesaran (2013). Econometric analysis of high dimensional VARs featuring a dominant unit. Econometric Reviews 32, 592-649. https://doi.org/10.1080/07474938.2012.740374.

Chudik, A. and R. Straub (2017). Size, openness, and macroeconomic interdependence. International Economic Review 58, 33-55. https://doi.org/10.1111/iere.12208.

Cochrane, J. H. (2011a). Inflation and debt. National Affairs (Washington/DC),(Fall 2011) 9, 5678.

Cochrane, J. H. (2011b). Understanding policy in the great recession: Some unpleasant fiscal arithmetic. European Economic Review 55(1), 2-30. 
https://dx.doi.org/10.1016/j.euroecorev.2010.11.002.

DeLong, J. B. and L. H. Summers (2012). Fiscal policy in a depressed economy. Brookings Papers on Economic Activity 2012(1), 233-297. https://doi.org/10.1353/eca.2012.0000.

Diamond, P. A. (1965). National debt in a neoclassical growth model. The American Economic Review 55(5), 1126-1150. https://www.jstor.org/stable/1809231.

Dungey, M. and D. R. Osborn (2013). Modelling large open economies with international linkages: The usa and euro area. Journal of Applied Econometrics 29(3), 377-393. https://doi.org/10.1002/jae.2323.

Dées, S., F. di Mauro, M. H. Pesaran, and L. V. Smith (2007). Exploring the international linkages of the Euro Area: A global VAR analysis. Journal of Applied Econometrics 22, 1-38. https://dx.doi.org/10.1002/jae.932.

Eberhardt, M. and A. F. Presbitero (2015). Public debt and growth: Heterogeneity and non-linearity. Journal of International Economics 97(1), 45-58. https://dx.doi.org/10.1016/j.jinteco.2015.04.005.

Elmendorf, D. W. and G. N. Mankiw (1999). Government debt. In J. B. Taylor and M. Woodford (Eds.), Handbook of Macroeconomics, Volume 1, Part C, pp. 1615-1669. Elsevier. https://dx.doi.org/10.1016/S1574-0048(99)10038-7.

Ghosh, A. R., J. I. Kim, E. G. Mendoza, J. D. Ostry, and M. S. Qureshi (2013). Fiscal fatigue, fiscal space and debt sustainability in advanced economies. The Economic Journal 123(566), F4-F30. https://dx.doi.org/10.1111/ecoj.12010.

Johansen, S. (1991). Estimation and hypothesis testing of cointegration vectors in gaussian vector autoregressive models. Econometrica 59, 1551-1580. https://doi.org/10.2307/2938278.

Krugman, P. (1988). Financing vs. forgiving a debt overhang. Journal of Development Economics 29, 253-268. https://dx.doi.org/10.1016/0304-3878(88)90044-2.

Onatski, A. and C. Wang (2018). Alternative asymptotics for cointegration tests in large vars. Econometrica 86, 1465-1478. https://doi.org/10.3982/ecta14649.

Panizza, U. and A. F. Presbitero (2013). Public debt and economic growth in advanced economies: A survey. Swiss Journal of Economics and Statistics 149, 175-204. https://doi.org/10.1007/bf03399388.

Pesaran, M. H. (2004). General diagnostic tests for cross section dependence in panels. CESifo Working Paper 1229, IZA Discussion Paper 1240, http://ifo.de/w/XdQFZH6G.

Pesaran, M. H. (2006). Estimation and inference in large heterogeneous panels with multifactor error structure. Econometrica 74, 967-1012. https://doi.org/10.1111/j.1468-0262.2006.00692.x.

Pesaran, M. H. (2015a). Testing weak cross-sectional dependence in large panels. Econometric Reviews 34, 1089-1117. https://doi.org/10.1080/07474938.2014.956623.

Pesaran, M. H. (2015b). Time series and panel data econometrics. Oxford University Press. https://doi.org/10.1093/acprof:oso/9780198736912.001.0001. 
Pesaran, M. H., T. Schuermann, and S. M. Weiner (2004). Modelling regional interdependencies using a global error-correcting macroeconometric model. Journal of Business and Economics Statistics 22, 129-162. https://doi.org/10.1198/073500104000000019.

Reinhart, C. M., V. R. Reinhart, and K. S. Rogoff (2012). Public debt overhangs: Advanced-economy episodes since 1800. The Journal of Economic Perspectives 26, 69-86. https://www.jstor.org/stable/41581132.

Reinhart, C. M. and K. S. Rogoff (2010). Growth in a time of debt. American Economic Review 100, 573-78. https://doi.org/10.1257/aer.100.2.573.

Reinhart, C. M. and K. S. Rogoff (2011). From financial crash to debt crisis. American Economic Review 101, 1676-1706. https://dx.doi.org/10.1257/aer.101.5.1676.

Saint-Paul, G. (1992). Fiscal policy in an endogenous growth model. The Quarterly Journal of Economics 107, 1243-1259. https://doi.org/10.2307/2118387.

Stock, J. H. and M. W. Watson (2005). Implications of dynamic factor models for VAR analysis. NBER Working Paper No. 11467, https://doi.org/10.3386/w11467.

Woo, J. and M. S. Kumar (2015). Public debt and growth. Economica 82(328), 705-739. https://dx.doi.org/10.1111/ecca.12138. 